\title{
MARIANA MIGUEL
}

Efeito do hormônio sintético $17 \alpha$-etinilestradiol no invertebrado aquático Daphnia magna (Crustacea, Cladocera)

São Carlos, SP 


\section{MARIANA MIGUEL}

Efeito do hormônio sintético 17 -etinilestradiol no invertebrado aquático Daphnia magna (Crustacea, Cladocera)

Dissertação apresentada à Escola de Engenharia de São Carlos, Universidade de São Paulo, como parte dos requisitos para obtenção do título de Mestre em Ciências Programa em Ciências da Engenharia Ambiental

Orientadora: $\operatorname{Prof}^{\mathrm{a}}$. Dr ${ }^{\mathrm{a}}$. Odete Rocha

São Carlos, SP

2016 


\section{AUTORIZO A REPRODUÇÃO TOTAL OU PARCIAL DESTE TRABALHO, POR QUALQUER MEIO CONVENCIONAL OU ELETRÔNICO, PARA FINS DE ESTUDO E PESQUISA, DESDE QUE CITADA A FONTE.}

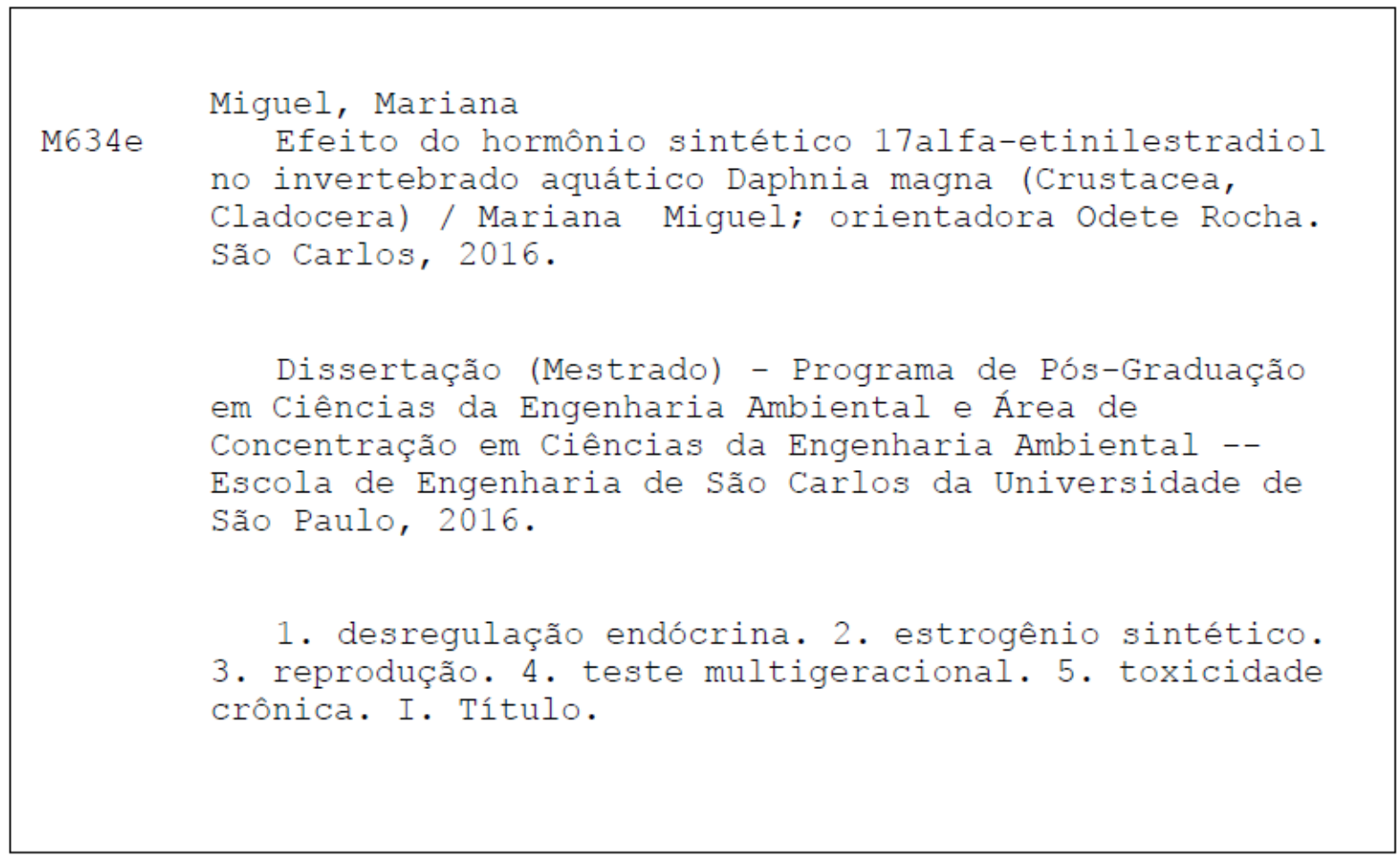




\section{FOLHA DE JULGAMENTO}

Candidata: Licenciada MARIANA MIGUEL.

Título da dissertação: "Efeito do hormônio sintético 17a-etinilestradiol no invertebrado aquático Daphnia magna (Crustacea, Cladocera)".

Data da defesa: 12/02/2016

Comissão Julgadora:

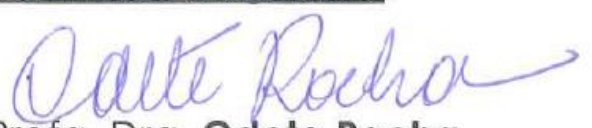

Profa. Dra. Odete Rocha

(Orientadora)

(Universidade Federal de São Carlos/UFSCar)

Suree D. $\alpha z^{\circ}$

Profa. Dra. Susana Trivinho Strixino

(Universidade Federal de São Carlos/UFSCar)

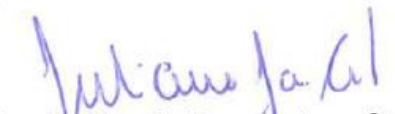

Prof. Dr. Juliano José Corbi

(Escola de Engenharia de São Carlos/EESC)

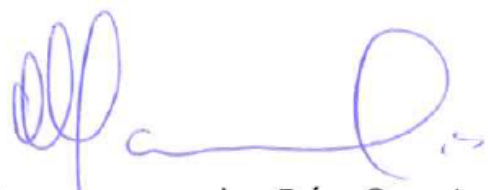

Coordenador do Programa de Pós-Graduação em Ciências da Engenharia Ambiental:

Prof. Associado Frederico Fabio Mauad

Presidente da Comissão de Pós-Graduação:

Prof. Associado Paulo César Lima Segantine
Resultado:

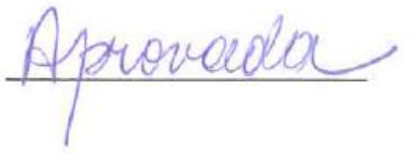

Aprovada

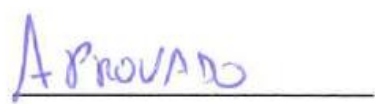


Dedico:

Ao meu avô Nelson "in memorian”, que sempre incentivou meus sonhos e aos meus pais, Nelson e Glamis, pelo incentivo, confiança e apoio em todos os momentos. 


\section{AGRADECIMENTOS}

À minha orientadora Profa. Dra. Odete Rocha pelo apoio, estímulo e principalmente pela orientação e valiosos ensinamentos durante o meu mestrado;

Ao CNPq (Conselho Nacional de Desenvolvimento Científico e Tecnológico) pela bolsa concedida;

Ao professor Dr. Evaldo Espíndola e professora Dra. Eny Maria Vieira pelas contribuições no Exame de Qualificação;

À Edna, pela ajuda, carinho e conversas.

À Adrislaine, por toda ajuda, apoio e incentivo.

Aos colegas do DEBE, Lidiane, Matheus, Marcos, Germano, Neto, Luis, Alcídio, Valdecir, Denise, Gisele e Emanuela;

À Babi, Greicy, Alana, Serena, Dani, Popinho, Carolzinha, Gabi, Mayara, Raquel, Marina, Heidi, Fran e Laine pelos momentos de descontração, apoio, risadas e amizade.

A todos os funcionários e estagiários do Departamento de Ecologia e Biologia Evolutiva.

À minha avó Lucilia e meu avô Nelson (in memorian), minha avó Glaucia e meu avô Raul (in memorian), pelo carinho e amor.

Ao meu irmão Pedro, pela paciência e apoio.

Aos meus pais, Glamis e Nelson, pelo apoio, dedicação, palavras de conforto, amor e confiança.

À minha família,

A todos que contribuíram de alguma forma para a realização deste trabalho. 
“A menos que modifiquemos a nossa maneira de pensar, não seremos capazes de resolver os problemas causados pela forma como nos acostumamos a ver o mundo"

Albert Einstein

“Por vezes sentimos que aquilo que fazemos não é senão uma gota de água no mar. Mas o mar seria menor se lhe faltasse uma gota"

Madre Teresa de Calcutá 


\section{RESUMO}

MIGUEL, M. Efeito do hormônio sintético 17a-etinilestradiol no invertebrado aquático Daphnia magna (Crustacea, Cladocera). 2016. 110 p. Dissertação (Mestrado) - Escola de Engenharia de São Carlos, Universidade de São Paulo, São Carlos, 2016.

Muitas substâncias descartadas no meio ambiente não são totalmente degradadas, podendo assim persistir no ambiente. Diversos compostos são continuamente introduzidos no ambiente podendo afetar a biota e inclusive o homem. Os fármacos são alguns desses compostos que depois de descartados podem chegar nos corpos de águas naturais, e dentre eles merecem especial atenção os hormônios sintéticos utilizados em larga escala por mulheres em todo o mundo, na forma de contraceptivos orais. O hormônio sintético 17a-etinilestradiol é um micropoluente no ambiente aquático, que pode causar distúrbios na reprodução de diversos organismos atuando como um desregulador endócrino. O presente estudo teve como objetivo principal analisar o efeito do hormônio sintético 17 1 -etinilestradiol sobre o cladócero Daphnia magna, por meio de testes ecotoxicológicos. Testes de toxicidade crônica foram realizados em duas gerações consecutivas deste microcrustáceo $\left(F_{0}\right.$ e $F_{1}$ ). Para os testes utilizaram-se neonatas com menos de 24 horas de idade, 6 concentrações do hormônio e dois controles. Foram estabelecidas 10 réplicas com 1 indivíduo por réplica. $\mathrm{O}$ ensaio foi realizado em incubadora com temperatura de $25 \pm 1^{\circ} \mathrm{C}$ e fotoperíodo de $12 \mathrm{~h}$ claro:12h escuro, com duração de $11\left(\mathrm{~F}_{0}\right)$ e 13 dias $\left(\mathrm{F}_{1}\right)$, com término coincidindo com o nascimento das neonatas da terceira ninhada no controle. Os resultados evidenciaram que a exposição ao hormônio diminuiu a fecundidade de Daphnia magna nas quatro maiores concentrações de etinilestradiol na $F_{0}$ e na concentração de $1000 \mu \mathrm{g} \mathrm{L}^{-1}$ da $F_{1}$,

revelando maior resistência ao contaminante na segunda geração. Na maior concentração do composto, o tempo para a produção das duas primeiras ninhadas foi maior na geração $\mathrm{F}_{1}$, quando comparada ao controle. Na concentração de $250 \mu \mathrm{g} \mathrm{L}^{-1}$ verificou-se a ocorrência de um indivíduo intersexo, apresentando tanto características de macho como de fêmea. Os resultados deste estudo evidenciaram que o 17 1 -etinilestradiol afeta a reprodução de Daphnia magna, e que também pode afetar a reprodução de diferentes invertebrados aquáticos, o que, a longo prazo pode causar danos às populações e comunidades aquáticas, diminuindo as populações e podendo até extinguilas eventualmente.

Palavras-chave: desregulação endócrina, estrogênio sintético, reprodução, teste multigeracional, toxicidade crônica 


\begin{abstract}
MIGUEL, M. The effect of the synthetic hormone $17 \alpha$-ethinyl estradiol on the aquatic invertebrate Daphnia magna (Crustacea, Cladocera). 2016. 110 p. Dissertation (Master in Sciences) -Engineering School of São Carlos, University of São Paulo, São Carlos, 2016.

Many substances are discarded in the environment and not completely degraded, thus persisting in the environment. Some of these are continuously introduced in the environment, affecting the biota, including man. Pharmaceutical drugs are some of these compounds that after discarded can occur in natural water bodies and among them the synthetic hormones deserve special attention for being used in large scale by women world widely, as oral contraceptives. The synthetic hormone $17 \alpha$-ethinyl estradiol is therefore a micropoluent in the aquatic environment, i. e. found in low concentrations that can cause deleterious effects in the reproduction of many organisms, acting as an endocrine disruptor. The present study had as main objective to analyze the effect of the synthetic estrogen $17 \alpha$-ethinyl estradiol on the cladoceran Daphnia magna, by carrying out ecotoxicological tests. Chronic toxicity tests were performed on two consecutive generations of this microcrustacean $\left(F_{0}\right.$ and $\left.F_{1}\right)$. In order to perform the tests, neonates aged less than 24 hours, 6 hormones concentrations and two types of controls were used. Ten replicates were established with one individual each. The test was performed in a growth chamber at the constant temperature of $25 \pm 1^{\circ} \mathrm{C}$ and $12 \mathrm{~h}$ light: $12 \mathrm{~h}$ dark photoperiod, had the duration of 11 and 13 days for the $F_{1}$ and $F_{0}$ generations, respectively, coinciding with the birth of the third brood in the control. The results evidenced that the exposition to the hormone decreased D. magna fecundity in the four highest of ethinyl estradiol in $F_{0}$, and in the concentration $1000 \mu \mathrm{g} \mathrm{L}^{-1}$ for the $\mathrm{F}_{1}$, indicating resistance increase in the second generation. In the highest concentration of this compound the time for the production of the first two broods were higher in the F1 generation as compared with the controls. In the hormone concentration of $250 \mu \mathrm{g} \mathrm{L}^{-1}$ the occurrence of an intersex individual was verified, simultaneously presenting characteristics of male and female. The results of this study evidenced the $17 \alpha$-ethinyil estradiol affect the reproduction of Daphnia magna, and can affect the reproduction of other aquatic invertebrates that at long term can cause damages to aquatic populations and communities by diminishing populations and eventually leading them to the extinction.
\end{abstract}

Key words: endocrine disruption, synthetic estrogen, reproduction, multigeneration test, chronic toxicity 


\section{Lista de Figuras}

Figura 1-Vista geral de indivíduos do cladócero Daphnia magna evidenciando as principais diferenças entre a fêmea (A e B - destaque para a região cefálica e carapaça abaixo da região cefálica) e o macho (C e D - destaque para a região cefálica e carapaça abaixo da região cefálica). Nas fêmeas (A e B): (1) presença de rostro alongado na região da cabeça; (2) primeira antena bem pequena; (3) processos abdominais, que são constituídos por expansões na parte posterior do pos-abdomen e (4) carapaça abaixo da cápsula cefálica com borda suave sem cerdas. No macho (C e D): (1) a porção frontal da região da cabeça é achatada; (2) primeira antena alongada; (3) ausência de processo abdominal e (4) carapaça abaixo da cápsula cefálica é modificada e com cerdas. Adaptado de Olmstead e LeBlanc, 2000. (Fotos: Miguel, M., 2015) 24

Figura 2-Esquema ilustrando a síntese do hormônio 17 $\alpha$-etinilestradiol a partir do hormônio natural $17 \beta$-estradiol. A síntese ocorre com a adição do grupo etinil ao C 17 . Peso molécular do $\mathrm{EE}_{2}=296,40 \mathrm{~g} \mathrm{~mol}^{-1}$. CAS n ${ }^{\circ}$ 57-63-6. Adaptado de Clouzot et al., 2008.

Figura 3-Recipientes plásticos atóxicos, com suspensão alimentar (30 mL de água reconstituída e microalga clorofícea Pseudokirchneriella subcapitata na concentração de $3 \times 10^{5}$ céls $\mathrm{mL}^{-1}$ ) onde foi realizado o cultivo de Daphnia magna para o estudo de seu ciclo de vida sob condições controladas de $25 \pm 1^{\circ} \mathrm{C}$, fotoperíodo de $12 \mathrm{~h}$ claro: $12 \mathrm{~h}$ escuro (Foto: Miguel, M., 2015).

Figura 4-Vista da lâmina escavada com 3 cavidades e pipeta Pasteur de boca larga usadas para o manuseio dos indivíduos de Daphnia magna durante o experimento para o estudo do ciclo de vida da espécie sob condições ótimas e controladas (Foto: Miguel, M., 2015). 36

Figura 5-Vista do arranjo experimental de um teste de toxicidade crônica $17 \alpha$-etinilestradiol $\left(E_{2}\right)$ já montado e mantido em incubadora do tipo BOD, com temperatura controlada de $25 \pm 1^{\circ}$ C e fotoperíodo 12h:12h claro/escuro (Foto: Miguel, M., 2015). 
Figura 6-Aspectos morfológicos das fases do desenvolvimento embrionário de Daphnia magna cultivada em laboratório a $25 \pm 1^{\circ} \mathrm{C}$ : (A) ovo esférico; (B) formação de uma parte clara em torno da periferia, antecedendo a primeira invaginação; (C) as metades direita e esquerda são bem marcadas, sendo desenvolvida a simetria bilateral; (D) embrião com uma maior diferenciação dos olhos; (E) embrião com os olhos colocados lateralmente bem pronunciados e espinho caudal aderido ao pós-abdômen; (F) final do desenvolvimento embrionário, espinho caudal não aderido ao pós-abdômen, embrião formado pronto para nascer. Os dados representam as observações em 7 réplicas. (Fotos: Miguel, M., 2015) 43

Figura 7-Aspectos morfológicos da pré-primípara (A, B, C e D) e da primípara (E e F) de Daphnia magna cultivada em laboratório a $25 \pm 1^{\circ} \mathrm{C}$, fotoperíodo de $12 \mathrm{~h}$ claro: $12 \mathrm{~h}$ escuro; (A) neonata (menos de 24 horas); (B) juvenil (mais de 24 horas de idade); (C) fêmea com o ovário em desenvolvimento; (D) fêmea com o ovário desenvolvido (antecede a deposição do ovo na câmara de incubação); (E) fêmea com os ovos na câmara de incubação e (F) fêmea com os embriões formados. (Fotos: Miguel, M., 2015). 44

Figura 8-Variação da fecundida média por ninhada de Daphnia magna, ao longo da fase reprodutiva do seu ciclo de vida quando cultivada a $25 \pm 1^{\circ} \mathrm{C}$, fotoperíodo de $12 \mathrm{~h}$ claro: $12 \mathrm{~h}$ escuro e alimentada com suspensão da microclorofícea Pseudokirchneriella subcapitata, na concentração de $3 \times 10^{5}$ células $\mathrm{mL}^{-1}$ e aditivo alimentar constituído de uma mistura de ração de peixe fermentada (TetraMin ${ }^{\circledR}$ ) e fermento biológico, na proporção de $1 \mathrm{~mL}$ para cada litro de suspensão. As barras representam os valores médios obtidos para sete réplicas e respectivos desvios-padrão.

Figura 9-Curva de crescimento individual de Daphnia magna cultivada a $25 \pm 1^{\circ} \mathrm{C}$ fotoperíodo de 12 h claro: 12 h escuro e alimentado com suspensão da microclorofícea Pseudokirchneriella subcapitata, na concentração de $3 \times 10^{5}$ células $\mathrm{mL}^{-1}$ e aditivo alimentar constituído de uma mistura de ração de peixe fermentada $\left(\right.$ TetraMin $^{\circledR}$ ) e fermento biológico, na proporção de $1 \mathrm{~mL}$ para cada litro de suspensão. Os pontos representam os valores empíricos do tamanho do corpo obtidos nas sete réplicas $\left(\mathrm{r}^{2}=0,9589\right)$. 
Figura 10-Faixa de sensibilidade de Daphnia magna exposta à substância de referência dicromato de potássio, em cinco testes de toxicidade aguda, $\mathrm{CE}_{50-48 \mathrm{~h}}\left(\mathrm{mg} \mathrm{L}^{-1}\right)$ nas condições constantes de $25^{\circ} \mathrm{C}$ e fotoperíodo de $12 \mathrm{~h}$ luz: $12 \mathrm{~h}$ escuro.

Figura 11-Tempo para geração das ninhadas (em dias) por Daphnia magna exposta ao hormônio sintético $17 \alpha$ - etinilestradiol $\left(\mathrm{EE}_{2}\right)$ em cada tratamento e no controle, para as gerações $\mathrm{F}_{\mathbf{0}}(\mathrm{A})$ e $\mathrm{F}_{\mathbf{1}}$ (B). As colunas indicam as concentrações testadas e os controles, sendo C (controle com água reconstituída) e $\mathrm{C}+\mathrm{S}$ (controle com o solvente metanol). O símbolo asterisco (*) indica os resultados com diferenças estatisticamente significativas em comparação com os controles. ..... 53

Figura 12-Número médio de neonatas produzidas por fêmea de Daphnia magna na primeira geração $F_{0}(A)$ e na segunda geração $F_{1}$ (B) quando submetidas ao teste de toxicidade crônica com o hormônio etinilestradiol. As colunas representam o número médio de neonatas produzidos nos controles e em cada concentração $\left(\mu \mathrm{g} \mathrm{L}^{-1}\right)$ e as linhas verticais representam os desviospadrão, para dez réplicas. O asterisco $\left(^{*}\right)$ representa a existência de diferenças estatisticamente significativas na fecundidade de Daphnia magna entre as concentrações de etinilestradiol testadas e os controles. 55

Figura 13-Tamaho corporal dos neonatas de Daphnia magna $(\mathrm{mm})$ na geração $\mathrm{F}_{0}(\mathrm{~A})$ e na geração $F_{1}(B)$ exposta ao hormônio sintético $17 \alpha$ - etinilestradiol $\left(\mathrm{EE}_{2}\right)$. As barras representam o valor médio do comprimento dos neonatas. O Asterisco $(*)$ representa diferença significativa com relação ao controle. (Não foi possível medir os neonatas da primeira ninhada da geração $\mathrm{F}_{0}$ ). ... 59

Figura 14-Ocorrência de forma intersexo em Daphnia magna exposta ao hormônio sintético $17 \alpha-$ etinilestradiol (A e B - zoom na região cefálica e na carapaça logo abaixo da região cefálica), mostrando ambas, caracteristicas de macho (1 e 2) e características de fêmea (3 e 4). (1) primeira antena alongada; (2) carapaça abaixo da cápsula cefálica modificada e com cerdas; (3) processos abdominais longos e (4) ovário desenvolvido. (Foto: Miguel, M, 2015). 61

Figura 15-Vista de um cultivo de alga clorofícea em fase exponencial de crescimento, em sala climatizada a $25 \pm 2{ }^{\circ} \mathrm{C}$, aeração constante e fotoperíodo $12 \mathrm{~h}$ claro: $12 \mathrm{~h}$ escuro. 80 


\section{Lista de tabelas}

Tabela 1-Concentrações médias do hormônio 17a-etinilestradiol registradas em diferentes países, e respectivos autores. ETE = Estação de Tratamento de Esgoto.

Tabela 2-Variáveis analisadas e respectivos parâmetros obtidos ao longo do ciclo de vida (média \pm desvio padrão) do cladócero Daphnia magna cultivado sob condições controladas de laboratório: $25 \pm 1^{\circ} \mathrm{C}$; fotoperíodo de $12 \mathrm{~h}$ claro: $12 \mathrm{~h}$ escuro e alimentado com suspensão da microclorofícea Pseudokirchneriella subcapitata, na concentração de $3 \times 10^{5}$ células $\mathrm{mL}^{-1} \mathrm{e}$ aditivo alimentar constituído de uma mistura de ração de peixe fermentada (TetraMin ${ }^{\circledR}$ ) e fermento biológico, na proporção de $1 \mathrm{~mL}$ para cada litro de suspensão.

Tabela 3-Valores da Concentração efetiva (CE50-48h) do dicromato de potássio expressos em $\mathrm{mg} \mathrm{L}^{-1}$ e seus respectivos intervalos de confiança (IC) com 95\% de confiabilidade, resultantes de testes toxicidade aguda com o cladócero Daphnia magna. São também apresentados o valor médio, o desvio padrão (DP), a variância e o coeficiente de variação (CV).

Tabela 4-Valores da maior concentração efetiva com efeito não observado (CENO, em $\mu \mathrm{g} \mathrm{L}^{-1}$ ) e da menor concentração efetiva com efeito observado (CEO, em $\mu \mathrm{g} \mathrm{L}^{-1}$ ) de $17 \alpha$ - etinilestradiol $\left(\mathrm{EE}_{2}\right)$ em relação à variável-resposta fecundidade total nas três primeiras ninhadas de D. magna, após exposição prolongada de indivíduos das gerações $F_{0}$ e $F_{1}$ a concentrações sub-letais deste hormônio 57

Tabela 5-Valores das concentrações de dicromato de potássio, do número de indivíduos de $D$. magna imóveis e valores medidos para as variaveis $\mathrm{pH}$, dureza e condutividade elétrica das soluções-teste, para o Teste no. 1. A dureza final não foi medida por falta de volume suficiente de solução teste 83 
Tabela 6-Valores das concentrações de dicromato de potássio, do número de indivíduos de $D$. magna imóveis e valores medidos para as variaveis $\mathrm{pH}$, dureza e condutividade elétrica das soluções-teste, para o Teste no. 2. A dureza final não foi medida por falta de volume suficiente de solução teste

Tabela 7-Valores das concentrações de dicromato de potássio, do número de indivíduos de $D$. magna imóveis e valores medidos para as variaveis $\mathrm{pH}$, dureza e condutividade elétrica das soluções-teste, para o Teste no. 3. A dureza final não foi medida por falta de volume suficiente de solução teste. 85

Tabela 8-Valores das concentrações de dicromato de potássio, do número de indivíduos de $D$. magna imóveis e valores medidos para as variaveis $\mathrm{pH}$, dureza e condutividade elétrica das soluções-teste, para o Teste no. 4. A dureza final não foi medida por falta de volume suficiente de solução teste. 86

Tabela 9-Valores das concentrações de dicromato de potássio, do número de indivíduos de $D$. magna imóveis e valores medidos para as variaveis $\mathrm{pH}$, dureza e condutividade elétrica das soluções-teste, para o Teste no. 5. A dureza final não foi medida por falta de volume suficiente de solução teste.

Tabela 10- Parâmetros iniciais (VI) das variáveis medidas na água. Teste de toxicidade crônica. Geração $\mathrm{F}_{0}$. (OD: Oxigênio dissolvido; $\mathrm{C}$ : controle; $\mathrm{C}+\mathrm{S}$ : controle do solvente). Início do teste: $18 / 08 / 2015$.

Tabela 11-Parâmetros iniciais (VI) e finais (VF) das variáveis medidas na água. Teste de toxicidade crônica. Geração $\mathrm{F}_{0}$. (OD: Oxigênio dissolvido; $\mathrm{C}$ : controle; $\mathrm{C}+\mathrm{S}$ : controle do solvente). Durante o teste foram medidas as variáveis dos controles, menor concentração, concentração média e maior concentração. Final do teste: 30/08/2015. 89 
Tabela 12-Parâmetros iniciais (VI) das variáveis medidas na água. Teste de toxicidade crônica. Geração $\mathrm{F}_{1}$. (OD: Oxigênio dissolvido; $\mathrm{C}$ : controle; $\mathrm{C}+\mathrm{S}$ : controle do solvente). Início do teste: $29 / 08 / 2015$.

Tabela 13-Parâmetros iniciais (VI) e finais (VF) das variáveis medidas na água. Teste de toxicidade crônica. Geração $\mathrm{F}_{1}$. (OD: Oxigênio dissolvido; $\mathrm{C}$ : controle; $\mathrm{C}+\mathrm{S}$ : controle do solvente). Durante o teste foram medidas as variáveis dos controles, menor concentração, concentração média e maior concentração. Final do teste: 11/09/2015 ..................................... 92

Tabela 14-Valores das concentrações de 17 $\alpha$-etinilestradiol, mortalidade, maturidade, número de neonatas e ninhada dos organismos de Daphnia magna, submetidos ao teste de toxicidade crônica (10 réplicas por concentração, mais controle e controle com solvente) à $25^{\circ} \mathrm{C}$. (M: mortalidade; Mt: maturidade; Ne: número de neonatas; N: ninhada; Im: imatura; OD: ovário desenvolvido; DO: desenvolvimento do ovário; O: ovada; Em: embrionada). Geração $\mathrm{F}_{0}$. Início do teste: $18 / 08 / 2015$. 95

Tabela 15-Valores das concentrações de 17 $\alpha$-etinilestradiol, mortalidade, maturidade, número de neonatas e ninhada dos organismos de Daphnia magna, submetidos ao teste de toxicidade crônica (10 réplicas por concentração, mais controle e controle com solvente) à $25^{\circ} \mathrm{C}$. (M: mortalidade; Mt: maturidade; Ne: número de neonatas; N: ninhada; Im: imatura; OD: ovário desenvolvido; DO: desenvolvimento do ovário; O: ovada; Em: embrionada). Geração $\mathrm{F}_{1}$. Início do teste: 29/08/2015. 103 


\section{Sumário}

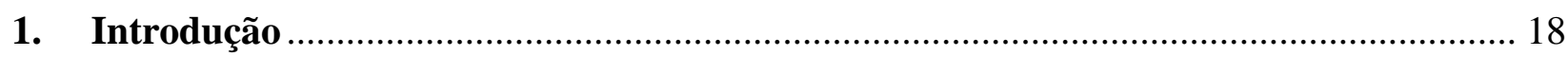

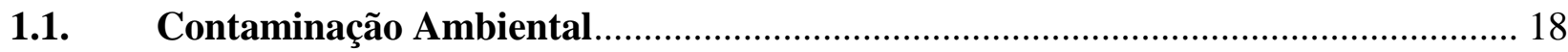

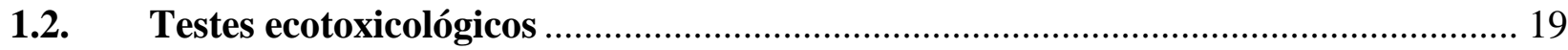

1.3. Hormônios como Disruptores Endócrinos ………………………………............ 25

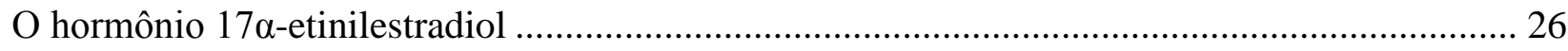

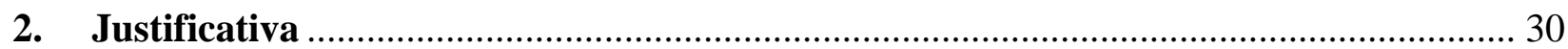

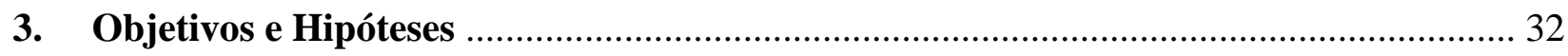

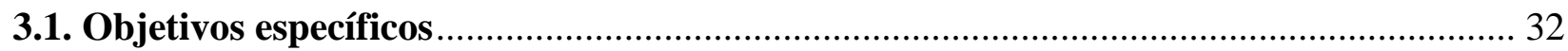

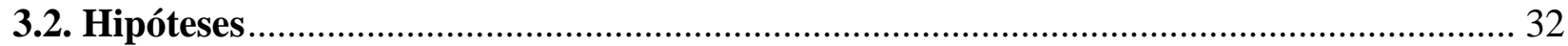

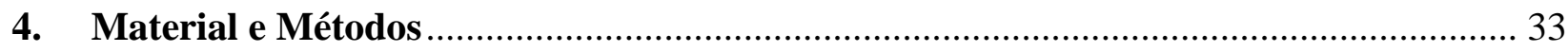

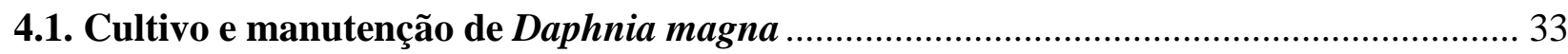

4.2. Principais Características do Ciclo de vida de Daphnia magna ....................................... 34

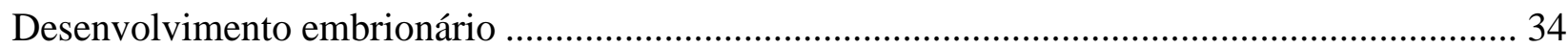

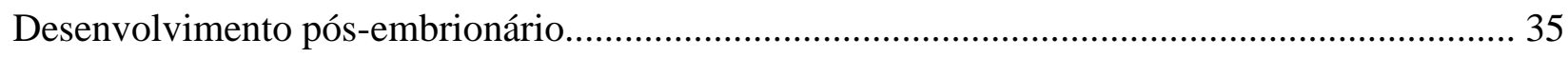

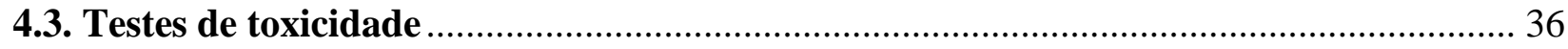

4.3.1. Determinação da Sensibilidade do Organismo-Teste....................................................... 36

4.4.2. Avaliação do Efeito de Disrupção Endócrina do Hormônio 17a-etinilestradiol sobre o

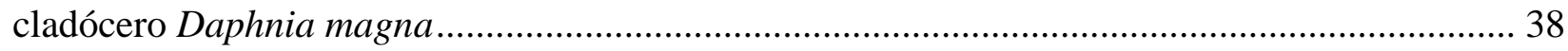

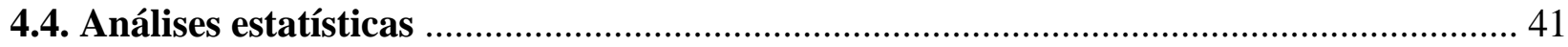

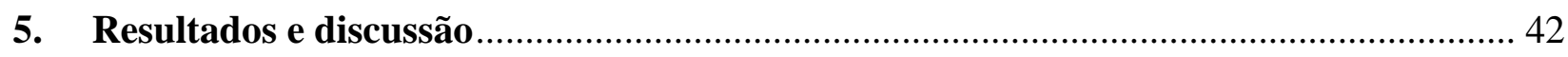

5.1. O Ciclo de vida da Daphnia magna ................................................................... 42

5.2. Avaliação da Sensibilidade de Daphnia magna …………........................................ 50

5.2.1. Teste de sensibilidade de Daphnia magna à substância de referência dicromato de

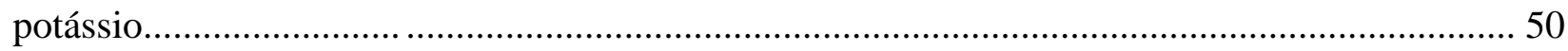

5.3. Disrupção endócrina do EE2 ao cladócero Daphnia magna - Teste de toxicidade

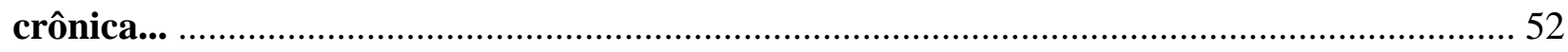

5.3.1. Ocorrência de indivíduos intersexo em Daphnia magna ............................................... 60

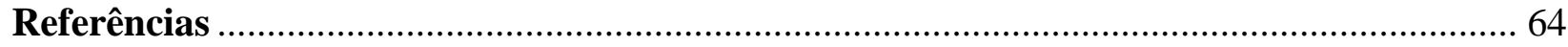

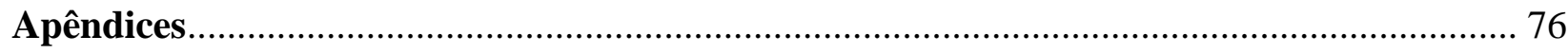


APÊNDICE A - Composição e Modo de preparação da Água reconstituída de Elevada

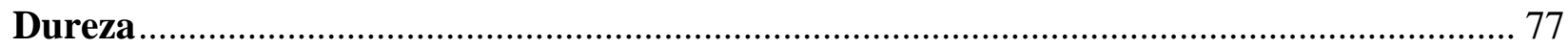

APÊNDICE B - Meio Oligo - Cultivo de alga........................................................... 78

APÊNDICE C - Meio Chu-12, cultivo de alga .................................................................. 79

APÊNDICE D - Procedimento de Inoculação da alga ..................................................... 80

APÊNDICE E - Preparo do aditivo alimentar (alimento composto) para o cultivo de

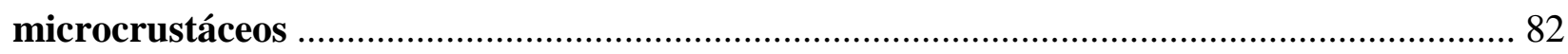

APENDICE F - Dados brutos obtidos em cinco testes de toxicidade aguda para determinação da sensibilidade do organismo teste Daphnia magna à substância de referência $\mathrm{K}_{2} \mathrm{Cr}_{2} \mathrm{O}_{7}$, nas condições laboratoriais adotadas. ........................................... 83 APÊNDICE G - Dados brutos referentes às variáveis físicas e químicas da água durante o

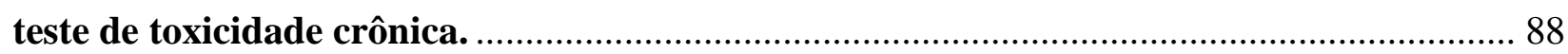
APENDICE H - Dados brutos obtidos no teste de toxicidade crônica do organismo teste Daphnia magna à substância teste $17 \alpha$-etinilestradiol, nas condições laboratoriais adotadas. 


\section{Introdução}

\subsection{Contaminação Ambiental}

Uma das consequências do desenvolvimento humano é o aumento significativo de compostos químicos de origem antrópica em ecossistemas aquáticos, causando sua degradação e colocando em risco a vida aquática (CAMPANHA et al., 2015). Durante décadas foram empreendidos esforços no desenvolvimento de produtos químicos de diferentes classes (por exemplo defensivos agrícolas, detergentes, fármacos e outros compostos sintéticos) para suprir diferentes necessidades humanas ou para manutenção da sua própria saúde como é o caso da produção de fármacos (AMÉRICO et al., 2012). O aumento exponencial da população humana acarretou um crescente uso de compostos sintéticos, que sem os devidos cuidados no descarte, podem trazer grandes prejuízos para o ambiente, como anomalias no sistema reprodutivo de peixes, aumento de peixes hermafroditas, efeito no fotossistema de microalgas e efeitos na reprodução de invertebrados (BALINA et al., 2015; CHRISTENSEN, 1998).

Os micropoluentes são compostos químicos presentes em pequenas concentrações, mas que desencadeiam efeitos sobre os sistemas em que estão presentes. Dentre os micropoluentes alguns compostos atuam como desreguladores endócrinos (REIS FILHO; ARAÚJO; VIEIRA, 2006), como é o caso de fármacos e alguns pesticidas (REIS FILHO; LUVIZOTTO-SANTOS; VIEIRA, 2007; SINGH; SINGH, 2014). Reis Filho, Araújo e Vieira (2006) apresentam uma breve descrição dos hormônios sexuais estrógenos, bem como das características físicas e químicas de alguns destes compostos e de sua relevância em termos de implicações ecológicas e de saúde pública, evidenciando com base na literatura, que o hormônio acarreta diversos efeitos na biota aquática, alterando taxas de fecundidade e fertilidade, modificando o comportamento dos organismos ou causando histopatologias. Além dos efeitos que podem ser ocasionados, estes autores ressaltam o uso, cada vez maior, dos métodos contraceptivos por meio de pílulas anticoncepcionais, os quais contribuem para a introdução de compostos estrogênicos no ambiente aquático. A presença desses compostos tem efeitos sobre a reprodução e o desenvolvimento da prole, podendo levar à diminuição de diversas populações que compõem a biota aquática (ARIS; 
SHAMSUDDIN; PRAVEENA, 2014; BHANDARI; VOOM SAAL; TILLIT, 2015; DIETRICH et al., 2010; GOTO; HIROMI, 2003; REIS FILHO; ARAÚJO; VIEIRA, 2006).

Além dos hormônios, muitos outros tipos dos chamados poluentes emergentes são também desreguladores endócrinos e podem afetar não só os organismos aquáticos, mas também a saúde humana. Os riscos para a população humana podem envolver alterações na idade de início da puberdade, risco de câncer, redução da qualidade dos espermatozoides e consequentes implicações para a fertilidade humana (DENT et al., 2015; REIS FILHO; LUVIZOTTOSANTOS; VIEIRA, 2007; TOURNAIRE et al., 2015).

Um dos grandes problemas em relação a alguns micropoluentes é o fato destes não serem completamente eliminados quando processados pelas Estações de Tratamento de Esgoto, sendo lançados no ambiente pelos efluentes destas (ERICKSON, 2002) constituindo um grave problema por serem continuamente introduzidos no ambiente, podendo resultar em sua persistência (CHRISTENSEN, 1998; REIS FILHO; ARAÚJO; VIEIRA, 2006) mesmo que tenham tempos curtos de meia vida, como é o caso do hormônio $\mathrm{EE}_{2}$, cuja meia vida pode ser de 54 horas (HALLGREN et al., 2012) ou $33 \pm 13$ horas (NAGPAL; MEAYS, 2009), dependendo da temperatura.

Considerando-se as características de micropoluentes e desreguladores endócrinos apresentadas pelos hormônios, os estudos sobre seus efeitos a organismos não-alvo são atualmente de grande relevância (AL-ANSARI et al., 2010; CHRISTEN et al., 2010; CONTARDO-JARA et al., 2011; DUSSAULT et al., 2009).

\subsection{Testes ecotoxicológicos}

A toxicidade diz respeito ao potencial de uma substância em causar algum efeito prejudicial aos organismos vivos. Esta toxicidade depende da concentração, das propriedades da substância química e do tempo de exposição do organismo ao agente tóxico (COSTA et al., 2008; WALKER et al., 2006).

As análises ecotoxicológicas constituem uma ferramenta importante para o monitoramento ambiental. Por meio destas análises é possível investigar e avaliar as ações de 
poluentes ambientais provenientes de várias fontes, como os efluentes urbanos e industriais, as atividades agrícolas e a mineração, os quais são causadores de graves problemas à biota aquática em geral (RAND, 1995).

Os testes de toxicidade são ensaios laboratoriais geralmente utilizados para avaliar a toxicidade de substâncias, da água, de sedimentos e de efluentes industriais. Estes testes são realizados sob condições experimentais específicas e controladas. Os dados obtidos pelos testes são utilizados para comparar a toxicidade das substâncias químicas, comparar a sensibilidade de um organismo a diferentes agentes tóxicos ou de diferentes organismos a uma mesma substância (COSTA et al., 2008).

Os testes de toxicidade são uma ferramenta de monitoramento ambiental, sendo empregados para avaliar tanto a qualidade das águas, como para o biomonitoramento da contaminação ambiental. Para os testes são utilizados organismos sensíveis que, por possuírem uma baixa tolerância a diversas substâncias químicas, respondem à toxicidade por meio de alterações fisiológicas, morfológicas ou comportamentais (MAGALHÃES; FERRÃO FILHO, 2008; RAND; PETROCELLI, 1985).

Os testes podem ser de toxicidade aguda ou crônica, diferindo na duração e nas respostas finais (COSTA et al., 2008; RAND; PETROCELLI, 1985). Os testes de toxicidade aguda avaliam a exposição ao agente tóxico por um curto período de tempo, geralmente de 24 a 96 horas, e as concentrações são letais, levando a respostas rápidas e severas. Já os testes de toxicidade crônica avaliam o efeito do agente tóxico sob condições de exposição prolongada a concentrações sub-letais, em que o organismo sobrevive, mas algumas de suas funções biológicas são afetadas (ADAMS, 1995; RAND, 1995).

Várias espécies podem ser utilizadas como organismo-teste em análises ecotoxicológicas, desde que sejam sensíveis aos contaminantes, tenham ampla ocorrência geográfica e ocorram em alta abundância populacional resultando em elevada disponibilidade, apresentem uniformidade e estabilidade genética nas populações e sejam de fácil adaptação e cultivo em laboratório (RAND, 1995).

Devido à grande importância e à degradação cada vez maior dos recursos hídricos, a preocupação da preservação de mananciais e da qualidade da água tem aumentado, sendo alvo de muitas pesquisas que buscam estratégias para a redução dos impactos sobre esses sistemas (CORBI et. al., 2006). Os testes de toxicidade são utilizados, para avaliar a qualidade da água, 
estimar a toxicidade de substâncias, avaliar a carga poluidora de efluentes e observar os efeitos que variados compostos podem causar na biota aquática (ZAGATTO; BERTOLETTI, 2006).

A resolução CONAMA No 357/2005 (BRASIL, 2005), alterada e complementada pela resolução CONAMA No 430/2011 (BRASIL, 2011) estabelece tanto a classificação dos corpos de água e diretrizes ambientais para o seu enquadramento, quanto as condições e padrões de lançamento de efluentes. A resolução No 357/2005 inclui os testes ecotoxicológicos como uma ferramenta de monitoramento, como pode ser observado no Capítulo III, Art. $7^{\mathrm{o}}, \S 4^{\mathrm{o}}$ : "As possíveis interações entre as substâncias e a presença de contaminantes não listados nesta Resolução, passíveis de causar danos aos seres vivos, deverão ser investigadas utilizando-se ensaios ecotoxicológicos, toxicológicos, ou outros métodos cientificamente reconhecidos".

Para a realização de testes de toxicidade, uma das etapas importantes é a seleção do organismo-teste. Em estudos de toxicidade aquática, um grupo de organismos bastante utilizado em testes de toxicidade são os microcrustáceos de água doce, principalmente os da Ordem Cladocera, por apresentarem ampla distribuição geográfica, constituírem elos importantes em muitas cadeias alimentares, apresentarem ciclo de vida curto, e reprodução predominantemente assexuada por partenogênese garantindo a produção de indivíduos na grande maioria geneticamente muito similares (sensibilidade mais constante por serem geneticamente mais homogêneos) e por serem de fácil cultivo em laboratório (COSTA et al, 2008; RAND, 1995).

Há um grande número de estudos que utilizaram cladóceros como organismos-teste, tais como: Phyu et al. (2013) avaliaram a toxicidade crônica da atrazina, permetrina e clorotalonil em Ceriodaphnia dubia, usando água coletada de um rio a noroeste de Sidney, Austrália, e água preparada em laboratório. Os resultados evidenciaram que as duas águas usadas podiam ser comparadas, pois não houve diferença significativa entre elas, e mostraram uma ordem decrescente de toxicidade dos três pesticidas, tendo o pesticida permetrina sido mais tóxico que o clorotalonil, que por sua vez foi mais tóxico que a atrazina.

Hayasaka et al. (2013) compararam a toxicidade aguda de dois inseticidas, o imidaclopride e a clotianidina, utilizando cinco espécies de cladóceros, Ceriodaphnia dubia, Ceriodaphnia reticulata, Daphnia magna, Daphnia pulex e Moina macrocopa, como organismos-teste. Neste estudo a sensibilidade dos cinco organismos foi comparada, revelando que, exceto para $C$. dubia que foi o organismo mais sensível, a toxicidade interespécies variou 
por um fator de 2 a 3 vezes para a clotianidina, e de 2 a 8 vezes para o imidaclopride, indicando que o grau de toxicidade de um dado agente tóxico é espécie-específico.

Moreira et al. (2014) compararam a sensibilidade de três cladóceros, D. magna, Ceriodaphnia silvestrii e Macrothrix flabelligera, ao herbicida Atrazina Atanor $50 \mathrm{SC}^{\circledR}$. Por meio de testes de sensibilidade demostraram que as espécies nativas Ceriodaphnia silvestrii e Macrothrix flabelligera são mais sensíveis a este pesticida do que a espécie D. magna, sendo então importantes organismos-teste a serem utilizados para o monitoramento da toxicidade em águas doces tropicais. Prestes et al. (2013) avaliaram a toxicidade de dois fungicidas à base de piraclostrobin e epoxiconazol, isoladamente e em mistura, para Daphnia similis. O teste foi conduzido por 21 dias, e foram avaliadas a mortalidade e a reprodução deste cladócero. Os autores observaram que, neste cladócero a exposição a concentrações crescentes dos fungicidas, resultou em aumento de mortalidade e diminuição da natalidade, sendo que o fungicida à base de piraclostrobin apresentou maior toxicidade, seguido pela mistura de ambos (piraclostrobim mais epoxiconazol), e por último pelo epoxiconazol.

Os cladóceros do gênero Daphnia são de ampla distribuição geográfica. Estes microcrustáceos se alimentam de algas, bactérias e outras pequenas partículas em suspensão por meio de filtração (RUPPERT; BARNES, 1996; STOLLEWERK, 2010) e possuem o corpo coberto por uma carapaça única que termina posteriormente em um espinho apical (não são todas as espécies que apresentam esse espinho) e o pós-abdômen portando garras e espinhos, que se move para frente e ventralmente, servindo para limpar partículas presas às setulas das patas natatórias (RUPPERT; BARNES, 1996) e também por meio de processos abdominais que se desenvolvem com a maturidade, e mantêm os ovos e embriões retidos dentro da câmara (RUPPERT; BARNES, 1996). São ecologicamente importantes, pois além de serem consumidores primários e converterem algas, bactérias e outras partículas em suspensão em proteína animal, são uma fonte de alimento para outros organismos, como outros invertebrados e peixes (HARRIS; BARTLETT; LLOYD, 2012).

Os indivíduos do gênero Daphnia podem se reproduzir assexuadamente, por partenogênese, ou sexuadamente, dependendo das condições ambientais (HARRIS; BARTLETT; LLOYD, 2012; TOYOTA et al., 2015). Na reprodução assexuada, os oócitos partenogênicos sofrem divisão meiótica equatorial, permanecem diploides e a embriogênese ocorre sem fertilização (HARRIS; BARTLETT; LLOYD, 2012), sendo que os ovos se desenvolvem 
diretamente em larvas na câmara de incubação das fêmeas adultas e são liberados para a água após seu completo desenvolvimento (STOLLEWERK, 2010).

Em condições ambientais adversas (HARRIS; BARTLETT; LLOYD, 2012), como as de mudanças de temperatura, aumento da densidade populacional e pouca disponibilidade de alimentos, esses microcrustáceos se reproduzem de forma sexuada e o zigoto fertilizado dá origem a um ovo de resistência (efípio) que é rico em nutrientes e revestido por um espesso envoltório de coloração opaca e escura. Esse efípio permanece em estado de dormência até as condições ambientais se tornarem favoráveis para seu desenvolvimento (STOLLEWERK, 2010). Estes mesmos fatores adversos podem estar associados com o aparecimento dos machos, que diferem das fêmeas pelo menor tamanho corporal, maior comprimento da primeira antena e ausência de processo abdominal (OLMSTEAD; LEBLANC, 2000). Na Figura 1 são apresentadas as principais diferenças entre macho e fêmea do cladócero Daphnia magna. 
A

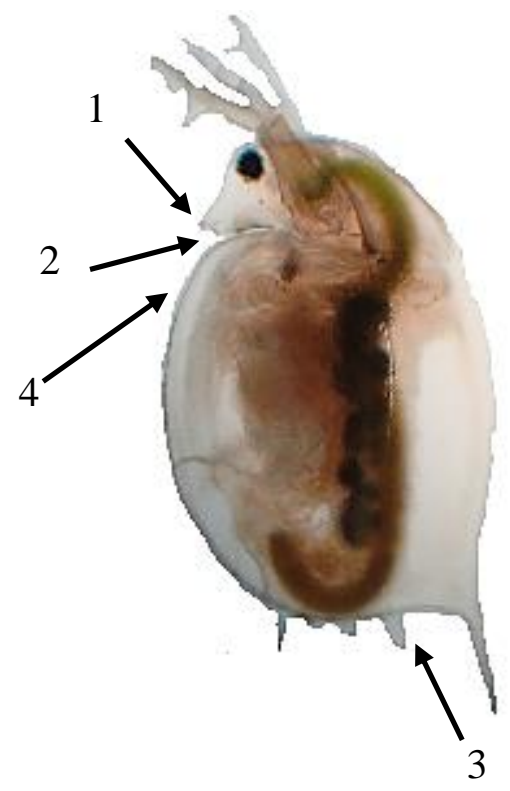

B

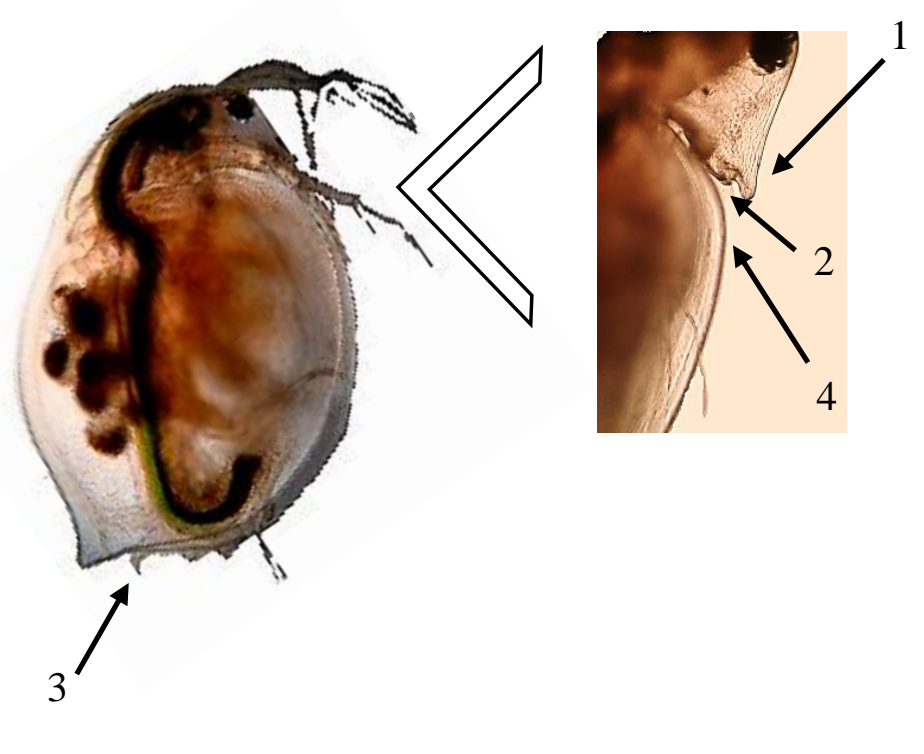

$\mathrm{C}$

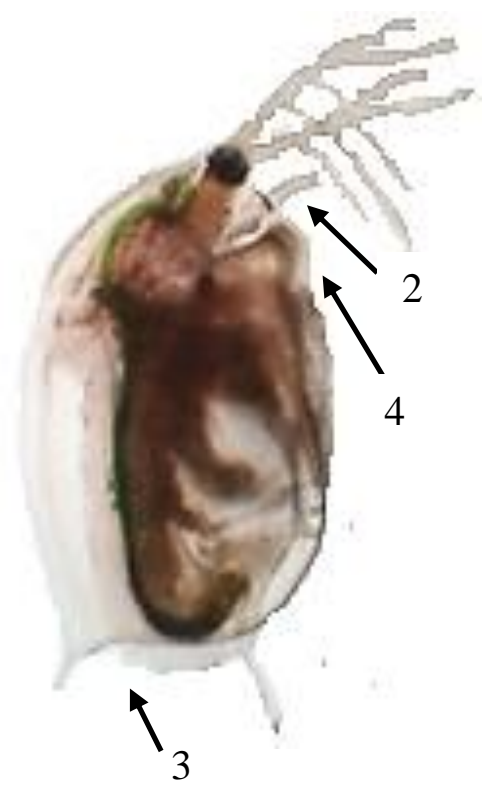

1

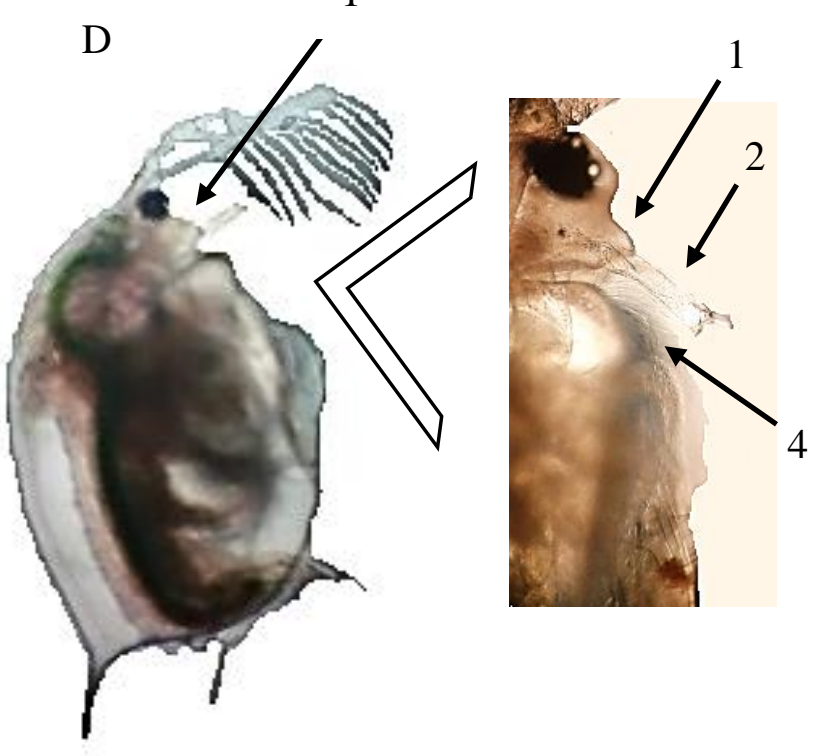

Figura 1-Vista geral de indivíduos do cladócero Daphnia magna evidenciando as principais diferenças entre a fêmea (A e B - destaque para a região cefálica e carapaça abaixo da região cefálica) e o macho (C e D - destaque para a região cefálica e carapaça abaixo da região cefálica). Nas fêmeas (A e B): (1) presença de rostro alongado na região da cabeça; (2) primeira antena bem pequena; (3) processos abdominais, que são constituídos por expansões na parte posterior do pós-abdômen e (4) carapaça abaixo da cápsula cefálica com borda suave sem cerdas. No macho (C e D): (1) a porção frontal da região da cabeça é achatada; (2) primeira antena alongada; (3) ausência de processo abdominal e (4) carapaça abaixo da cápsula cefálica é modificada e com cerdas. Adaptado de Olmstead e LeBlanc, 2000. (Fotos: Miguel, M., 2015) 
Os cladóceros passam por quatro estágios principais ao longo do seu ciclo de vida: ovo, neonata (juvenis recém-liberados da câmara de incubação de suas mães até completarem 24 horas de idade), juvenil (após 24 horas de idade até o final da pré-primípara) e adulto (após a primípara, primeira reprodução, sofrer ecdise e o primeiro lote de ovos serem liberados na câmara de incubação) (RAND, 1995; WANG; LU; CHANG, 2011).

Dentre as diversas espécies de cladóceros utilizadas como organismo-teste em todo o mundo, a mais frequentemente utilizada é Daphnia magna (TATARAZAKO; ODA, 2007).

A espécie Daphnia magna é um cladócero de tamanho relativamente grande, com adultos atingindo comprimentos de aproximadamente $6,0 \mathrm{~mm}$, os quais se reproduzem por partenogênese sob condições normais, mas que recorrem à reprodução sexuada sob condições de estresse, e apresentam elevada fecundidade (HEBERT, 1978). Por ter um tamanho maior, seu manuseio em laboratório é mais fácil do que o de cladóceros de tamanhos menores (KOIVISTO, 1995).

\subsection{Hormônios como Disruptores Endócrinos}

Substâncias químicas que podem alterar o funcionamento natural do sistema endócrino de diferentes tipos de organismos, incluindo o homem, são denominados desreguladores endócrinos (“endocrine disruptors”). Estas substâncias, mesmo presentes em baixas concentrações, da ordem de $\mu \mathrm{g} \mathrm{L}^{-1}$ ou ng $\mathrm{L}^{-1}$ são capazes de interferir no funcionamento natural do sistema endócrino causando efeitos adversos tanto em um organismo e sua descendência, como em populações (GHISELLI; JARDIM, 2007; SCHWINDT et al., 2014; SNYDER et al., 2003; VOLKOVA et al, 2015a; 2015b). Dentre os desreguladores endócrinos, os fármacos têm sido bastante investigados quanto aos seus efeitos adversos aos organismos não-alvo, pois quando ingeridos, uma parte é metabolizada pelo organismo e outra parte é excretada pela urina ou fezes, sendo encontrados com frequência nos esgotos sanitários (BILA; DEZOTTI, 2003; CALDWELL et al., 2008; LUO et al, 2014; TORRES et al., 2015), podendo de alguma forma afetar a biota aquática. Borgmann et al. (2007) estudaram o efeito de 7 fármacos (acetaminofeno, diclofenaco, genfibrozila, ibuprofeno, naproxeno, ácido salicílico e triclosano) sobre o anfípodo Hyalella azteca, observando as alterações na sobrevivência, no crescimento e na reprodução desta espécie. Os 
efeitos observados foram: diminuição no comprimento dos machos e na sobrevivência, menor número de jovens produzidos e maior ocorrência de machos. Os impactos foram pouco significativos, mas importantes para evidenciar que os fármacos causam efeitos deletérios aos indivíduos expostos.

Dentre as substâncias consideradas desreguladores endócrinos podem ser incluídos os hormônios sexuais, naturais e sintéticos, como o estrogênio (ARIS; SHAMSUDDIN; PRAVEENA, 2014; GHISELLI; JARDIM, 2007). Os estrogênios sintéticos são muito utilizados como contraceptivos orais (MIERZWA; AQUINO, 2009; TORRES et al., 2015) e no ambiente eles podem afetar desde microinvertebrados até vertebrados maiores (REIS FILHO; ARAÚJO; VIEIRA, 2006).

Os estrogênios sintéticos mais comumente utilizados são o etinilestradiol e o mestranol (GHISELLI; JARDIM, 2007; LINTELMANN et al., 2003).

O $17 \alpha$-etinilestradiol se tornou um problema no ambiente aquático por ser resistente ao processo de degradação e por ter tendência para a absorção de matéria orgânica e se acumular em sedimentos. Além disso, esse composto pode afetar a biota alterando a determinação do sexo, retardando a maturidade sexual e diminuindo as características sexuais secundárias, agindo assim como um desregulador endócrino (ARIS; SHAMSUDDIN; PRAVEENA, 2014).

$\underline{\text { O hormônio } 17 \alpha \text {-etinilestradiol }}$

O $17 \alpha$-etinilestradiol $\left(\mathrm{EE}_{2}\right)$ é um hormônio sintético muito utilizado para a formulação de contraceptivos orais (ARIS; SHAMSUDDIN; PRAVEENA, 2014). É derivado do hormônio natural 17 $\beta$-estradiol, com a adição de um grupo etinil ao C17 (Figura 2). Essa configuração faz com que o hormônio $\mathrm{EE}_{2}$ seja mais resistente à degradação do que o hormônio natural (CLOUZOT et al., 2008). 


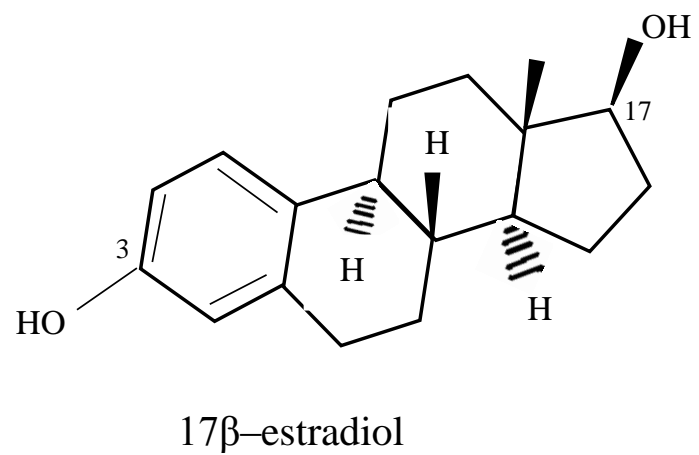

$17 \beta$-estradiol

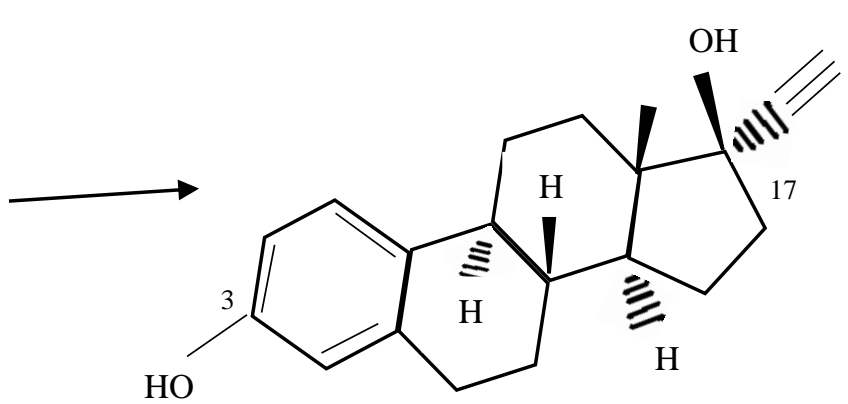

$17 \alpha-$-etinilestradiol

Figura 2-Esquema ilustrando a síntese do hormônio $17 \alpha$-etinilestradiol a partir do hormônio natural $17 \beta$-estradiol. A síntese ocorre com a adição do grupo etinil ao C 17. Peso molecular $\mathrm{EE}_{2}=296,40 \mathrm{~g} \mathrm{~mol}^{-1}$. CAS n ${ }^{\circ}$ 57-63-6. Adaptado de Clouzot et al., 2008.

$\mathrm{O} \mathrm{EE}_{2}$, cuja fórmula é $\mathrm{C}_{20} \mathrm{H}_{24} \mathrm{O}_{2}$, possui uma baixa solubilidade em água, 4,8 - 11,3 $\mathrm{mg} \mathrm{L}^{-}$ ${ }^{1}$ a $27^{\circ} \mathrm{C}$, e tem um coeficiente de partição octanol-água relativamente alto $\left(\mathrm{K}_{\mathrm{ow}}=3,6-4,2\right)$, sendo considerado lipossolúvel, com meia vida de aproximadamente $33 \pm 13$ horas (NAGPAL; MEAYS, 2009) ou $54 \pm 5,4$ horas (HALLGREN et al., 2012). O tempo de meia vida, assim como as características físicas e químicas, podem variar de acordo com as condições de análise (como por exemplo diferentes temperaturas) de cada estudo.

Por ter um coeficiente de partição octanol-água relativamente alto, o hormônio sintético se prende rapidamente aos sólidos suspensos e na matéria orgânica presente na água, conferindo, além do caráter de persistência, o caráter de bioacumulação (LAI; SCRIMSHAW; LESTER, 2002).

$\mathrm{O} \mathrm{EE}_{2}$ pode se comportar como um desregulador endócrino, podendo causar distúrbios na reprodução de alguns organismos (NAGPAL; MEAYS, 2009; TORRES et al., 2015). Van Den Belt, Verheyen e Witters (2003) estudaram o efeito do 17 $\alpha$-etinilestradiol em peixes da espécie Danio rerio, com foco no crescimento e na diferenciação sexual. Os resultados evidenciaram que a exposição do indivíduo ao hormônio acarretou a diminuição do crescimento corporal, o aumento da vitelogenina em ambos os sexos (com aparecimento nos machos) e a diminuição do sucesso reprodutivo das fêmeas.

A exposição de peixes ao estrogênio causa alterações fisiológicas e comportamentais. Xu et al. (2008) avaliaram os efeitos do $\mathrm{EE}_{2}$ nas funções reprodutivas de Danio rerio. Observaram uma diminuição do comprimento do corpo dos indivíduos, bem como uma diminuição da 
fecundidade e da viabilidade dos ovos. Observaram também que nas maiores concentrações o tecido gonadal não se diferenciou e ocorreram anormalidades nos peixes machos, como malformação do ducto espermático, alterações nas proporções dos tipos de células germinativas e redução no número de espermatozoides. Já Colman et al. (2009) analisaram os efeitos deste hormônio no comportamento também de Danio rerio e observaram que a atividade de corte diminuiu, reduzindo desta forma o sucesso reprodutivo dos indivíduos.

Além de alterações na reprodução, o $\mathrm{EE}_{2}$ pode afetar processos neurais, como foi evidenciado por Ceccarelli et al. (2015) que avaliaram a modulação das respostas à dor induzidas por injeções de formalina em proles de ratos de oito meses de idade do sexo masculino e feminino, após as ratas parentais serem tratadas com o $\mathrm{EE}_{2}$ durante a gestação e lactação. Os machos e as fêmeas tiveram respostas diferentes, sendo que os filhotes machos tiveram um aumento na dor, evidenciado pelo aumento na intensidade do comportamento de lambidas e flexões na perna induzidas pela dor, enquanto que as fêmeas não mostraram diferenças nas respostas à dor. Assim, este estudo demonstrou que o $\mathrm{EE}_{2}$ pode afetar o sistema nervoso da prole quando este foi administrado em fêmeas de ratas grávidas e lactantes.

Em relação aos invertebrados, Vandenbergh et al. (2003) testaram o efeito do $\mathrm{EE}_{2}$ sobre o anfípodo Hyalella azteca, utilizando como principais variáveis-resposta (end-points) a reprodução e as características sexuais secundárias. Eles registraram uma diminuição do tamanho do gnatópodo secundário dos machos, o qual é utilizado para prender a fêmea em amplexo prolongado, indícios de hermafroditismo e distúrbios na maturação de células germinativas.

Indivíduos de Hydra vulgaris expostos ao $\mathrm{EE}_{2}$ tiveram sua estrutura, fisiologia e reprodução sexual afetados, apresentando corpo contraído, tentáculos danificados, número de testículos reduzidos, redução no tempo do esperma ativo, redução no número de oócitos e redução no tempo de permanência do oócito fixado ao pólipo (PASCOE et al., 2002).

Os gastrópodos Nassarius burchardi e Nassarius jonasii apresentaram respostas diferentes um do outro quando expostos ao $\mathrm{EE}_{2}$. A espécie $N$. burchardi quando exposta à maior concentração testada do hormônio $\left(50 \mu \mathrm{g} \mathrm{L}^{-1}\right)$ obteve um aumento no sucesso de eclosão dos embriões e de sobrevivência das larvas, porém foram observados aumento na incidência de anormalidades e deformações das neonatas, aumento no número de ovos inviáveis e diminuição de neonatas com potencial para se desenvolverem até a fase adulta. Já $N$. jonasii quando exposta nesta mesma concentração teve menor sucesso de desenvolvimento dos embriões e de eclosão e 
sobrevivência das larvas, e afetou o tempo necessário para as larvas eclodirem de suas cápsulas (BORYSKO; ROSS, 2014).

Além dos efeitos adversos em animais vertebrados e invertebrados, o hormônio $\mathrm{EE}_{2}$ é também capaz de danificar células fitoplânctônicas. Balina et al. (2015) em um estudo laboratorial, avaliaram o efeito do $\mathrm{EE}_{2}$ na microalga Desmodesmus communis utilizando como variáveis-resposta a biomassa algal, a atividade fotossintética e a fixação de carbono. Observaram que a exposição ao hormônio diminui a biomassa algal, reduz a atividade fotossintética e influencia negativamente a fixação de carbono. Essa diminuição da biomassa algal pode impedir o funcionamento e desenvolvimento dos ecossistemas aquáticos, se tornando um problema sério a longo prazo.

Os efeitos adversos da exposição dos organismos não-alvo ao estrogênio sintético são principalmente relacionados à reprodução, como evidenciado pela maioria dos trabalhos já realizados e brevemente ilustrados pelos estudos citados. 


\section{Justificativa}

O descarte de substâncias químicas no ambiente é um problema de escala mundial (LUO et al, 2014) pelo fato de muitas das substâncias químicas descartadas não serem degradadas pelo tratamento de esgoto, nem pela biota do solo ou dos corpos de água receptores, podendo assim ser bioacumuladas e persistirem no ambiente, afetando a biota aquática e também o homem (CHRISTENSEN, 1998). Essas substâncias químicas podem ser encontradas em água residuais, de superfície, subterrânea e potável (LUO et al, 2014). Os fármacos são compostos presentes em corpos de água naturais, pois apesar de uma parte deles ser metabolizada pelo organismo, uma parte residual é eliminada junto com as fezes e urina (BILA; DEZOTTI, 2003; CHRISTENSEN, 1998; LUO et al, 2014; TORRES et al., 2015). Os hormônios sintéticos são fármacos utilizados pelas mulheres na forma de contraceptivos orais, na maioria dos países do mundo (CLOUZOT et al., 2008; LAURENSON et al., 2014) e que mesmo em baixas concentrações podem causar danos tanto aos animais vertebrados e invertebrados como às algas fitoplanctônicas.

O hormônio sintético selecionado para o presente estudo (17a-etinilestradiol) é frequentemente encontrado nos ambientes aquáticos variando de $\mu \mathrm{g} \mathrm{L}^{-1}$ a ng L $\mathrm{L}^{-1} \mathrm{e}$ em diferentes condições como em efluentes de Estações de Tratamento de Esgoto (ETE), águas superficiais e água potável. Na Tabela 1 são apresentadas as concentrações médias de $\mathrm{EE}_{2}$ registradas em diferentes países, evidenciando que a ocorrência deste desregulador endócrino é um problema de escala mundial.

Devido ao fato de ser encontrado em todo o mundo e por acarretar efeitos deletérios em diferentes espécies da biota aquática em baixas concentrações, é de grande relevância que seja avaliado o impacto do estrogênio em organismos representantes de comunidades aquáticas, por meio da realização de testes de toxicidade. 
Tabela 1-Concentrações médias do hormônio 17 $\alpha$-etinilestradiol registradas em diferentes países, e respectivos autores. ETE = Estação de Tratamento de Esgoto.

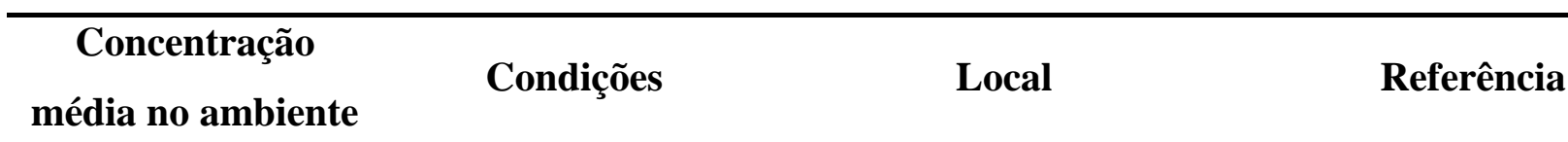

$1 \mathrm{ng} \mathrm{L} \mathrm{L}^{-1} \quad$ Efluente de ETE $\quad$ Frankfurt-Alemanha $\quad$ TERNES et al., 1999

$9 \mathrm{ng} \mathrm{L}^{-1} \quad$ Efluente de ETE Ontario- Canadá $\quad$ TERNES et al., 1999

$73 \mathrm{ng} \mathrm{L}^{-1} \quad$ Água corrente Rios dos EUA* $\quad$ KOLPIN et al., 2002

0,2 a $7,0 \mathrm{ng} \mathrm{L}^{-1} \quad$ Efluente de ETE $\quad \begin{array}{cc}7 \text { efluentes ETE- } & \text { Inglaterra** }\end{array} \quad$ DESBROW et al., 1998

0,45 ng L ${ }^{-1} \quad$ Efluente de ETE Roma-Itália $\quad$ BARONTI et al., 2000

6 a $310 \mathrm{ng} \mathrm{L}^{-1} \quad$ Água superficial Campinas-Brasil $\quad$ SODRÉ et al., 2007

1,4 ng L $\mathrm{n}^{-1} \quad$ Efluente de ETE Alemanha** ${ }^{* *} \quad$ KUCH e

BALLSCHMITER, 2001

$0,8 \mathrm{ng} \mathrm{L}^{-1} \quad$ Água natural Alemanha**

$\mathrm{KUCH}$ e

BALLSCHMITER, 2001

$0,35 \mathrm{ng} \mathrm{L}^{-1} \quad$ Água potável Alemanha**

$\mathrm{KUCH}$ e

BALLSCHMITER, 2001

$\begin{array}{ccc}6,1 \mathrm{ng} \mathrm{L}^{-1} \quad \text { Água superficial } & \text { Israel** } & \begin{array}{c}* * \\ \text { BAREL-COHEN } \text { et al. }\end{array} \text {, }\end{array}$

$5,27-10,20 \mathrm{ng} \mathrm{L}^{-1} \quad$ Água superficial $\quad \begin{array}{cc}\text { Arredores do Lago Taihu- } \\ \text { China }\end{array} \quad$ YAN et al., 2012

24-480 ng L $\mathrm{L}^{-1} \quad$ Água superficial $\quad$ Piracicaba - Brasil $\quad$ TORRES et al., 2015

*Locais não citados. **Vários locais. 


\section{Objetivos e Hipóteses}

A presente pesquisa teve como objetivo principal avaliar os efeitos do hormônio sintético $17 \alpha$-etinilestradiol $\left(\mathrm{EE}_{2}\right)$ sobre o ciclo de vida do cladócero Daphnia magna, com ênfase na sua reprodução.

\subsection{Objetivos específicos}

- Analisar o ciclo de vida de Daphnia magna cultivado em laboratório numa temperatura de $25 \pm 1^{\circ} \mathrm{C}$ para um melhor entendimento da espécie de estudo;

- Realizar testes de toxicidade crônica para avaliar os efeitos do $17 \alpha$-etinilestradiol sobre o crescimento e a reprodução de D. magna;

- Verificar a ocorrência de alterações morfológicas nas proles de D. magna expostas ao $17 \alpha$-etinilestradiol, incluindo as mudanças de sexo e deformações.

\subsection{Hipóteses}

- A exposição ao $\mathrm{EE}_{2}$ acarreta um aumento no tempo de geração de Daphnia magna na $\mathrm{F}_{0}$

- A exposição ao $\mathrm{EE}_{2}$ acarreta um aumento no tempo de geração de Daphnia magna na $\mathrm{F}_{1}$;

- A exposição ao $\mathrm{EE}_{2}$ leva a um aumento da fecundidade nas fêmeas;

- A exposição ao $\mathrm{EE}_{2}$ acarreta à diminuição no tamanho das neonatas produzidas;

- Os efeitos do $\mathrm{EE}_{2}$ são transgeracionais e cumulativos e afetam a segunda geração $\left(\mathrm{F}_{1}\right)$ em maior intensidade do que a primeira $\left(\mathrm{F}_{0}\right)$. 


\section{Material e Métodos}

\subsection{Cultivo e manutenção de Daphnia magna}

O inóculo para os cultivos de Daphnia magna foi obtido no laboratório de Ecotoxicologia do Centro de Energia Nuclear na Agricultura (CENA) em Piracicaba, SP, e tem sido mantido há mais de cinco anos no laboratório de Ecotoxicologia na Universidade Federal de São Carlos, em São Carlos, SP.

Para o cultivo foi utilizado como meio a água reconstituída, preparada com 73,5 $\mathrm{g} \mathrm{L}^{-1}$ de $\mathrm{CaCl}_{2} .2 \mathrm{H}_{2} \mathrm{O}, 123,3 \mathrm{~g} \mathrm{~L}^{-1}$ de $\mathrm{MgSO}_{4} .7 \mathrm{H}_{2} \mathrm{O}, 5,8 \mathrm{~g} \mathrm{~L}^{-1}$ de $\mathrm{KCl}$ e $64,8 \mathrm{~g} \mathrm{~L}^{-1}$ de $\mathrm{NaHCO}_{3}$, dissolvidos em 1 L de água destilada, de acordo com as normas da ABNT (2009). Esta água reconstituída, usada para o cultivo e para preparação das soluções-teste, foi preparada de forma a apresentar $\mathrm{pH}$ entre 7,6 e 8,0 e dureza total entre 175 e $225 \mathrm{mg} \mathrm{CaCO}_{3} \mathrm{~L}^{-1}$ (ABNT, 2009).

Os cultivos foram mantidos em béqueres de $2 \mathrm{~L}$ e inicialmente inoculados com 40 indivíduos de D. magna e mantidos em incubadoras com temperatura controlada de $25 \pm 1^{\circ} \mathrm{C}$ e fotoperíodo de 12h claro:12h escuro. Para evitar a evaporação do meio de cultura, os béqueres foram recobertos por um filme de plástico. Para a manutenção das culturas, semanalmente foram realizadas três trocas do meio de cultivo, quando era também fornecido novo alimento às culturas, sendo duas trocas totais e uma parcial. As trocas seguiram a ordem: total, parcial e total. $\mathrm{Na}$ água de cultivo foi também adicionada a vitamina FreshTamin ${ }^{\circledR}$ (1 gota para cada 2 L de água reconstituída). Os indivíduos foram alimentados com suspensão algácea de Pseudokirchneriella subcapitata, inicialmente cultivada em meio Oligo (ABNT, 2011), na concentração de 3 x $10^{5}$ células $\mathrm{mL}^{-1}$ e aditivo alimentar constituído da mistura de ração fermentada de peixe (TetraMin ${ }^{\circledR}$ ) e fermento biológico, na proporção de $1 \mathrm{~mL} \mathrm{~L}^{-1}$ (Informações detalhadas sobre o preparo dos meios, o cultivo da alga e o preparo da suspensão alimentar são apresentadas nos Apêndices A, B, C, D e E).

Posteriormente, na produção de neonatas para realização de testes com o hormônio $\mathrm{EE}_{2}$ foram também utilizados cultivos com $P$. subcapitata cultivada em meio Chu-12 (fórmula do meio descrita no Apêndice C) na concentração de 1 x $10^{6}$ células $\mathrm{mL}^{-1}$ em virtude do 
aparecimento de neonatos machos em cultivos em que D. magna foi alimentada com Pseudokirchneriella subcapitata cultivada em meio Oligo.

\subsection{Principais Características do Ciclo de vida de Daphnia magna}

\section{$\underline{\text { Desenvolvimento embrionário }}$}

A duração do desenvolvimento embrionário de D. magna a $25 \pm 1^{\circ} \mathrm{C}$ foi determinada acompanhando-se e registrando-se o tempo de desenvolvimento do óvulo desde a sua transferência para a câmara incubadora da fêmea adulta (brood chamber) até o nascimento das neonatas. Para isso, fêmeas ovígeras foram isoladas e mantidas em recipientes separados até o nascimento das neonatas, cujo horário foi registrado. O comprimento do corpo de cada neonata foi medido em microscópio LEICA, com ocular micrometrada em aumento de até 40 vezes. Cada neonata foi mantida isoladamente em recipiente plástico, atóxico, com $50 \mathrm{~mL}$ de capacidade, em $30 \mathrm{~mL}$ de suspensão alimentar preparada com água reconstituída e células da microclorofícea $P$. subcapitata na concentração de $3,0 \times 10^{5}$ cels. $\mathrm{mL}^{-1}$. Foram estabelecidas 7 réplicas (Figura 3). A cada seis horas as neonatas eram observadas, e medidas a cada passagem para novo instar, até o estágio de primípara, isto é, a primeira produção de ovos. Os ovos desta primeira ninhada foram contados e fotografados acompanhando-se e registrando-se continuamente as transformações dos embriões a cada 3 horas, para a determinação das diferentes fases e duração do desenvolvimento embrionário. 


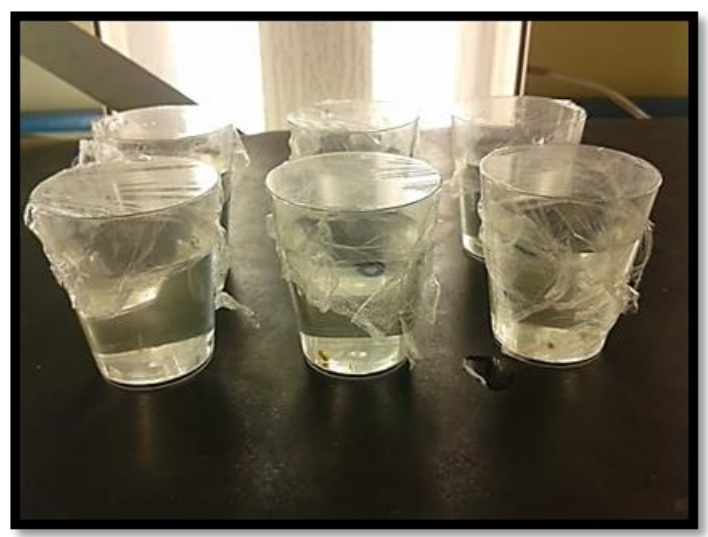

Figura 3-Recipientes plásticos atóxicos, com suspensão alimentar $(30 \mathrm{~mL}$ de água reconstituída e microalga clorofícea Pseudokirchneriella subcapitata na concentração de $3 \times 10^{5}$ céls $\mathrm{mL}^{-1}$ ) onde foi realizado o cultivo de Daphnia magna para o estudo de seu ciclo de vida sob condições controladas de $25 \pm 1{ }^{\circ} \mathrm{C}$, fotoperíodo de $12 \mathrm{~h}$ claro:12h escuro (Foto: Miguel, M., 2015).

\section{Desenvolvimento pós-embrionário}

Para o desenvolvimento pós-embrionário foram estabelecidas sete réplicas em que indivíduos foram mantidos isolados em recipientes plásticos com $30 \mathrm{~mL}$ de água reconstituída e nas mesmas condições controladas já descritas para os cultivos-estoque de Daphnia magna. As medições do tamanho do corpo foram feitas no sentido antero-posterior do corpo, sob microscópio estereoscópico. Para estas medições, os indivíduos foram transferidos, em cada observação, para lâminas escavadas de três cavidades $(75 \mathrm{~mm}$ de comprimento X $25 \mathrm{~mm}$ de largura) utilizando uma pipeta Pasteur com boca larga (Figura 4).

Os dados de comprimento $(\mathrm{mm})$ foram plotados em função do tempo (dias) e o ajustamento da curva de crescimento foi realizado pela equação de Von Bertalanffy, após obtenção do parâmetro inicial pela transformação de Ford-Walford. O modelo utilizado foi:

$$
\mathrm{L}_{\mathrm{t}}=\mathrm{L}_{\infty}\left[1-\mathrm{e}^{-\mathrm{K}(\mathrm{t}-\mathrm{t})}\right]
$$

Onde: $\mathrm{L}_{\mathrm{t}}=$ tamanho do corpo no intervalo de tempo $\mathrm{t}$, expresso em $\mathrm{mm} ; \mathrm{L}_{\infty}=$ comprimento máximo, expresso em $\mathrm{mm} ; \mathrm{K}=$ constante relacionada com a taxa de crescimento; e = base do 
logaritmo neperiano; $\mathrm{T}_{0}=$ parâmetro, expresso em dias, relacionado com o $\mathrm{L}_{\mathrm{t}}$ médio no instante do nascimento dos indivíduos.

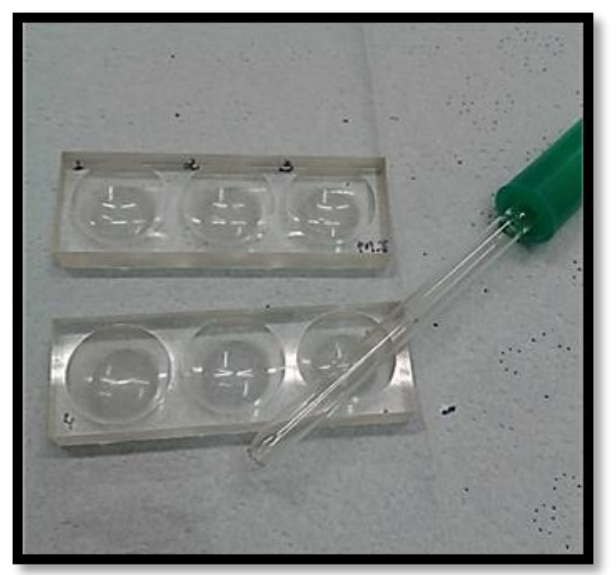

Figura 4-Vista da lâmina escavada com 3 cavidades e pipeta Pasteur de boca larga usadas para o manuseio dos indivíduos de Daphnia magna durante o experimento para o estudo do ciclo de vida da espécie sob condições ótimas e controladas (Foto: Miguel, M., 2015).

Para determinação da fecundidade, diariamente foram contados o número de ovos produzidos por cada fêmea. A longevidade foi determinada acompanhando-se o ciclo de vida, desde o nascimento até a morte de cada indivíduo. O tamanho do corpo e o tempo de geração, que é a idade da primípara (início da primeira reprodução), também foram determinados.

\subsection{Testes de toxicidade}

\subsubsection{Determinação da Sensibilidade do Organismo-Teste}

A faixa de sensibilidade de uma espécie é determinada por meio da realização de testes de toxicidade com uma substância de referência. Para a checagem da sensibilidade de Daphnia magna no presente estudo para as condições laboratoriais utilizadas, foi adotada como substância de referência o dicromato de potássio $\left(\mathrm{K}_{2} \mathrm{Cr}_{2} \mathrm{O}_{7}\right)$, com pureza analítica (p.a.) de $99 \%$ (Synth). A 
escolha deste composto deveu-se ao fato da faixa de sensibilidade desta espécie já ter sido previamente determinada para este composto (OLIVEIRA, 2014).

Para a realização dos testes foi preparada uma solução estoque de $100 \mathrm{mg} \mathrm{L}^{-1}$ de $\mathrm{K}_{2} \mathrm{Cr}_{2} \mathrm{O}_{7}$. A partir desta solução estoque foram preparadas soluções-teste em diferentes concentrações, por meio de diluições em série em água reconstituída (ABNT, 2009; OECD, 2004).

$\underline{\text { Teste de toxicidade aguda com o dicromato de potássio }}$

Antes de serem iniciados os testes de toxicidade crônica, foram realizados 5 testes de toxicidade aguda com a substância de referência dicromato de potássio para monitorar as condições fisiológicas dos indivíduos de Daphnia magna mantidos em cultivo no laboratório, a fim de verificar a sensibilidade dos mesmos nas condições laboratoriais estabelecidas para o presente estudo e checar se estes apresentavam a qualidade necessária para serem submetidos aos testes de toxicidade crônica para avaliação do potencial de disrupção endócrina do hormônio sintético etinilestradiol a esta espécie, em elevada temperatura.

Os testes de toxicidade aguda foram realizados segundo o protocolo da OECD (OECD, 2004). Os testes foram estáticos, ou seja, sem renovação do meio, e foram utilizados como organismos-teste as neonatas de Daphnia magna com menos de 24 horas de idade. Foram estabelecidas seis concentrações: 0,$1 ; 0,2 ; 0,4 ; 0,8 ; 1,6$ e $3,2 \mathrm{mg} \mathrm{L}^{-1}$ de dicromato de potássio, além do controle.

O teste foi feito em recipientes plásticos com capacidade de $50 \mathrm{~mL}$ sendo utilizado $10 \mathrm{~mL}$ de solução-teste e água de diluição (controle) em cada réplica. Foram feitas 4 réplicas por concentração, com 5 indivíduos em cada réplica (OECD, 2004). Para evitar a evaporação, os copos foram vedados com filme de plástico transparente.

Os recipientes-teste não foram aerados durante o experimento (48 h de duração) e os indivíduos não foram alimentados, sendo mantidos sob baixa luminosidade (OECD, 2004). O experimento foi mantido em câmara incubadora e BOD 347 CDG, Fanem ${ }^{\circledR}$, sob condição de temperatura controlada, $25 \pm 1{ }^{\circ} \mathrm{C}$. As variáveis $\mathrm{pH}$ e condutividade elétrica foram medidas no início e fim do teste. A dureza foi medida apenas no início do teste. 
Após 48 horas, os indivíduos foram observados em microscópio estereoscópico e contados, registrando-se os indivíduos imóveis para o cálculo da $\mathrm{CE}_{50}$ (concentração efetiva em que $50 \%$ dos indivíduos se apresentam imóveis) (OECD, 2004).

\subsubsection{Avaliação do Efeito de Disrupção Endócrina do Hormônio 17a-etinilestradiol sobre o cladócero Daphnia magna}

O hormônio 17 $\alpha$-etinilestradiol $\left(\mathrm{C}_{20} \mathrm{H}_{24} \mathrm{O}_{2}\right)\left(\mathrm{EE}_{2}\right)$ da marca Sigma Aldrich, com pureza $\geq$ 98\% (CAS: 57-63-6) foi adquirido. Por possuir baixa solubilidade em água, o metanol, com grau de pureza 99,5\% (Merck) foi utilizado como solvente para o preparo da solução estoque de $\mathrm{EE}_{2}$.

Para o teste preliminar de toxicidade crônica foi preparada uma solução estoque de $10 \mathrm{mg}$ $\mathrm{mL}^{-1}$. Para isto, $5 \mathrm{mg}$ de $\mathrm{EE}_{2}$ foram dissolvidos em $0.5 \mathrm{~mL}$ de metanol e diluídos para $5 \mathrm{~L}$ de água reconstituída, obtendo-se uma concentração final de solvente de $0,01 \%$.

Para o teste definitivo de toxicidade crônica foi preparada uma solução estoque de $40 \mathrm{mg}$ $\mathrm{mL}^{-1}$. Para isto, $10 \mathrm{mg}$ de $\mathrm{EE}_{2}$ foram dissolvidos em 0,25 mL metanol e diluídos em $5 \mathrm{~L}$ de água reconstituída, atingindo uma concentração final de solvente de $0,005 \%$.

A partir desta solução-estoque foram preparadas as soluções-teste em diferentes concentrações por meio de diluições em série, em água reconstituída.

$\underline{\text { Teste de toxicidade crônica do } 17 \alpha \text {-etinilestradiol }\left(\mathrm{EE}_{2}\right)}$

Não foram realizados testes de toxicidade aguda para o hormônio $\mathrm{EE}_{2}$, sendo que as concentrações testadas no teste preliminar de toxicidade crônica foram estabelecidas com base na literatura, acrescentando-se uma concentração acima e uma abaixo daquelas recomendadas (CLUBBS; BROOKS, 2007). O teste preliminar teve por objetivo observar os efeitos subletais na faixa de concentrações estabelecidas e visando a definir quais seriam as concentrações a serem 
utilizadas no teste definitivo. Os testes de toxicidade crônica foram realizados segundo o protocolo da OECD (2008).

O teste realizado foi semi - estático, sendo a renovação do meio feita dia sim e dia não. Os recipientes-teste consistiram de recipientes plásticos atóxicos, com capacidade de $120 \mathrm{~mL}$, nos quais foram adicionados $50 \mathrm{~mL}$ de solução-teste em cada réplica. Foram feitas 10 réplicas por concentração e por controle, com um indivíduo em cada. Os recipientes-teste não receberam aeração e os indivíduos foram alimentados a cada troca da solução-teste e permaneceram em incubadora com temperatura e fotoperíodo controlados, de acordo com os procedimentos estabelecidos na norma número 211 (OECD, 2008).

A cada troca, eram preparados novos meios tanto para os controles quanto para as diferentes concentrações do hormônio. $\mathrm{O}$ alimento foi renovado no momento das trocas, sendo este homogeneizado na água de diluição e na solução-teste. Foram fornecidos como alimento a suspensão algácea de Pseudokirchneriella subcapitata, na concentração de $3 \times 10^{5}$ células $\mathrm{mL}^{-1} \mathrm{e}$ um aditivo alimentar constituído de uma mistura de ração de peixe fermentada (TetraMin ${ }^{\circledR}$ ) e fermento biológico, na proporção de $1 \mathrm{~mL}$ para cada litro de meio. Os indivíduos-teste foram transferidos para o novo meio utilizando pipeta de Pasteur de boca larga para não os danificar (OECD, 2008). O teste foi mantido em incubadora com temperatura controlada de $25 \pm 1^{\circ} \mathrm{C}$ e fotoperíodo 12h:12h claro/escuro (Figura 5). Para evitar evaporação os recipientes-teste foram vedados com filme de plástico. 


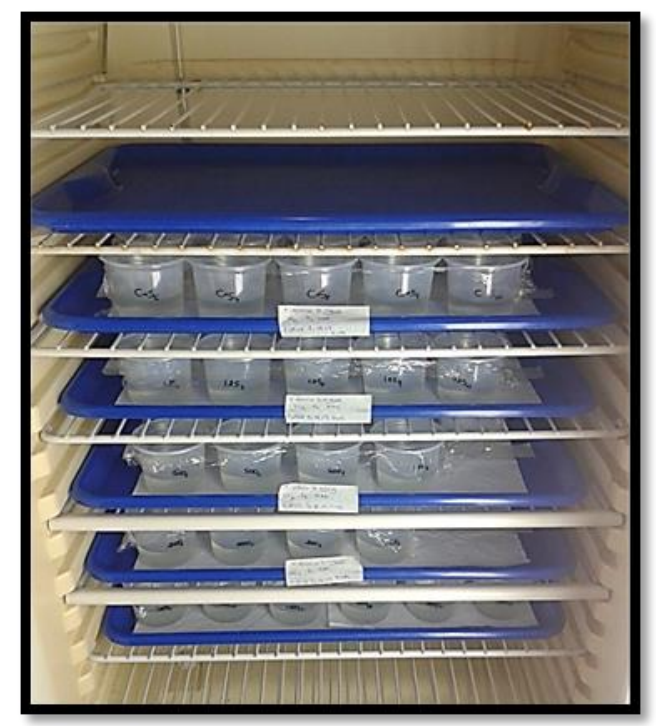

Figura 5-Vista do arranjo experimental de um teste de toxicidade crônica 17 1 -etinilestradiol $\left(\mathrm{EE}_{2}\right)$ já montado e mantido em incubadora do tipo BOD, com temperatura controlada de $25 \pm 1^{\circ} \mathrm{C}$ e fotoperíodo $12 \mathrm{~h}: 12 \mathrm{~h}$ claro/escuro (Foto: Miguel, M., 2015).

Para o teste preliminar foi utilizada uma solução estoque de $10 \mathrm{mg} \mathrm{mL}^{-1}$ de $\mathrm{EE}_{2}$, tendo sido estabelecidas seis concentrações $\left(31,25 ; 62,5 ; 125 ; 250 ; 500\right.$ e $\left.1000 \mu \mathrm{g} \mathrm{L}^{-1}\right)$ além do controle, e o controle com solvente metanol (concentração de solvente de 0,01\%), tendo como duração o período até a produção da terceira ninhada pelo grupo controle. Os indivíduos foram observados diariamente durante o decorrer do teste, registrando-se a mortalidade, a fase de desenvolvimento, o número da ninhada, e o número de neonatas produzidas.

Para o teste definitivo utilizou-se uma solução estoque de $40 \mathrm{mg} \mathrm{mL}^{-1}$ de $\mathrm{EE}_{2}$. Para realização de um teste multigeracional, avaliando-se a geração parental $\left(\mathrm{F}_{0}\right)$ e a primeira geração filial $\left(\mathrm{F}_{1}\right)$. Foram estabelecidas seis concentrações-teste: 62,$5 ; 125 ; 250 ; 500 ; 1000$ e $2000 \mu \mathrm{g} \mathrm{L}^{-1}$ além do controle com água reconstituída e o controle com o solvente metanol (concentração do solvente de 0,005\%). A geração $\mathrm{F}_{0}$ se iniciou com as neonatas com menos de 24 horas de idade, isolados a partir dos cultivos pré-teste. A duração do teste foi estabelecida como sendo o tempo desde a montagem do teste com neonatas com menos de 24 horas de idade, até que todos os indivíduos do controle produzissem a terceira ninhada. A partir da terceira ninhada produzida pela $\mathrm{F}_{0}$, foi realizado o teste com a geração $\mathrm{F}_{1}$. Para isso neonatas com menos de 24 horas de idade em cada grupo (grupo controle ou grupos tratados com hormônio em diferentes concentrações) foram transferidos, aleatoriamente, para novos meios com a mesma concentração 
em que se encontravam na geração $\mathrm{F}_{0}$. Esses neonatas foram analisadas durante todo o teste até produzirem a terceira ninhada de acordo com os procedimentos já descritos anteriormente (CLUBBS; BROOKS, 2007). O teste com a Fo durou 11 dias e o teste com a F1 teve a duração de 13 dias. Os indivíduos da $\mathrm{F}_{\mathbf{0}}$ e $\mathrm{F}_{\mathbf{1}}$ foram observados diariamente e foram analisadas as mesmas variáveis-resposta avaliadas nos testes anteriores.

As variáveis abióticas nas soluções-teste ( $\mathrm{pH}$, oxigênio dissolvido, dureza e temperatura) foram medidas no início, uma vez no decorrer da semana e no final do teste para: controle com água reconstituída, controle com o solvente metanol, soluções com a mais baixa, a mediana e a mais alta concentração do hormônio $\mathrm{EE}_{2}$ (OECD, 2008). As neonatas de cada ninhada e os adultos de cada ninhada foram, ao final do teste fixados com solução de formol a 4\%, para posteriores medições do tamanho corporal.

\subsection{Análises estatísticas}

Para o cálculo da CE50-48h e seu intervalo de $95 \%$ de confiança, foi utilizada a análise probit com o PriProbit Software livre (SAKUNA, 1998).

A análise da sobrevivência foi calculada pelo teste de Fisher. Para a análise dos dados de reprodução foi utilizado o programa Statistica 7.0 (STATSOFT, 2004). Inicialmente foram testadas a normalidade dos dados pelo teste de Kolmogorov-Smirnov e a homogeneidade das variâncias pelo teste de Bartlett. Quando os dados apresentaram distribuição normal, foi feita uma ANOVA paramétrica seguida do teste de Tukey (que compara cada tratamento com todos os outros) e do teste de Dunnet (que compara os tratamentos com o controle) (DEMŠAR, 2006; ZAR, 2010). Quando os dados não apresentaram distribuição normal, foi feita uma ANOVA não paramétrica seguida do teste de Kruskal-Wallis, que compara cada tratamento com todos os demais (THEODORSSON-NORHEIM, 1986; ZAR, 2010). 


\section{Resultados e discussão}

\subsection{O Ciclo de vida da Daphnia magna}

Algumas fases do desenvolvimento embrionário podem ser vistas na Figura 6. A fase embrionária de Daphnia magna inicia-se com a deposição dos ovos na câmara incubadora e prossegue à medida que o ovo vai sofrendo mudanças até a formação completa do embrião.

A primeira mudança no desenvolvimento é a presença de invaginações nos ovos, indicando a possível região cefálica. Durante seu desenvolvimento, os ovos passam por estágios de constrição, que indicam a simetria bilateral e estágios de mudança de tamanho e alongamento, formando o gânglio cerebral, olhos compostos, coração e outras características para a formação do embrião. No embrião, os olhos são posicionados para ficarem na lateral e o espinho caudal fica aderido ao pós-abdômen. No final do desenvolvimento embrionário, o espinho caudal não está mais aderido ao pós-abdômen e o embrião está pronto para sair da câmara de incubação da fêmea e ser livre natante.

Os aspectos morfológicos do desenvolvimento embrionário da Daphnia magna explicado anteriormente foram descritos pela primeira vez por Obreshkove e Fraser (1940) quando estes estudaram o crescimento e a diferenciação de ovos de Daphnia magna in vitro. Um padrão muito similar foi observado para outros cladóceros, como por exemplo por Freitas e Rocha (2006) para a espécie Pseudosida ramosa e por Kotov et al. (2013) para o cladócero Dunhevedia crassa.

Os aspectos morfológicos da pré-primípara, neonata, juvenil, fêmea com ovário em desenvolvimento, fêmea com ovário desenvolvido, primípara, ovos na câmara incubadora e embriões já formados antes de nascer, para a espécie Daphnia magna são apresentados na Figura 7. 
A

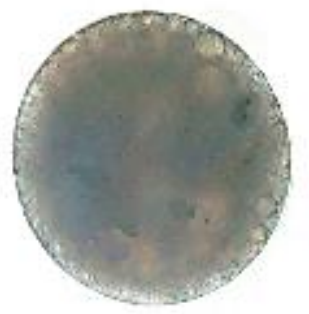

$\mathrm{C}$
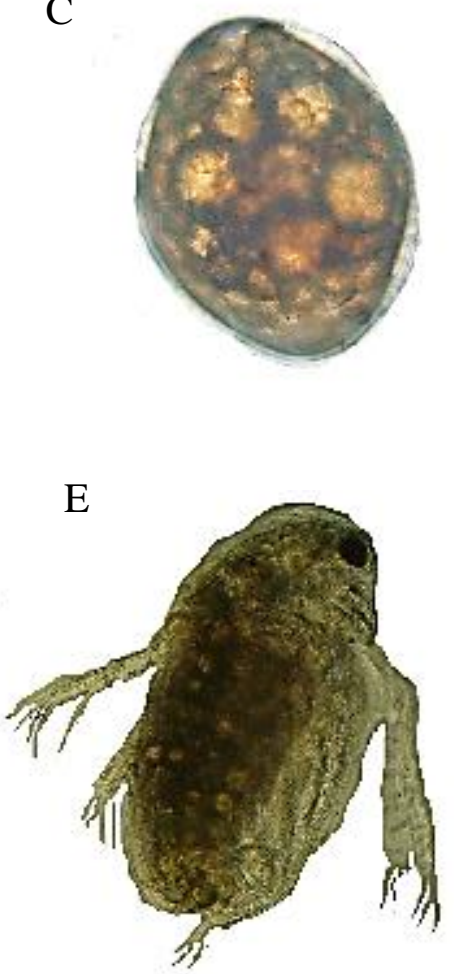

B

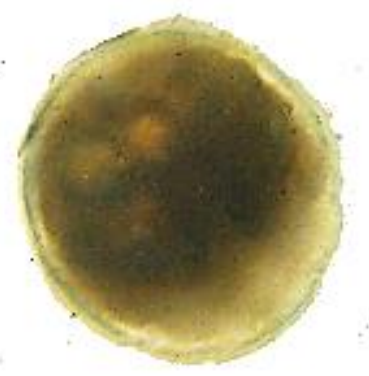

$\mathrm{D}$

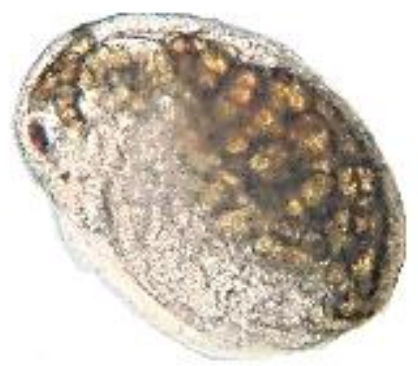

F

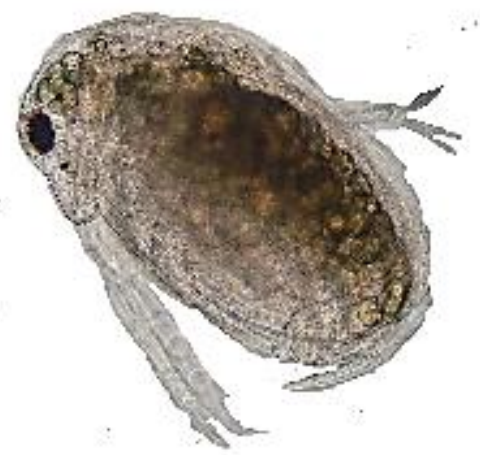

Figura 6-Aspectos morfológicos das fases do desenvolvimento embrionário de Daphnia magna cultivada em laboratório a $25 \pm 1^{\circ} \mathrm{C}$ : (A) ovo esférico; (B) formação de uma parte clara em torno da periferia, antecedendo a primeira invaginação; (C) as metades direita e esquerda são bem marcadas, sendo desenvolvida a simetria bilateral; (D) embrião com uma maior diferenciação dos olhos; (E) embrião com os olhos colocados lateralmente bem pronunciados e espinho caudal aderido ao pós-abdômen; (F) final do desenvolvimento embrionário, espinho caudal não aderido ao pós-abdômen, embrião formado pronto para nascer. Os dados representam as observações em 7 réplicas. (Fotos: Miguel, M., 2015). 
A

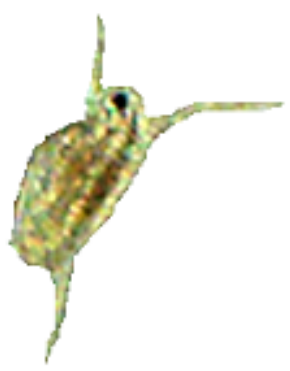

C

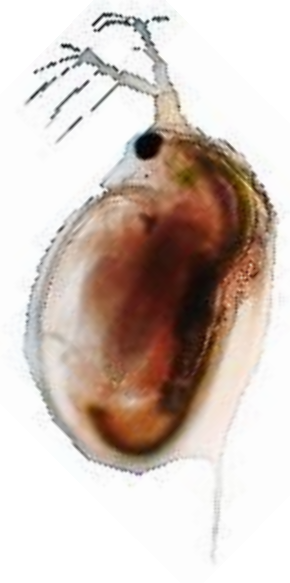

$\mathrm{E}$

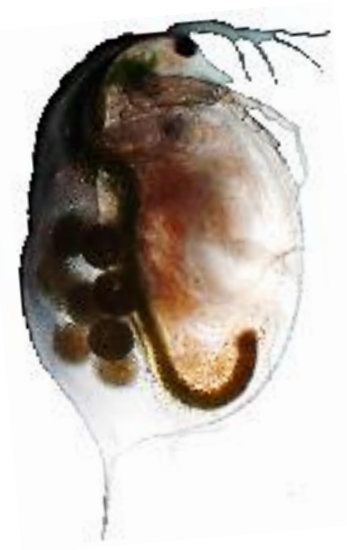

B

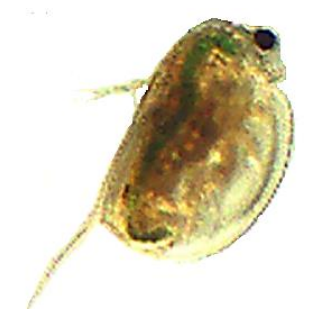

$\mathrm{D}$

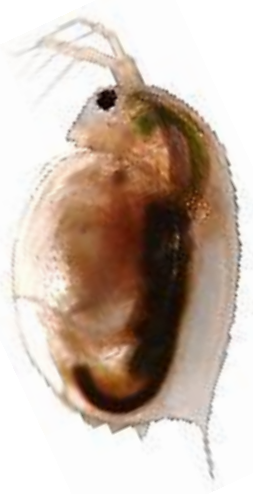

F

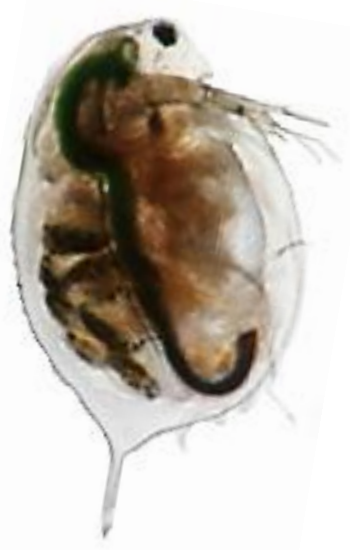

Figura 7-Aspectos morfológicos da pré-primípara (A, B, C e D) e da primípara (E e F) de Daphnia magna cultivada em laboratório a $25 \pm 1^{\circ} \mathrm{C}$, fotoperíodo de $12 \mathrm{~h}$ claro:12h escuro; (A) neonata (menos de 24 horas); (B) juvenil (mais de 24 horas de idade); (C) fêmea com o ovário em desenvolvimento; (D) fêmea com o ovário desenvolvido (antecede a deposição do ovo na câmara de incubação); (E) fêmea com os ovos na câmara de incubação e (F) fêmea com os embriões formados. (Fotos: Miguel, M., 2015). 
O desenvolvimento embrionário de Daphnia magna, desde a produção do ovo até o nascimento da primeira ninhada, teve duração média, de 43,47 $\pm 1,69$ horas, o que corresponde a $1,81 \pm 0,07$ dias.

A fecundidade média total para sete fêmeas e a fecundidade média de uma fêmea, a $25 \pm$ $1^{\circ} \mathrm{C}$ e outros parâmetros do ciclo de vida estão apresentados na Tabela 2.

Tabela 2-Variáveis analisadas e respectivos parâmetros obtidos ao longo do ciclo de vida (média \pm desvio padrão) do cladócero Daphnia magna cultivado sob condições controladas de laboratório: $25 \pm 1^{\circ} \mathrm{C}$; fotoperíodo de $12 \mathrm{~h}$ claro: $12 \mathrm{~h}$ escuro e alimentado com suspensão da microclorofícea Pseudokirchneriella subcapitata, na concentração de $3 \mathrm{x}$ $10^{5}$ células $\mathrm{mL}^{-1}$ e aditivo alimentar constituído de uma mistura de ração de peixe fermentada (TetraMin ${ }^{\circledR}$ ) e fermento biológico, na proporção de $1 \mathrm{~mL}$ para cada litro de suspensão.

\begin{tabular}{cc}
\hline Variáveis do ciclo de vida & Parâmetros \\
\hline Tamanho médio da neonata $(\mathrm{mm})$ & $1,16 \pm 0,05$ \\
Tamanho médio da primípara (mm) & $2,92 \pm 0,13$ \\
\hline Idade média da primípara (dias) & $4,19 \pm 0,31$ \\
\hline Tamanho médio do adulto na terceira geração (mm) & $3,38 \pm 0,21$ \\
\hline Tamanho médio do adulto na sexta geração (mm) & $3,69 \pm 0,06$ \\
\hline Fecundidade média (No de ovos por fêmea) & $28,17 \pm 26,5$ \\
\hline Fecundidade total (No de ovos em toda vida) & $189,14 \pm 44,43$ \\
\hline Longevidade média (dias) & $68,14 \pm 14,36$ \\
\hline Longevidade máxima (dias) & $1,81 \pm 0,07$ \\
\hline Duração do desenvolvimento embrionário (dias) & \\
\hline
\end{tabular}

Para Daphnia magna a temperatura é uma variável responsável por alteração dos parâmetros do ciclo de vida obtidos para as variáveis longevidade, fecundidade, duração do desenvolvimento embrionário e idade da primípara. 
No presente estudo, a $25^{\circ} \mathrm{C}$ a duração do desenvolvimento embrionário da espécie Daphnia magna foi de 1,8 dias, sendo que nos estudos de Rocha (1983), para a mesma espécie, na temperatura de $20^{\circ} \mathrm{C}$ a duração do desenvolvimento embrionário foi de 3,5 dias.

A temperatura é um fator que pode alterar o desenvolvimento de organismos (MELÃO; ROCHA, 2006), sendo que temperaturas mais altas podem acelerar o desenvolvimento, diminuindo o tempo de duração do desenvolvimento embrionário e pós-embrionário e, portanto, o tempo de geração (GOSS; BUNTING, 1983). Obreshkove e Fraser (1940) observaram que quando os ovos de D. magna eram submetidos a uma temperatura mais baixa, o completo desenvolvimento embrionário era prolongado.

Freitas e Rocha (2006) analisaram o ciclo de vida do cladócero Pseudosida ramosa sob duas temperaturas $\left(25\right.$ e $\left.30 \pm 0,5^{\circ} \mathrm{C}\right)$, e tiveram como resultado que o desenvolvimento embrionário a $25 \pm 0,5^{\circ} \mathrm{C}$ foi de 50 horas, enquanto a $30 \pm 0,5^{\circ} \mathrm{C}$ foi de 33 horas, demonstrando que o aumento da temperatura diminuiu o tempo de desenvolvimento embrionário dos organismos estudados. A diminuição do tempo de desenvolvimento embrionário com o aumento da temperatura também foi observada por Melão e Rocha (2006) para a espécie Bosminopsis deitersi (Cladocera) mantido em temperaturas de 20 e $25 \pm 1^{\circ} \mathrm{C}$, apresentando tempos de desenvolvimento embrionário médios de 1,62 dias e 1,21 dias, respectivamente,

Allan (1976) avaliou os parâmetros do ciclo de vida de microcrustáceos e rotífero cultivados em três temperaturas: 10,20 e $25^{\circ} \mathrm{C}$. Para o grupo dos cladóceros, ele constatou que em menores temperaturas ocorria um crescimento e maturação mais lenta, sendo que o tempo de maturação (ovo a ovo) de Daphnia sp foi de $20-24$ dias a $10^{\circ} \mathrm{C}$; de $7-8$ dias a $20^{\circ} \mathrm{C}$; e de 5,5 a 6,5 dias a $25^{\circ} \mathrm{C}$.

Um outro parâmetro do ciclo de vida de D. magna alterado pela temperatura foi a idade da primípara a qual apresentou um valor médio de aproximadamente 4 dias, a $25^{\circ} \mathrm{C}$, enquanto Rocha (1983) obteve o valor foi de 7,5 dias a $20^{\circ} \mathrm{C}$. Em estudos com outras espécies de cladóceros foram observadas alterações semelhantes em relação à idade da primípara sob diferentes condições de temperatura, como por exemplo, para Bosminopsis deitersi cultivado a $20^{\circ} \mathrm{C}$ a idade da primípara foi de 4,5 dias, enquanto a $25^{\circ} \mathrm{C}$ foi de aproximadamente 3 dias (MELÃO; ROCHA, 2006). Dessa forma, em temperaturas mais elevadas, o metabolismo do indivíduo é acelerado. 
A variação nos valores da fecundidade média por ninhada durante todo o ciclo de vida do cladócero Daphnia magna, estão apresentados na Figura 8. Pode-se observar que o maior número médio de ovos por fêmea ocorreu na quarta ninhada com aproximadamente 19 ovos, seguido da décima segunda ninhada com 15 ovos.

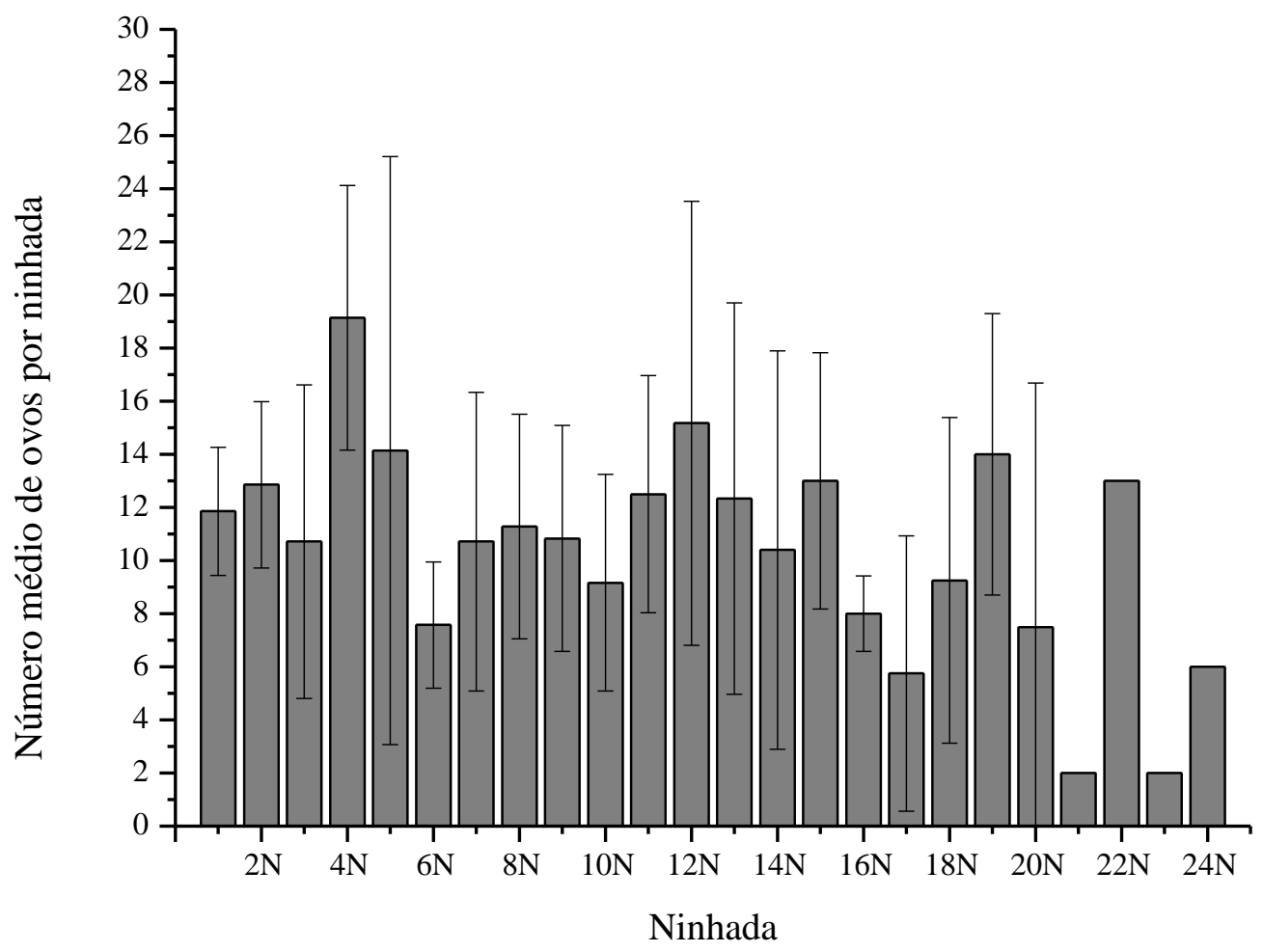

Figura 8-Variação da fecundidade média por ninhada de Daphnia magna, ao longo da fase reprodutiva do seu ciclo de vida quando cultivada a $25 \pm 1^{\circ} \mathrm{C}$, fotoperíodo de $12 \mathrm{~h}$ claro: $12 \mathrm{~h}$ escuro e alimentada com suspensão da microclorofícea Pseudokirchneriella subcapitata, na concentração de $3 \times 10^{5}$ células $\mathrm{mL}^{-1}$ e aditivo alimentar constituído de uma mistura de ração de peixe fermentada (TetraMin ${ }^{\circledR}$ ) e fermento biológico, na proporção de $1 \mathrm{~mL}$ para cada litro de suspensão. As barras representam os valores médios obtidos para sete réplicas e respectivos desvios-padrão.

Com relação à fecundidade média, o aumento da temperatura faz com que ocorra uma redução no número de ovos por fêmea (ANDERSON; JENKINS, 1942; GOSS; BUNTING, 1983) como evidenciado no estudo de Goss e Bunting (1983), que avaliaram o desenvolvimento e a reprodução da $D$. magna e $D$. pulex em diferentes temperaturas. Foi constatado que o aumento da temperatura acelerava o desenvolvimento, porém o número de neonatas produzidos por fêmea nos três primeiros instares adultos aumentava até $20^{\circ} \mathrm{C}$ e depois diminuía. Em média, para $D$. magna os referidos autores registraram até o terceiro instar adulto, um total de 65,5 neonatas por 
fêmea a $20^{\circ} \mathrm{C}$ e de 46,0 neonatas por fêmea a $25^{\circ} \mathrm{C}$, um valor um pouco mais elevado que o obtido no presente estudo, que foi em média, de 36, aproximadamente, ovos por fêmea. Essa variação em relação ao número de neonatas produzidas também ocorreu com a outra espécie em estudo, D. pulex, para a qual foi observado que em temperaturas abaixo de $15^{\circ} \mathrm{C}$ e acima de $20^{\circ}$ C pode ocorrer uma diminuição dos neonatas produzidos nos primeiros três instares adultos, sendo que a $20^{\circ} \mathrm{C}$ teve uma média de 55,6 neonatas.

Um outro parâmetro obtido para $D$. magna foi a longevidade média que, no presente estudo, foi de 48 dias a $25^{\circ} \mathrm{C}$. A longevidade é também uma variável diretamente influenciada pela temperatura. Em maiores temperaturas a longevidade média dos organismos diminui, como observado por Allan (1976), que para cladóceros do gênero Daphnia cultivados a $20^{\circ} \mathrm{C}$ obteve longevidade média de 50 dias, enquanto para os indivíduos cultivados a $25{ }^{\circ} \mathrm{C}$ a longevidade média foi de 40 dias. Essa redução foi também observada para outros grupos por ele estudados, como espécies de rotíferos, que apresentaram uma redução de 15 dias na longevidade com a mudança de temperatura de $10^{\circ} \mathrm{C}$ para $25^{\circ} \mathrm{C}$, e para os copépodos, com redução de 45 dias com a alteração da temperatura de $10^{\circ} \mathrm{C}$ para $25^{\circ} \mathrm{C}$. Esse mesmo padrão foi observado para o cladócero da família Sididae Pseudosida ramosa, no qual a longevidade média decresceu com o aumento da temperatura tendo sido de aproximadamente 37 dias a $25{ }^{\circ} \mathrm{C}$ e de 15 dias a $30{ }^{\circ} \mathrm{C}$ (FREITAS; ROCHA, 2006) e para o cladócero Bosminopsis deitersi, com a longevidade média foi de 11,85 dias a $20^{\circ} \mathrm{C}$ e 9,41 dias a $25^{\circ} \mathrm{C}$ (MELÃO; ROCHA, 2006).

A longevidade média de aproximadamente 48 dias obtida para Daphnia magna no presente estudo pode ser indício da seleção de organismos por evolução mais rápida em temperaturas mais elevadas para o clone desta espécie já adaptado por um longo período (cerca de 5 anos) a temperaturas de $25^{\circ} \mathrm{C}$ ou mais.

No presente estudo o crescimento individual de Daphnia magna foi analisado plotando-se as variações de comprimento do corpo em relação à idade dos indivíduos. A curva de crescimento obtida é apresentada na Figura 9. Essa curva de crescimento pode ser descrita por uma função logística, pois após um período de crescimento exponencial, a taxa de crescimento diminuiu, como resultado de um crescimento mais lento. 


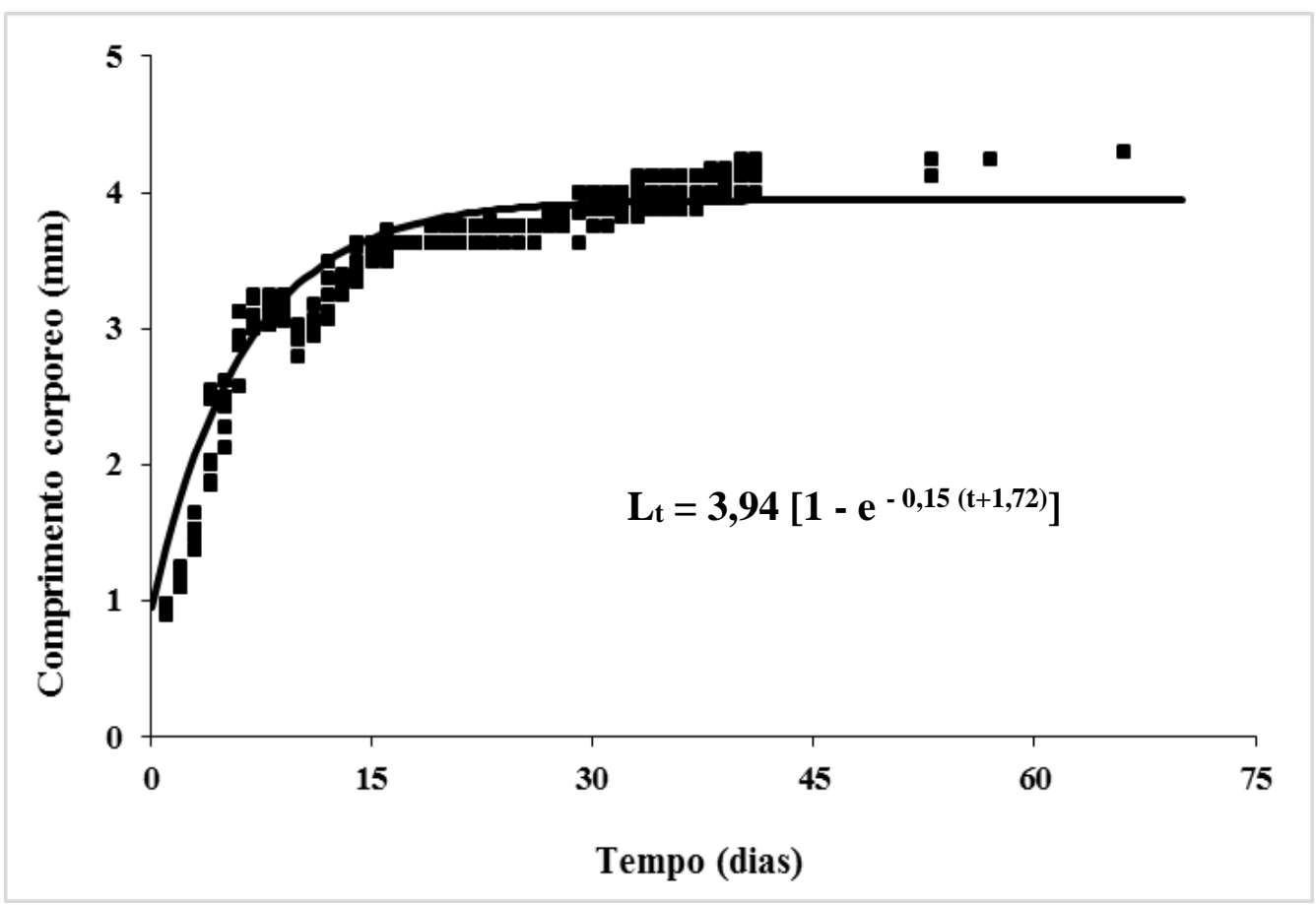

Figura 9-Curva de crescimento individual de Daphnia magna cultivada a $25 \pm 1^{\circ} \mathrm{C}$ fotoperíodo de $12 \mathrm{~h}$ claro: $12 \mathrm{~h}$ escuro e alimentado com suspensão da microclorofícea Pseudokirchneriella subcapitata, na concentração de $3 \times 10^{5}$ células $\mathrm{mL}^{-1}$ e aditivo alimentar constituído de uma mistura de ração de peixe fermentada (TetraMin ${ }^{\circledR}$ ) e fermento biológico, na proporção de $1 \mathrm{~mL}$ para cada litro de suspensão. Os pontos representam os valores empíricos do tamanho do corpo obtidos nas sete réplicas $\left(\mathrm{r}^{2}=0,9589\right)$.

Observa-se na Figura 9 que as neonatas de D. magna apresentam maior crescimento na fase inicial de seu ciclo de vida com uma taxa de crescimento acelerada até aproximadamente 10 dias, alcançando um pouco mais de $3 \mathrm{~mm}$. Uma vez atingido esse tamanho, o organismo atinge a maturidade, começa a se reproduzir e a taxa de crescimento diminui, embora não cesse completamente. Essa estratégia de canalizar energia inicialmente no crescimento e posteriormente em reprodução já foi amplamente demonstrada para outras espécies de cladóceros (Scapholeberis rammneri) como descrito por Dumont (1987) e também por Fonseca e Rocha (2004) para Ceriodaphnia silvestrii, mantida a $25^{\circ} \mathrm{C}$ e fotoperíodo $12 \mathrm{~h}$ claro: $12 \mathrm{~h}$ escuro e por Castilho, Wisniewski e Santos-Wisniewski (2012) para Scapholeberis armata freyi, cultivada a a $23 \pm 0,5^{\circ} \mathrm{C}$ e fotoperíodo $12 \mathrm{~h}$ claro: $12 \mathrm{~h}$ escuro.

O valor médio do comprimento da neonata de D. magna foi de aproximadamente $1 \mathrm{~mm}$ e o do adulto na produção da terceira e da sexta ninhada foram, respectivamente, 3,3 e 3,6 mm. O tamanho máximo dos adultos $(4,3 \mathrm{~mm})$ foi inferior ao já registrado em estudos anteriores como os valores de 5 a $6 \mathrm{~mm}$ registrados por Koivisto (1995), ou de $5 \mathrm{~mm}$ obtido por Allan (1976). 
Com a elevação da temperatura o metabolismo é acelerado e o custo energético aumenta exponencialmente diminuindo o tamanho do corpo e da ninhada. Em geral, maiores comprimentos corpóreos geram ninhadas maiores, em menores temperaturas (Allan, 1976).

Após avaliar o ciclo de vida da Daphnia magna, um organismo que habita regiões temperadas, a $25^{\circ} \mathrm{C}$, ou seja, em temperatura mais elevada do que aquelas usualmente experimentadas em sua área de distribuição geográfica natural pode-se considerar que o aumento futuro na temperatura da água devido às já previstas alterações climáticas globais (EEA, 2012) possivelmente acarretaria alterações no ciclo de vida dos organismos e no funcionamento de ecossistemas aquáticos (STRAILE; ADRIAN; SCHINDLER, 2012; WALTHER et al., 2002; WINDER; SCHINDLER, 2004). Essas alterações puderam ser constatadas para Daphnia magna, no presente estudo em que o aumento da temperatura acelerou o metabolismo do indivíduo, assim como diminuiu a longevidade e a fecundidade média. As diferenças observadas em alguns parâmetros do ciclo de vida obtidos no presente estudo e em de outros estudos para esta mesma espécie de cladócero são provavelmente resultantes de adaptações intrínsecas dos clones desta espécie a diferentes temperaturas e ou a diferenças na nutrição das culturas de laboratório.

\subsection{Avaliação da Sensibilidade de Daphnia magna}

\subsubsection{Teste de sensibilidade de Daphnia magna à substância de referência dicromato de potássio}

Os dados brutos referentes aos testes de toxicidade aguda do dicromato de potássio para Daphnia magna são apresentados no Apêndice F.

Os resultados relativos aos valores de $\mathrm{CE}_{50-48 \mathrm{~h}}$ do dicromato de potássio para Daphnia magna, e os respectivos valores do desvio-padrão, variância e coeficiente de variação, são apresentados na Tabela 3. 
Tabela 3-Valores da Concentração efetiva (CE50-48h) do dicromato de potássio expressos em $\mathrm{mg} \mathrm{L}^{-1}$ e seus respectivos intervalos de confiança (IC) com 95\% de confiabilidade, resultantes de testes toxicidade aguda com o cladócero Daphnia magna. São também apresentados o valor médio, o desvio padrão (DP), a variância e o coeficiente de variação $(\mathrm{CV})$.

\begin{tabular}{ccc}
\hline Teste & CE $_{\mathbf{5 0 - 4 8 h}}$ & IC (95\%) \\
\hline $\mathbf{1}$ & 0,534 & $0,415-0,684$ \\
\hline $\mathbf{2}$ & 0,344 & $0,154-0,756$ \\
\hline $\mathbf{3}$ & 0,493 & $0,412-0,589$ \\
\hline $\mathbf{4}$ & 0,282 & $0,241-0,330$ \\
\hline $\mathbf{5}$ & 0,368 & $0,146-1,140$ \\
\hline Média & \multicolumn{2}{c}{0,404} \\
\hline DP & \multicolumn{2}{c}{0,105} \\
\hline Variância & \multicolumn{2}{c}{0,011} \\
\hline CV (\%) & \multicolumn{2}{c}{26} \\
\hline
\end{tabular}

A CE50-48h variou de 0,282 a 0,534 mg de dicromato de potássio por litro. As variáveis abióticas das soluções-teste tiveram as seguintes faixas de variação: pH 7,65 a 8,55; dureza 124 a $228 \mathrm{mg} \mathrm{CaCO}_{3} \mathrm{~L}^{-1}$ e condutividade elétrica 607 a $983 \mu \mathrm{S} \mathrm{cm}^{-1}$.

No presente estudo a faixa de sensibilidade de Daphnia magna ao dicromato de potássio situou-se entre 0,19 e $0,61 \mathrm{mg} \mathrm{L}^{-1}$, com valor médio de $\mathrm{CE}_{50}$ de 0,404 $\mathrm{mg} \mathrm{L}^{-1}$. Essa faixa pode ser observada na Figura 10.

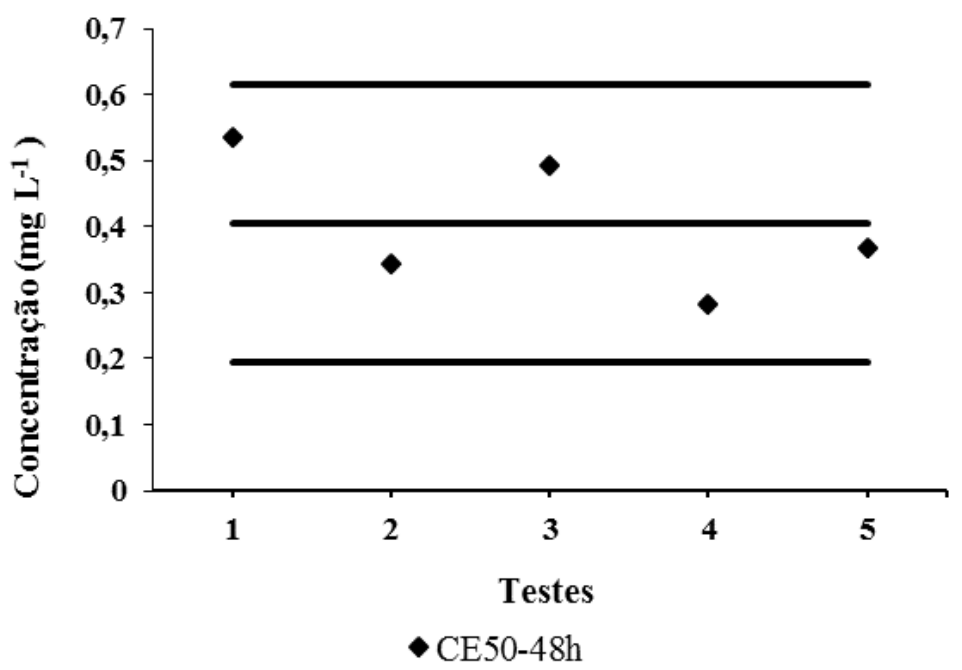

Figura 10-Faixa de sensibilidade de Daphnia magna exposta à substância de referência dicromato de potássio, em cinco testes de toxicidade aguda, $\mathrm{CE}_{50-48 \mathrm{~h}}(\mathrm{mg} \mathrm{L}-1)$ nas condições constantes de $25^{\circ} \mathrm{C}$ e fotoperíodo de $12 \mathrm{~h}$ luz: $12 \mathrm{~h}$ escuro. 
Estes resultados indicaram que os organismos cutivados encontravam-se saudáveis e sensíveis ao dicromato de potássio dentro da faixa de sensibilidade anteriormente estabelecida por outros autores: Persoone et al. (2009) obtiveram um valor médio de CE50-24h do dicromato de potássio para $D$. magna de $1,46 \mathrm{mg} \mathrm{L}^{-1}$, para um total de 129 testes realizados em um conjunto de laboratórios especializados e também Yeon, Yun e Min (2011) obtiveram um valor médio de $\mathrm{CE}_{50-48 \mathrm{~h}}$ de $1,25 \mathrm{mg} \mathrm{L}^{-1}$ para a do dicromato de potássio A maior sensibilidade de D.magna no presente estudo (valor médio de $\mathrm{CE}_{50-48 \mathrm{~h}}$ do dicromato de potássio de 0,404 $\mathrm{mg} \mathrm{L}^{-1}$ ) provavelmente resulta do fato de que nos testes realizados pelos referidos autores o tempo de exposição foi menor (de 24 horas no estudo de Persoone et al., 2009) e em temperatura mais baixa $\left(22^{\circ} \mathrm{C}\right.$, nos testes dos autores citados e $25^{\circ} \mathrm{C}$ no presente estudo).

\subsection{Disrupção endócrina do EE2 ao cladócero Daphnia magna - Teste de toxicidade crônica}

Os dados brutos referentes às variáveis físicas e químicas medidas nas soluções-teste são apresentadas no Apêndice G. As variáveis medidas durante o experimento com a geração parental (Fo) tiveram as seguintes faixas de variação: pH de 7,7 a 7,9; dureza de 172 a $204 \mathrm{mg}$

$\mathrm{CaCO}_{3} \mathrm{~L}^{-1}$; oxigênio dissolvido de 4,92 a 7,90 $\mathrm{mg} \mathrm{L}^{-1}$ e temperatura de 24,5 a $25,4{ }^{\circ} \mathrm{C}$. Para a segunda geração $\left(\mathrm{F}_{1}\right)$ as faixas de variação foram: $\mathrm{pH}$ de 7,7 a 7,95; dureza de 170 a $200 \mathrm{mg}$ $\mathrm{CaCO}_{3} \mathrm{~L}^{-1}$; oxigênio dissolvido de 4,03 a $6,05 \mathrm{mg} \mathrm{L}^{-1}$ e temperatura de 19 a $25,6{ }^{\circ} \mathrm{C}$.

Para a sobrevivência, de acordo com o teste de Fisher não ocorreram diferenças estatisticamente significativas entre as concentrações testadas e os controles em $\mathrm{F}_{0}(\mathrm{p}=0,7571)$ e em $F_{1}(p=0,7571)$.

Os resultados sobre a tempo de geração da ninhada, ou seja, quanto tempo o adulto demora para gerar seus descendentes (primeira, segunda e terceira ninhada), estão plotados na Figura 11. Para a geração $\mathrm{F}_{0}$ não foi observada diferença significativa entre as concentrações e os controles com relação ao tempo para gerar cada ninhada. A geração F1 apresentou diferença significativa na primeira e na segunda ninhada, demorando mais dias para gerar essas ninhadas quando comparadas ao controle. 

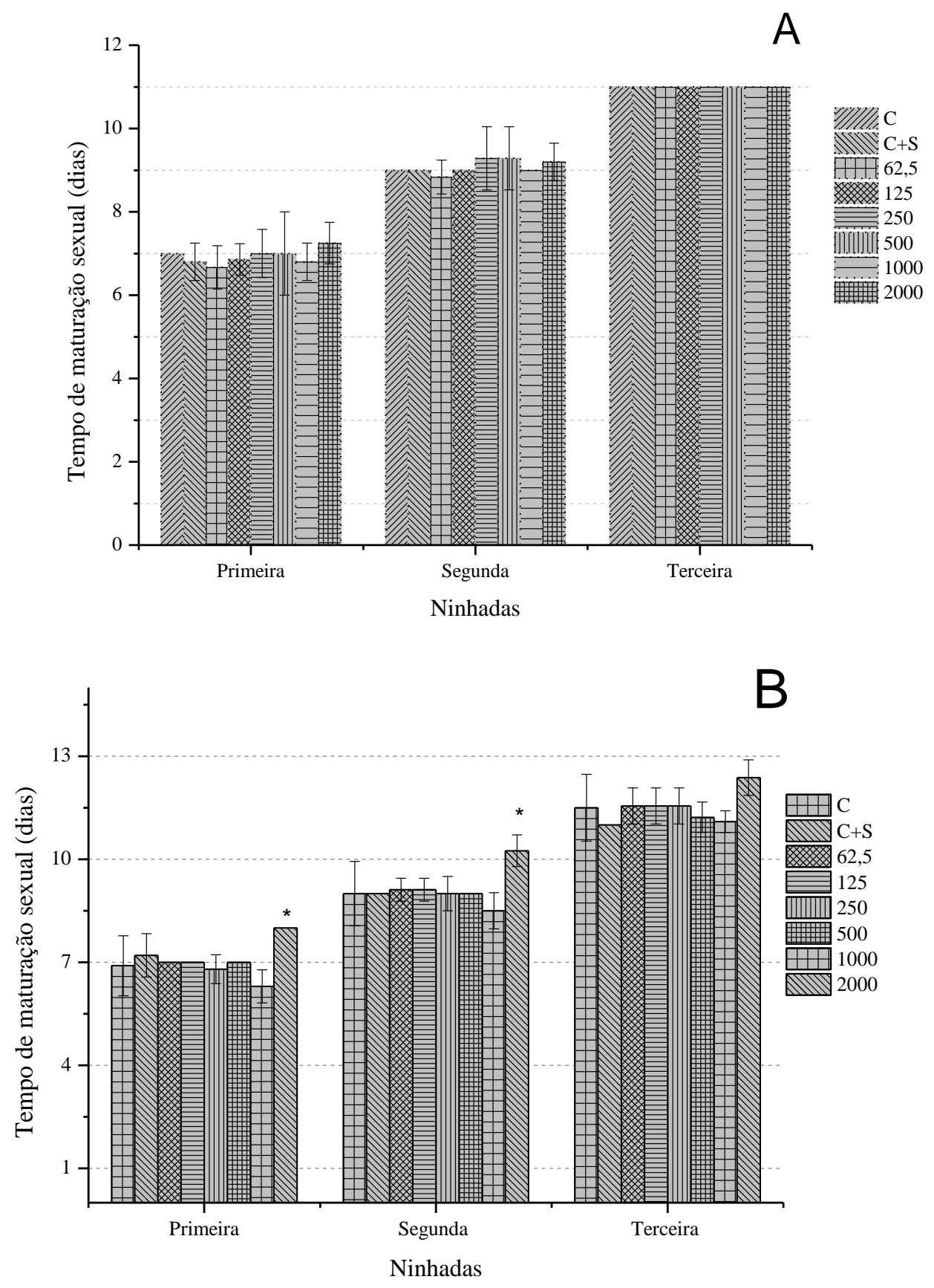

Figura 11-Tempo para geração das ninhadas (em dias) por Daphnia magna exposta ao hormônio sintético $17 \alpha$ etinilestradiol $\left(\mathrm{EE}_{2}\right)$ em cada tratamento e no controle, para as gerações $\mathrm{F}_{\mathbf{0}}(\mathrm{A})$ e $\mathrm{F}_{\mathbf{1}}(\mathrm{B})$. As colunas indicam as concentrações testadas e os controles, sendo C (controle com água reconstituída) e $\mathrm{C}+\mathrm{S}$ (controle com o solvente metanol). O símbolo asterisco (*) indica os resultados com diferenças estatisticamente significativas em comparação com os controles. 
Dietrich et al. (2010) observaram que os indivíduos de D. magna da geração $\mathrm{F}_{0}$ exposta ao $\mathrm{EE}_{2}$ atingiram maturidade mais rapidamente do que os do controle. Nas outras gerações $\left(\mathrm{F}_{1}\right.$, $F_{2}, F_{3}, F_{4}$ e $\left.F_{5}\right)$ não foram observadas diferenças significativas no efeito do hormônio etinilestradiol entre as concentrações e os controles. Outros compostos por eles estudados, carbamazepina, diclofenaco e metoprolol (isolados e em mistura também com o $\mathrm{EE}_{2}$ ) tiveram efeitos diferentes, sendo que carbamazepina e diclofenaco atrasaram a maturidade dos indivíduos da geração $\mathrm{F}_{0}$ enquanto, o metoprolol e a mistura dos fármacos aceleraram a maturidade dos indivíduos. Em relação às outras gerações, comparadas com o controle, houve atraso da maturidade apenas com o tratamento de diclofenaco na geração $F_{2}$, e comparado com a mistura, houve atraso da maturidade no tratamento com diclofenaco na geração $F_{1}$ e $F_{2}$ e no tratamento com carbamazepina na geração $F_{2}$. A mistura, na geração $F_{2}$, diminuiu a idade da primeira reprodução dos indivíduos quando comparado com o controle. As gerações $F_{3}, F_{4}$ e $F_{5}$ não tiveram a idade da primeira reprodução afetada.

Os valores médios do número de neonatas produzidas pelas fêmeas de D. magna (até a terceira ninhada) nas gerações $F_{0}$ e $F_{1}$ no decorrer do experimento com exposição ao hormônio sintético $17 \alpha$ - etinilestradiol $\left(\mathrm{EE}_{2}\right)$ são apresentados na Figura 12. 

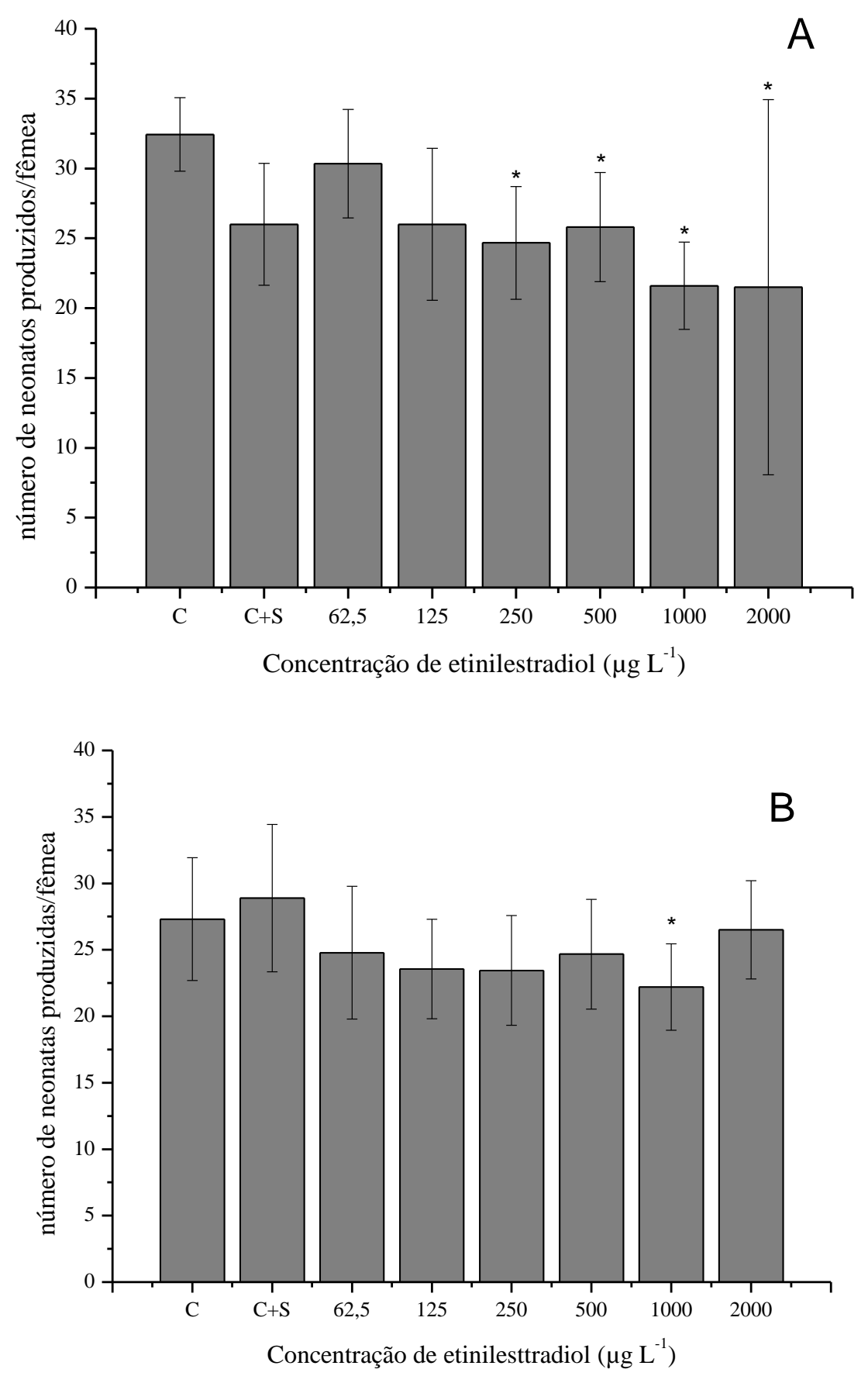

Figura 12-Número médio de neonatas produzidas por fêmea de Daphnia magna na primeira geração $\mathrm{F}_{0}$ (A) e na segunda geração $F_{1}(B)$ quando submetidas ao teste de toxicidade crônica com o hormônio etinilestradiol. As colunas representam o número médio de neonatas produzidos nos controles e em cada concentração $\left(\mu \mathrm{g} \mathrm{L}{ }^{-1}\right)$ e as linhas verticais representam os desvios-padrão, para dez réplicas. O asterisco $(*)$ representa a existência de diferenças estatisticamente significativas na fecundidade de Daphnia magna entre as concentrações de etinilestradiol testadas e os controles. 
Ocorreram diferenças significativas em relação ao número de neonatas produzidas pelas fêmeas da geração Fo expostas ao hormônio etinilestradiol nas concentrações de $250 \mu \mathrm{L}^{-1}$ (p = 0,012), $500 \mu \mathrm{L}^{-1}(\mathrm{p}=0,047), 1000 \mu \mathrm{L}^{-1}(\mathrm{p}=0,0008)$ e $2000 \mu \mathrm{L}^{-1}(\mathrm{p}=0,014)$, quando comparadas aos controles, sendo que nestes tratamentos a produção de neonatas foi menor do que nos controles. Já para a geração F1 só ocorreu diferença significativa na produção de neonatas na concentração de $1000 \mu \mathrm{L}^{-1}(\mathrm{p}=0,032)$. Nessa concentração o número médio de neonatas por fêmea foi significativamente menor que nos controles

Os resultados obtidos rejeitam, portanto, a hipótese levantada de que a fecundidade aumentaria nos indivíduos de D. magna após exposição prolongada ao $\mathrm{EE}_{2}$.

Clubbs e Brooks (2007) avaliaram a resposta de D. magna aos compostos $\mathrm{EE}_{2}, 20$ hidroxiecdisona, faslodex e testosterona. Para o $\mathrm{EE}_{2}$, observaram uma diminuição da fecundidade de $\mathrm{F}_{0}$ em todas as concentrações testadas na terceira ninhada e uma diminuição da fecundidade na geração $\mathrm{F}_{1}$ na concentração mais elevada, de $1000 \mu \mathrm{g} \mathrm{L}^{-1}$. Para todos os compostos testados, a geração $F_{1}$ não foi tão afetada como a geração $F_{0}$, ou seja, as ninhadas afetadas na geração $F_{0}$ nem sempre foram afetadas na geração $\mathrm{F}_{1}$, indicando que os organismos de gerações sucessivas podem adquirir resistência ao contaminante. A resistência ao contaminante, assim como a diminuição da fecundidade, também foi observada por Dietrich et al. (2010) que expuseram $D$. magna a quatro fármacos, entre eles o $\mathrm{EE}_{2}$.

A resistência ao contaminante pode ser fisiológica ou genética. Os organismos podem adquirir tolerância a substâncias contaminantes por aclimatação (evento fisiológico) ou por uma adaptação genética devido à seleção natural (DIETRICH et al., 2010; KLERKS; WEIS, 1987). No caso do presente estudo, pode-se supor que a resistência foi adquirida por aclimatação.

Nem todos os organismos expostos ao etinilestradiol adquirem resistências nas gerações subsequentes. O estudo de Bhandari, voom Saal e Tillit (2015) com peixes da espécie Oryzias latipes mostrou que o $\mathrm{EE}_{2}$ produziu efeitos trangeracionais, diminuindo a taxa de fertilização e aumentando a incidência da mortalidade embrionária. No caso, que não ocorreram diferenças significativas na fertilidade nas gerações $F_{0}$ e $F_{1}$, mas na geração $F_{2}$ ocorreu uma redução. Com relação a sobrevivência dos embriões, não ocorreram diferenças significativas nas gerações $\mathrm{F}_{0}, \mathrm{~F}_{1}$ e $F_{2}$, mas nas gerações subsequentes ocorreu uma redução nessa sobrevivência. Efeitos transgeracionais também são observados nos peixes da espécie Pimephales promelas, estudados 
por Schwindt et al. (2014), demonstrando também que não foi possível a recuperação da população dos peixes expostos, quando estes foram submetidos à água sem o contaminante.

No estudo de Goto e Hiromi (2003), a espécie D. magna foi exposta a dois compostos que constituem contraceptivos orais, o $\mathrm{EE}_{2}$ e Noretindrona. Observaram que nas duas maiores concentrações do $\mathrm{EE}_{2}$ (100 e 500 ppb), a fecundidade do cladócero diminuiu.

A diminuição da fecundidade de organismos expostos ao $\mathrm{EE}_{2}$ foi encontrada também em peixes da espécie Danio rerio (VAN DEN BELT; VERHEYEN; WITTERS, 2003; XU et al., 2008) e Pimephales promelas (SCHWINDT et al., 2014).

Alguns estudos não observaram diferenças significativas na fecundidade dos organismos expostos ao $\mathrm{EE}_{2}$, como Luna, Plautz e Salice (2013) que analisaram os efeitos no gastrópode Physa pomilia e Hallgren et al. (2012) que estudaram os gastrópodes Radix balthica e Bithynia tentaculata.

Os valores de CENO e CEO em relação à fecundidade total nas três primeiras ninhadas de D. magna após exposição prolongada a concentrações sub-letais do hormônio $\mathrm{EE}_{2}$, para as gerações $F_{0}$ e F1, são apresentados na Tabela 4.

Tabela 4-Valores da maior concentração efetiva com efeito não observado (CENO, em $\mu \mathrm{g} \mathrm{L}^{-1}$ ) e da menor concentração efetiva com efeito observado $\left(\mathrm{CEO}\right.$, em $\left.\mu \mathrm{g} \mathrm{L}^{-1}\right)$ de $17 \alpha$ - etinilestradiol $\left(\mathrm{EE}_{2}\right)$ em relação à variávelresposta fecundidade total nas três primeiras ninhadas de D. magna, após exposição prolongada de indivíduos das gerações $F_{0}$ e $F_{1}$ a concentrações sub-letais deste hormônio.

\begin{tabular}{ccc}
\hline Composto e geração & CENO & CEO \\
\hline $\mathrm{EE}_{2} \mathrm{~F}_{\mathbf{0}}$ & 125 & 250 \\
\hline $\mathrm{EE}_{2} \mathrm{~F}_{\mathbf{1}}$ & 500 & 1000 \\
\hline
\end{tabular}

No presente estudo o valor calculado de CENO (maior concentração que não causa efeito estatisticamente significativo na reprodução) para a geração $\mathrm{F}_{0}$ de D. magna $\left(125 \mu \mathrm{g} \mathrm{L}^{-1}\right.$ de $17 \alpha-$ etinilestradiol) foi menor que o valor de CENO para a geração $F_{1}\left(500 \mu \mathrm{g} \mathrm{L}^{-1}\right.$ de $17 \alpha-$ etinilestradiol), e também o valor calculado de CEO (menor concentração que causa efeito estatisticamente significativo na reprodução) para a geração $F_{0}$ D. magna $\left(250 \mu \mathrm{g} \mathrm{L}^{-1}\right.$ de $17 \alpha-$ etinilestradiol) também foi menor que para a geração $\mathrm{F}_{1}\left(1000 \mu \mathrm{g} \mathrm{L} \mathrm{L}^{-1}\right.$ de $17 \alpha$ - etinilestradiol). 
Com relação ao tamanho do corpo das neonatas (Figura 13), na geração $F_{0}$ houve diferença significativa no tamanho das neonatas na segunda ninhada para a concentração de 500 $\mu \mathrm{g} \mathrm{L} \mathrm{L}^{-1}(\mathrm{p}=0,0028)$, sendo o comprimento das neonatas maiores que nas do controle. Na geração $\mathrm{F}_{1}$, as diferenças significativas ocorreram na primeira e terceira ninhada. Na primeira ninhada a concentração de $2000 \mu \mathrm{g} \mathrm{L}^{-1}(\mathrm{p}=0,0015)$ apresentou neonatas com tamanho corporal menor que as do controle. Na terceira ninhada as neonatas da concentração de $500 \mu \mathrm{g} \mathrm{L}^{-1}(\mathrm{p}=0,0002), 1000$ $\mu \mathrm{g} \mathrm{L}^{-1}(\mathrm{p}<0,0001)$ e $2000 \mu \mathrm{g} \mathrm{L}^{-1}(\mathrm{p}<0,0001)$, também apresentaram tamanho corporal menor que as do controle. 

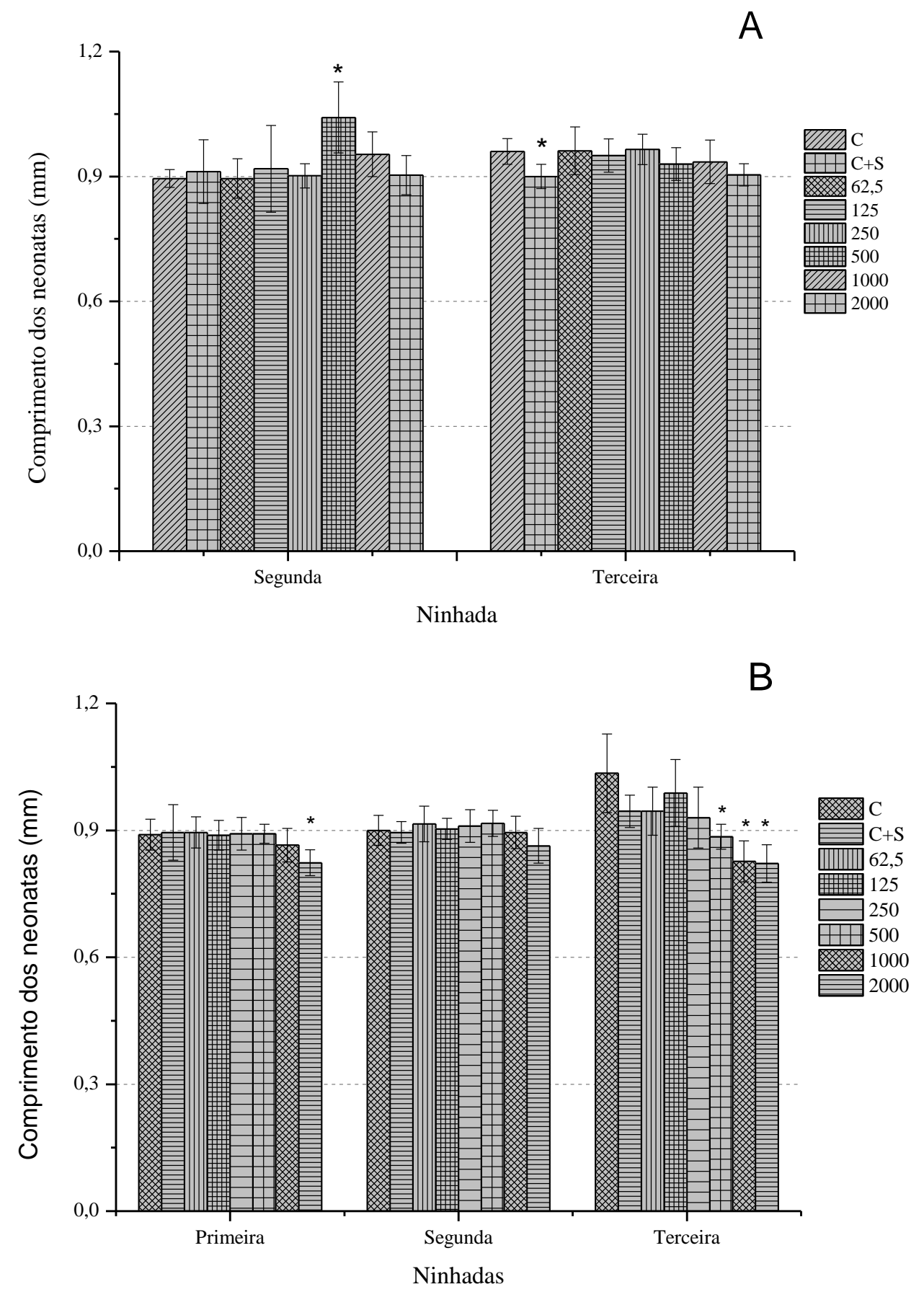

Figura 13-Tamaho corporal dos neonatas de Daphnia magna $(\mathrm{mm})$ na geração F0 (A) e na geração F1 (B) exposta ao hormônio sintético $17 \alpha$ - etinilestradiol $\left(\mathrm{EE}_{2}\right)$. As barras representam o valor médio do comprimento dos neonatas. $\mathrm{O}$ Asterisco $(*)$ representa diferença significativa com relação ao controle. (Não foi possível medir os neonatas da primeira ninhada da geração $\mathrm{F}_{0}$ ). 
Redução no tamanho do corpo das neonatas de Daphnia magna expostas ao $\mathrm{EE}_{2}$ também foi encontrado por Dietrich et al. (2010), na $\mathrm{F}_{5}$. Esses mesmo autores observaram que, para o metoprolol houve redução do comprimento das neonatas na $F_{5}$ e para diclofenaco ocorreu aumento do tamanho do corpo na $F_{1}$ e $F_{5}$. Essa diminuição do comprimento das neonatas foi observado por Clubbs e Brooks (2007) para a espécie D. magna na terceira ninhada da $\mathrm{F}_{0}$ quando expostas aos compostos 20-hidroxiecdisona e testosterona, e na terceira ninhada da $F_{1}$ para a 20hidroxiecdisona.

\subsubsection{Ocorrência de indivíduos intersexo em Daphnia magna}

Durante a preparação para a realização do teste de toxicidade crônica com o hormônio sintético $17 \alpha$ - etinilestradiol $\left(\mathrm{EE}_{2}\right)$, foi verificada a ocorrência de indivíduos machos nos controles bem como em todas as concentrações testadas. A ocorrência de machos não foi desencadeada pelo efeito do etinilestradiol, visto que estes ocorreram naturalmente na cultura estoque, sem formação de efípios e só foi detectado no período de separação das neonatas para a realização dos testes. Esta ocorrência permitiu a análise do efeito de disrupção endócrina pelo $\mathrm{EE}_{2}$ a ambos, tanto neonatas machos como fêmeas.

$\mathrm{Na}$ concentração de $250 \mu \mathrm{g} \mathrm{L}^{-1}$ foi encontrado um único indivíduo com características simultâneas de macho e fêmea, denominado intersexo ou hermafrodita (Figura 14). Esse indivíduo apresentou ovário desenvolvido, mas não produziu ovos. Além do ovário, o indivíduo

apresentou processos abdominais, sendo ambas características de fêmeas. Esse indivíduo apresentou a primeira antena alongada e a carapaça abaixo da região cefálica modificada e com cerdas, sendo estas características de machos.

Além das características morfológicas apresentadas, esse indivíduo intersexo tinha um comprimento maior do que os machos "normais". O comprimento foi de 3,18 mm, bastante maior que os machos presentes no teste que tiveram comprimentos variando de 2,4 a 2,58 mm. 

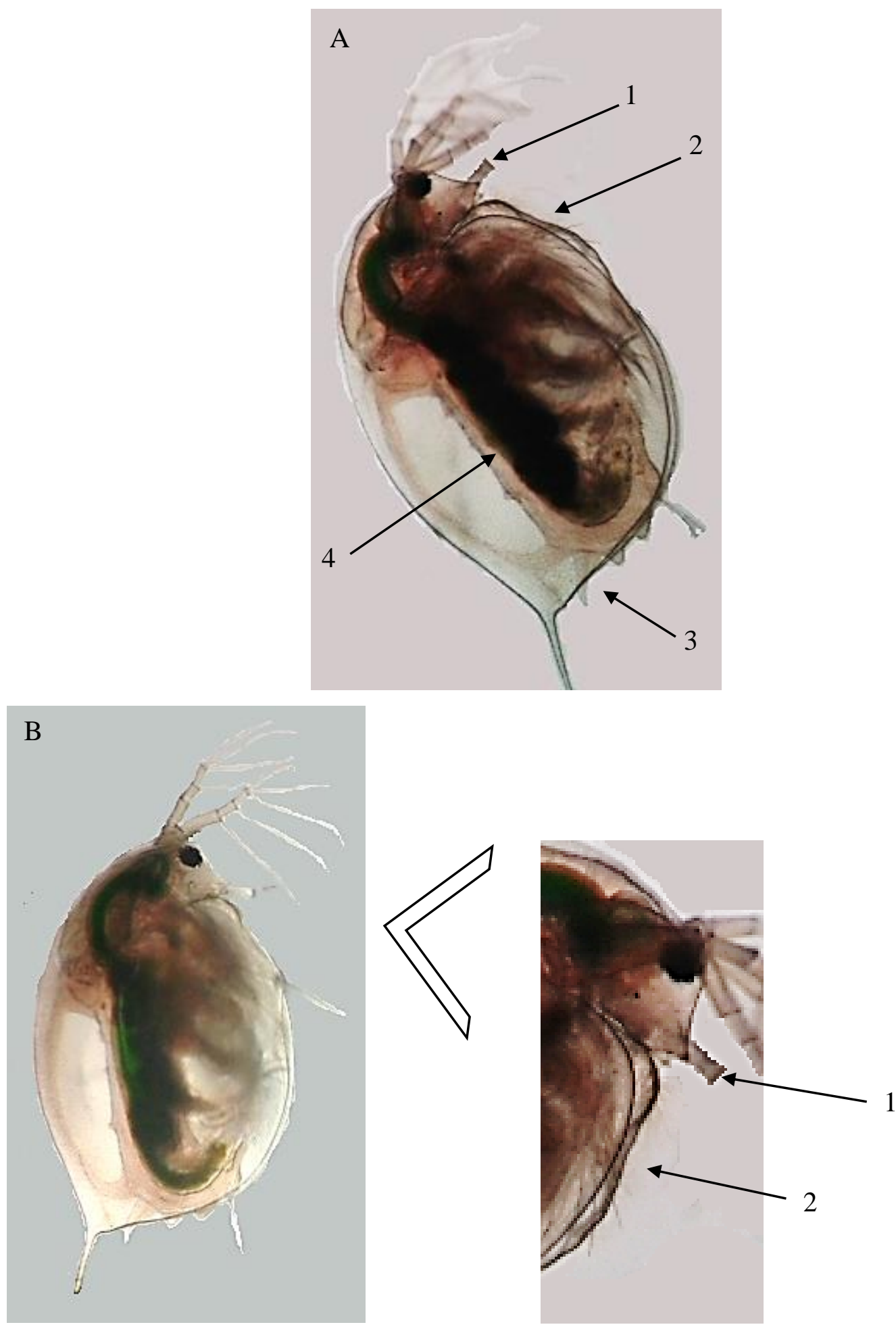

Figura 14-Ocorrência de forma intersexo em Daphnia magna exposta ao hormônio sintético 17a- etinilestradiol (A e B - zoom na região cefálica e na carapaça logo abaixo da região cefálica), mostrando ambas, características de macho (1 e 2) e características de fêmea (3 e 4). (1) primeira antena alongada; (2) carapaça abaixo da cápsula cefálica modificada e com cerdas; (3) processos abdominais longos e (4) ovário desenvolvido. (Foto: Miguel, M, 2015). 
A intersexualidade é o aparecimento anormal de algumas características masculinas e femininas que ocorrem simultaneamente. Essas características podem ser externas com as características sexuais secundárias ou podem ser dentro dos órgãos reprodutivos (características internas). A intersexualidade pode ocorrer por causa de parasitismo, de adversidades ambientais, por causa de alguma anormalidade genética ou poluição (FORD, 2012).

Ocorrência de intersexo em Daphnia magna foi observada após exposição de neonatas ao hormônio metil farnesoato (OLMSTEAD; LEBLANC, 2002), e após exposição a elevada temperatura - $30^{\circ} \mathrm{C}$ (MITCHELL, 2001). Ocorrência de intersexo foram bem reportados para a Daphnia longispina quando submetidas a mudanças de temperatura (SANFORD, 1947).

Vandenbergh et al. (2003) registraram indícios de hermafroditismo no anfípodo Hyalella azteca quando exposto ao $\mathrm{EE}_{2}$. Observaram anormalidades celulares no trato reprodutor masculino, perturbação na maturação das células germinativas e na espermatogênese, além de efeitos sobre características sexuais secundárias. Atribuíram o aparecimento do intersexo à exposição ao $\mathrm{EE}_{2}$, por não encontrarem sinais histológicos de intersexo no controle. 


\section{Conclusões}

Rejeita-se a hipótese de que a exposição ao hormônio aumenta o tempo de geração na $\mathrm{F}_{0}$, pois nesta geração não houve mudança estatisticamente significativa.

A segunda hipótese de que a exposição ao $\mathrm{EE}_{2}$ aumenta o tempo de geração na $\mathrm{F}_{1}$ foi aceita, pois os resultados mostraram que na maior concentração o tempo de geração foi maior, ou seja, comparado com o controle, o tempo até a primeira reprodução foi maior na concentração de $2000 \mu \mathrm{g} \mathrm{L}^{-1}$ do hormônio. Isso também foi observado na segunda ninhada da geração $\mathrm{F}_{1}$.

A hipótese levantada de que a exposição ao $\mathrm{EE}_{2}$ levaria a um aumento da fecundidade das fêmeas expostas foi rejeitada, pois os resultados revelaram uma diminuição da fecundidade nas quatro maiores concentrações $\left(250,500,1000\right.$ e $\left.2000 \mu \mathrm{g} \mathrm{L}^{-1}\right)$ deste hormônio na $\mathrm{F}_{0}$ e uma redução na concentração de $1000 \mu \mathrm{g} \mathrm{L}^{-1}$ do etinilestradiol para a geração $\mathrm{F}_{1}$.

Os indivíduos que foram afetados nos tratamentos da $\mathrm{F}_{0}$ não apresentaram o mesmo efeito que os da $F_{1}$, ou seja, o efeito do $E_{2}$ não afetou a segunda geração $\left(F_{1}\right)$ em maior intensidade do que a primeira. Contrariamente a isso, os dados mostraram que os indivíduos expostos podem adquirir resistência ao contaminante por adaptação fisiológica.

Com relação ao comprimento dos neonatas, a hipótese de que sob o efeito do $\mathrm{EE}_{2}$ este seria menor foi aceita, pois houve uma diminuição no tamanho corpóreo dos neonatas na $\mathrm{F}_{1}$.

Houve a ocorrência da forma intersexo apesar de se tratar de apenas um indivíduo, o que pode ser um indicio de que a exposição ao $\mathrm{EE}_{2}$ pode induzir a intersexualidade.

Este estudo evidenciou que o hormônio $\mathrm{EE}_{2}$ pode afetar a reprodução de organismos aquáticos e mesmo causando efeitos sutis, a presença do hormônio nas águas causa efeitos que a longo prazo podem causar danos à biota aquática. Além disso, o estudo mostra que um aumento na temperatura pode causar alterações no ciclo de vida de organismos e no funcionamento de ecossistemas aquáticos. 


\section{Referências}

ABNT - ASSOCIAÇÃO BRASILEIRA DE NORMAS TÉCNICAS. 2009. Ecotoxicologia aquática - Toxicidade aguda - Método de ensaio com Daphnia spp (Crustacea, Cladocera). ABNT NBR 12713.

ABNT - ASSOCIAÇÃO BRASILEIRA DE NORMAS TÉCNICAS. 2011. Ecotoxicologia aquática - Toxicidade crônica - Método de ensaio com algas (Chlorophyceae). ABNT NBR 12648.

ADAMS, W.J. 1995. Aquatic toxicology testing methods. 25-46 p. In: HOFFMAN, D.J., RATTNER, B.A., BURTON, G.A.Jr., CAIRNS, J.Jr. Handbook of ecotoxicology. EUA: Lewis Publishers. 755 p.

AL-ANSARI, A.M., SALEEM, A., KIMPE, L.E., SHERRY, J.P., MCMASTER, M.E., TRUDEAU, V.L., BLAIS, J.M. 2010. Bioaccumulation of the pharmaceutical 17 $\alpha$ ethinylestradiol in shorthead redhorse suckers (Moxostoma macrolepidotum) from the St. Clair River, Canada. Environmental Pollution, Vol. 158, 2566-2571 p.

ALLAN, J.D. 1976. Life history patterns in zooplankton. Amer. Natur., Vol 110, No 971, 165$180 \mathrm{p}$.

AMÉRICO, J.H.P., MESSIAS, T.G., TORRES, N.H., AMÉRICO, G.H.P. 2012.Desreguladores endócrinos no ambiente e seus efeitos na biota e saúde humana. Pesticidas: r. Ecotoxicol. e Meio Ambiente, Vol. 22, 17-34 p.

ANDERSON, B.G., JENKINS, J.C. 1942. A time of events in the life span of Daphnia magna. Biol. Bull., Vol 83, No 2, 260-272.

ARIS, A.Z., SHAMSUDDIN, A.S., PRAVEENA, S.M. 2014. Occurrence of 17 $\alpha$ ethynylestradiol (EE2) in the environment and effect on exposed biota: a review. Environment International, Vol. 69, 104-119 p.

BALINA, K.; BALODE, M.; MUZIKANTE, L.; BLUMBERGA, D. 2015. Impact of synthetic hormone $17 \alpha$-ethinylestradiol on growth of microalgae Desmodesmus communis. Agron. Res. Vol. 13, No. 2, 445-454. 
BAREL-COHEN, K., SHORE, L.S., SHEMESH, M., WENZEL, A., MUELLER, J, KRONFELD-SCHOR, N. 2006. Monitoring of natural and synthetic hormones in a polluted river. Journal of Environmental Management, Vol. 78, 16-23 p.

BARONTI, C., CURINI, R., D’ ASCENZO, G., DI CORCIA, A., GENTILI, A., SAMPERI, R. 2000. Monitoring natural and synthetic estrogens at activated sludge sewage treatment plants and in a receiving river water. Environ Sci. Technol., Vol. 34, N. 24, 5059-5066 p.

BHANDARI, R.K.; VOOM SAAL, F.S; TILLIT, D.E. 2015. Transgerational effects from early developmental exposures to bisphenol A or $17 \alpha$-ethinylestradiol in medaka, Oryzias latipes. Scientific Reports 5, article No. 9303. Accessed on-line on www.nature.com/articles/srp/9303, in 06 October, 2015.

BILA, D.M., DEZOTTI, M. 2003. Fármacos no Meio Ambiente. Quim. Nova, Vol. 26, N. 4, 523-530 p.

BORGMANN, U., BENNIE, D.T., BALL, A.L., PALABRICA, V. 2007. Effect of a mixture of seven pharmaceuticals on Hyalella azteca over multiple generations. Chemosphere, Vol. $66,1278-1283 \mathrm{p}$.

BORYSKO, L., ROSS, P.M. 2014. Adult exposure to the synthetic hormone 17 $\alpha$ ethynylestradiol affects offspring of the gastropods Nassarius burchardi and Nassarius jonasii. Ecotoxicology and Environmental Safety, Vol. 103, 91-100 p.

BRASIL. Ministério do Meio Ambiente, Conselho Nacional do Meio Ambiente - CONAMA. 2005. Resolução $\mathbf{N}^{*} 357$, de 16 março de 2005. Dispõe sobre a classificação dos corpos de água e diretrizes ambientais para o seu enquadramento, bem como estabelece as condições e padrões de lançamento de efluentes e dá outras providências. Diário Oficial da União, Brasília, DF, 18 de março de 2005.

BRASIL. Ministério do Meio Ambiente, Conselho Nacional do Meio Ambiente - CONAMA. 2011. Resolução $\mathbf{N}^{\mathbf{0}}$ 430, de 13 de maio de 2011. Dispõe sobre as condições e padrões de lançamento de efluentes, complementa e altera a Resolução $\mathbf{N}^{0} 357$, de 17 de março de 2005, do Conselho Nacional do Meio Ambiente - CONAMA. Diário Oficial da União, Brasília, DF, 16 de maio de 2011. 
CALDWELL, D.J., MASTROCCO, F., HUTCHINSON, T.S., LÄNGE, R., HEIJERICK, D., JANSSEN, C., ANDERSON, P.D., SUMPTER, J.P. 2008. Derivation of an aquatic predicted no-effect concentration for the synthetic hormone, 17 $\alpha$-ethinylestradiol. Environ. Sci. Technol., Vol. 42, No. 19, 7046-7054 p.

CAMPANHA, M.B., AWAN, A.T., SOUSA, D.N.R., GROSSELI, G.M., MOZETO, A.A., FADINI, P.S. 2015. A 3-year study on occurrence of emerging contaminants in an urban stream of São Paulo State of Southeast Brazil. Environ. Sci. Pollut. Res., Vol. 22, 7936$7947 \mathrm{p}$.

CASTILHO, M.C.A, WISNIEWSKI, C., SANTOS-WISNIEWSKI, M.J. 2012. Life cycle of Scapholeberis armata freyi Dumont \& Pensaert, 1983 (Cladocera, Daphnidae). Biota Neotrop., vol. 12, no. 4, 56-60 p.

CECCAREll, I., FIORENZANI, P., SETA, D.D., ALOISI, A.M. 2015. Perinatal 17 $\alpha$ ethinylestradiol exposure affects formalin-induced responses in middle-aged male (but not female) rats. Hormones and Behavior, Vol. 73, 116-124 p.

CHRISTEN, V., HICKMANN, S., RECHENBERG, B., FENT, K. 2010. Highly active human pharmaceuticals in aquatic systems: A concept for their identification based on their mode of action. Aquatic Toxicology, Vol. 96, 167-181p.

CHRISTENSEN, F.M. 1998. Pharmaceuticals $\mathrm{n}$ the environment - A human risk? Regulatory Toxicology and Pharmacology, Vol. 28, 212-221 p.

CLOUZOT, L., MARROT, B., DOUMENQ, P., ROCHE, N. 2008. 17 $\alpha$-Ethinylestradiol: An endocrine disrupter of great concern. Analytical methods and removal processes applied to water purification. A review. Environ. Progress, Vol 27, No 3, 383-396 p.

CLUBBS, R.L., BROOKS, B.W. 2007. Daphnia magna responses to a vertebrate strogen receptor agonist and an antagonist: A multigenerational study. Ecotoxicology and Environmental Safety, Vol 67, 385-398 p.

COLMAN, J.R., BALDWIND, D., JOHNSON, L.L., SCHOLZ, N.L. 2009. Effects of the synthetic estrogen, 17 $\alpha$-ethinylestradiol, on aggression and courtship behavior in male zebrafish (Danio rerio). Aquatic toxicology, Vol. 91, No. 4, 346-354 p. 
CONTARDO-JARA, V., LORENZ, C., PFLUGMACHER, S., NÜTZMANN, G., KLOAS, W., WIEGAND, C. 2011. Molecular effects and bioaccumulation of levonorgestrel in the non-target organism Dreissena polymorpha. Environmental Pollution, Vol. 159, 38-44 p.

CORBI, J. J., STRIXINO, S. T., SANTOS, A., DEL GRANDE, M. 2006. Diagnóstico ambiental de metais organoclorados em córregos adjacentes a áreas de cultivo de Cana-de-açúcar (Estado de São Paulo, Brasil). Quim. Nova, Vol. 29, N. 1, 61-65 p.

COSTA, C.R, OLIVI, P., BOTTA, C.M.R., ESPINDOLA, E.L.G. 2008. A toxicidade em ambientes aquáticos: discussão e método de avaliação. Quim. Nova, Vol. 31, N. 7, 1820$1830 \mathrm{p}$.

DEMŠAR, J. 2006. Statistical Comparisons of classifier over multiple data sets. Journal of Machine Learning Research, Vol. 7, 1-30 p.

DENT, M.P., CARMICHAEL, P.L., JONES, K.C., MARTIN, F,L. 2015. Towards a non-animal risk assessment for anti-androgenic effects in humans. Environment International, No. $83,94-106 \mathrm{p}$.

DESBROW, C., ROUTLEDGE, E.J., BRIGHTY, G.C., SUMPTER, J.P., WALDOCK, M. 1998. Identification of estrogenic chemicals in STW effluent. 1. Chemical fractionation and in Vitro Biological Screening. Environ. Sci. Technol., Vol. 32, N. 11, 1549-1558 p.

DIETRICH, S., PLOESSL, F., BRACHER, F., LAFORSCH, C. 2010. Single and combined toxicity of pharmaceuticals at environmentally relevant concentrations in Daphnia magna - A multigenerational study. Chemosphere, Vol 79, 60-66 p.

DUMONT, H.J. 1987. A population study of Scapholeberis rammneri Dumont and Pensaert (Cladocera: Daphniidae). Hydrobiol., Vol. 145, 275-284 p.

DUSSAULT, E.B., BALAKRISHNAN, V.K., BORGMANN, U., SOLOMON, K.R., SIBLEY, P.K. 2009. Bioaccumulation of the synthetic hormone 17a-ethinylestradiol in the benthic invertebrates Chironomus tentans and Hyalella Azteca. Ecotoxicology and Environmental Safety, Vol.72, 1635-1641 p.

EEA - European Environment Agency. 2012. Water temperature. 1-11 p., 2012. 
ERICKSON, B.E. 2002. Analyzing the ignored environmental contaminants. Environ. Sci. Technol. (Web), Vol 36, No 7, 140A-145A p.

FONSECA, A.L., ROCHA, O. 2004. The life-cycle of Ceriodaphnia silvestrii Daday, 1902, a Neotropical endemic species (Crustacea, Cladocera, Daphnidae). Acta Limnol. Bras., Vol. 16, No. 4, 319-328 p.

FORD, A.T. 2012. Intersexuality in Crustacea: An environmental issue? Aquatic Toxicology, Vol. 108, 125- 129 p.

FREITAS, E.C., ROCHA, O. 2006. The life cycle of Pseudosida ramosa, Daday 1904, an endemic Neotropical cladoceran. Acta Limnol. Bras., Vol 18, No 34, 293-303 p.

GHISELLI, G., JARDIM, W.F. 2007. Interferentes endócrinos no ambiente. Quim. Nova, Vol. 30, No. 3, 695-706 p.

GOSS, L.B., BUNTING, D.L. 1983. Daphnia development and reproduction: responses to temperature. J. Therm. Biol., Vol. 8, No. 4, 375-380 p.

GOTO, T., HIROMI, J. 2003. Toxicity of 17a-ethynylestradiol and norethindrone, constituents of an oral contraceptive pill to the swimming and reproduction of cladoceran Daphnia magna, with special reference to their synergetic effect. Marine Pollution Bulletin, No. 47, 139-142 p.

HALlGREN, P., SORITA, Z., BERGLUND, O., PERSSON, A. 2012. Effects of 17 $\alpha$ ethinylestradiol on individual life-history parameters and estimated population growth rates of the freshwater gastropods Radix balthica and Bithynia tentaculata. Ecotoxicology, No. 21, 803-810 p.

HARRIS, K.D.M., BARTLETT, N.J., LLOYD, V.K. 2012. Daphnia as an Emerging Epigenetic Model Organism. Genetics Research International, Vol. 2012, Article ID 147892, 8 p.

HAYASAKA, D.; SUZUKI, K.; NISHIYAMA, M.; NAGAI, T.; SANCHEZ-BAYO, F.; GOKA, K. 2013. Comparison of acute toxicity of two neocotinoid insecticides, imidacloprid and chlotianidin, to five cladocerans species. J. Pestic. Sci. Vol. 38, No. 1, 44-47 p. 
HEBERT, P.D.N. 1978. The Population Biology of Daphnia (Crustacea, Daphnidae). Biol. Rev.,Vol. 53, No. 3, 387-423 p.

KLERKS, P.L., WEIS, J.S. 1987. Genetic adaptation to heavy metals in aquatic organisms: a review. Environmental Pollution, Vol 45, 173-205 p.

KOIVISTO, S. 1995. Is Daphnia magna an ecologically representative zooplankton species in toxicity tests? Environmental Pollution, Vol. 90, No. 2, 263-267 p.

KOLPIN, D.W., FURLONG, E.T., MEYER, M.T., THURMAN, E.M., ZAUGG, S.D., BARBER, L.B., BUXTON, H.T. 2002. Pharmaceuticals, hormones, and other organic wastewater contaminants in U.S. Streams, 1999-2000: A National Reconnaissance. Environ. Sci. Technol., Vol. 36, N. 6, 1202-1211 p.

KOTOV, A.A., SAEHENG, S. MAIPHAE, S., VAN DAMME, K. 2013. Study of the embryogenesis of Dunhevedia crassa King, 1853 (Cladocera: Chydoridae) and a comparison of embryonic instar durations in different cladocerans. J. Limnol., Vol. 72, No. 3, 564-572 p.

KUCH, H.M., BALLSCHMITER, K. 2001. Determination of Endocrine-Disrupting Phenolic Compounds and Estrogens in Surface and Drinking Water by HRGC-(NCI)-MS in the Picogram per Liter Range. Environ. Sci. Technol., Vol. 35, 3201-32 p.

LAI, K.M., SCRIMSHAW, M.D., LESTER, J.N. 2002. Prediction of the bioaccumulation factors and body burden of natural and synthetic estrogens in aquatic organisms in the river systems. The Science of the Total Environment, Vol 289, 159-168 p.

LAURENSON, J.P., BLOOM, R.A., PAGE, S., SADRIEH, N. 2014. Ethinyl Estradiol and Other Human Pharmaceutical Estrogens in the Aquatic Environment: A Review of Recent Risk Assessment Data. The AAPS Journal, V. 16, No 2, 299-310 p.

LINTELMANN, J., KATAYAMA, A., KURIHARA, N., SHORE, L., WENZEL, A. 2003. Endocrine disruptors in the environment (IUPAC Technical Report). Pure Appl. Chem., Vol. 75, No. 5, 631-681 p. 
LUNA, T.O., PLAUTZ, S.C., SALICE, C.J. 2013. Effects of 17 $\alpha$-ethynylestradiol, fluoxetine, and the mixture on life history traits and population growth rates in a freshwater gastropod. Environ. Toxicol. Chem., Vol. 32, No. 12, 2771-2778 p.

LUO, Y., GUO, W., NGO, H.H., NGHIEM, L.D., HAI, F.I., ZHANG, J., LIANG, S., WANG, X.C. 2014. A review on the occurrence of micropollutants in the aquatic environment and their fate and removal during wastewater treatment. Science of the Total Environment, Vol. S, 473-474, 619-641 p.

MAGALHÃES, P. D.P., FERRÃO FILHO, A. S. F. 2008. A ecotoxicologia como ferramenta do biomonitoramento de ecossistemas aquáticos. Oecol. Bras., Vol.ed. 12, N. 3, 355-81 p.

MELÃO, M.G.G., ROCHA, O. 2006. Life history, population dynamics, standing biomass and production of Bosminopsis deitersi (Cladocera) in a shallow tropical reservoir. Acta Limnol. Bras., Vol. 18, No. 4, 433-450 p.

MIERZWA, J.C., AQUINO, S.F. de. 2009. Contaminantes orgânicos presentes em microquantidades em mananciais de água para abastecimento público. In: PÁDUA, V.L. (coord.). Remoção de microorganismos emergentes e microcontaminantes orgânicos no tratamento de água para consumo humano. Rio de Janeiro: ABES, 2009. 44-73 p.

MITCHELL, S.E. 2001. Intersex and male development in Daphnia magna. Hydrobiol., Vol. $442,145-156 \mathrm{p}$.

MOREIRA, R.A., MANSANO, A.S., SILVA, L.C. DA, ROCHA, O. 2014. A comparative study of the acute toxicity of the herbicide atrazine to cladocerans Daphnia magna, Ceriodaphnia silvestrii and Macrothrix flabelligera. Acta Limnologica Brasiliensia, Vol. 26, No 1, 1-8 p.

NAGPAL, N.K., MEAYS, C.L. 2009. Water quality guidelines for pharmaceutically-activecompounds (PhACs): 17 $\alpha$-Ethinylestradiol (EE2). Ministry of Environmental Province of British Columbia. Technical Appendix. 1-27 p.

OBRESHKOVE, V., FRASER, A.W. 1940. Growth and differentiation of Daphnia magna eggs in vitro. The Biological Bulletin, 428-236 p. 
OECD Guideline for testing of chemicals. 2004. Guideline 202: Daphnia sp, Acute Immobilisation Test. Adopted April 2004.

OECD Guidelines for testing of chemicals. 2008. Guideline 211: Daphnia magna Reproduction Test. Adopted October 2008.

OLIVEIRA, L.L.D. 2014. Biomarcadores enzimáticos e testes ecotoxicológicos na avaliação da toxicidade de fármacos em invertebrados aquáticos. Tese de doutorado. Escola de Engenharia de São Carlos, Universidade de São Paulo, São carlos, 257 p., 2014.

OLMSTEAD, A.W., LEBLANC, G.A. 2000. Effects of endocrine-active chemicals on the development of sex characteristics of Daphnia magna. Environ. Toxicol. Chem., Vol. 19, No. 8, 2107-2113 P.

OLMSTEAD, A.W., LEBLANC, G.A. 2002. Juvenoid Hormone Methyl Farnesoate Is a Sex Determinant in the Crustacean Daphnia magna. Journal of Experimental Zoology, Vol. 293, 736-739 p.

PASCOE, D., CARROLL, K., KARNTANUT, W., WATTS, M.M. 2002. Toxicity of $17 \alpha-$ Ethinylestradiol and Bisphenol A to the Freshwater Cnidarian Hydra vulgaris. Arch. Environ. Contam. Toxicol., Vol. 43, 56-63 p.

PERSOONE, G., BAUDO, R., COTMAN, M., BLAISE, C., THOMPSON, K.Cl., MOREIRASANTOS, M., VOLlAT, B., TÖRÖKNE, A., HAN, T. 2009. Review on the acute Daphnia magna toxicity test - Evaluation of the sensitivity and the precision of assays performed with organisms from laboratory cultures or hatched from dormant eggs. Knowl. Managt. Aquatic. Ecosyst., Vol. 393, No. 01, 1-29 p.

PHYU, Y.L., PALMER, C.G., WARNE, M.St.J., DOWSE, R., MUELLER, S., CHAPMAN, J., HOSE, G.C., LIM, R.P. 2013. Assessing the chronic toxicity of atrazine, permethrin, and chlorothalonil to the Cladoceran Ceriodaphnia cf. dubia in laboratory and natural river water. Arch. Environ. Contam. Toxicol., Vol. 64, N. 3, 419-426 p.

PRESTES, E.B., JONSSON, C.M., CASTRO, V.L.S.S., PARAÍBA, C.C.M. 2013.Avaliação da toxicidade crônica de piraclostrobin, epoxiconazol e sua mistura em Daphnia similis. Ecotoxicol. Environ. Contam., Vol. 8, N. 1, 113-117 p. 
RAND, G.M. 1995. Fundamentals of aquatic toxicology: effects, environmental fate, and risk assessment. $2^{\mathrm{a}}$ ed. Boca Raton: CRC Press, 1995, 1125 p.

RAND, G.M., PETROCELLI, S.R. 1985. Fundamentals of aquatic toxicology: methods and application. Hemisphere Publishing, New York, 1985.

REIS FILHO, R.W., ARAÚJO, J.C., VIEIRA, E.M. 2006. Hormônios sexuais estrógenos: contaminantes bioativos. Quim. Nova, Vol. 29, N. 4, 817-822 p.

REIS FILHO, R.W., LUVIZOTTO-SANTOS, R., VIEIRA, E.M. 2007. Poluentes emergentes como desreguladores endócrinos. J. Braz. Soc. Ecotoxicol., Vol. 2, N. 3, 283-288 p.

ROCHA, O. 1983. The influence of food-temperature combinations on the duration of development, body size, growth and fecundity of Daphnia species. Tese de doutorado, Universidade de Londres, $337 \mathrm{p}$.

RUPPERT, E.E., BARNES, R.D. 1996. Zoologia dos invertebrados. 6 ed. São Paulo: Ed. Roca. 1996. $1028 \mathrm{p}$.

SAKUNA, M. 1998. Probit analysis of preference data. Appl. Entomol. Zool., Vol 33, N0 3, 339-347 p.

SANFORD, K.K. 1947. The effect of temperature on the intersex character of Daphnia longispina. Physiological Zoology, Vol. 20, No. 4, 325-332 p.

SCHWINDT, M., WINKELMAM, D.L., KETELES, K., MURPHY, M., VAJDA, A.M. 2014. An environmental oestrogen disrupts fish population dynamics through direct and transgerational effects on survival and fecundity. J. Appl. Ecol., Vol. 51, $582-591$ p.

SINGH, V., SINGH, M.F. 2014. Pharmaceutical Drugs Metabolites: A Curse to the Ecosystem. Gu. Dron. Jour.Pharm. Res. Vol. 2, No. 1, 27-33.

SNYDER, S.A., WESTERHOFF, P., YOON, Y.,SEDLAK, D.L. 2003. Pharmaceuticals, Personal Care Products and Endocrine Disruptors in Water: Implications for Water Industry. Environ. Eng. Sci. Vol 20, No. 5, 449-469. 
SODRÉ, F.F., MONTAGNER, C.C., LOCATELLI, M.A.F., JARDIM, W.F. 2007. Ocorrência de Interferentes Endócrinos e Produtos Farmacêuticos em Águas Superficiais da Região de Campinas (SP, Brasil). J. Braz. Soc. Ecotoxicol., Vol. 2, No 2, 187-196 p.

STATSOFT, INC. (2004) STATISTICA (data analysis software system), version 07. www.statsoft.com. Acessado em 20 de setembro de 2015.

STOLLEWERK, A. 2010. The water flea Daphnia - a 'new' model system for ecology and evolution? J. Biol., Vol. 9, No. 21, 1-4 p.

STRAILE, D., ADRIAN, R., SCHINDLER, D.E. 2012. Uniform Temperature Dependency in the Phenology of a Keystone Herbivore in Lakes of the Northern Hemisphere. PLoS ONE, Vol. 7, N. 10, e45497.

TATARAZAKO, N., ODA, S. 2007. The water flea Daphnia magna (Crustacea, Cladocera) as a test species for screening and evaluation of chemicals with endocrine disrupting effects on crustaceans. Ecotoxicology, Vol. 16, 197-203 p.

TERNES, T.A., STUMPF, M., MUELLER, J., HABERER, K., WILKEN, R.-D., SERVOS, M. 1999. Behavior and occurrence of estrogens in municipal sewage treatment plants - I. Investigations in Germany, Canada and Brazil. The Science of the Total Environment, Vol. 225, No. 1-2, 81-90 p.

THEODORSSON-NORHEIM, E. 1986. Kruskal-Wallis test: BASIC computer program to perform nonparametric one-way analysis of variance and multiple comparisons on ranks of several independent samples. Computer Methods and Programs in Biomedicine, Vol 23, 57-62 p.

TORRES, N.H., AGUIAR, M.M., FERREIRA, L.F.R., AMÉRICO, J.H.P., MACHADO, A.M., CAVALCANTI, E.B., TORNISIELO, V.L. 2015. Detection of hormones in surface and drinking water in Brazil by LC-ESI-MS/MS and ecotoxicological assessment with Daphnia magna. Environ. Monit. Assess., Vol. 187, No. 379, 2-13 p.

TOURNAIRE, M., DEVOUCHE, E., ESPIÉ, M., ASSELAIN, B., LEVADOU, A., CABAU, A., DUNBAVAND, A., GROSCLAUDE, P., EPELBOIN, S. 2015. Cancer Risk in Women Exposed to Diethylstilbestrol in Utero. Thérapie, 1-9 p. 
TOYOTA, K., MIYAKAWA, H., HIRUTA, C., FURUTA, K., YUKIKO OGINO, Y., SHINODA, T., TATARAZAKO, N., MIYAGAWA, S., SHAW, J.R., IGUCHI, T. 2015. Methyl farnesoate synthesis is necessary for the environmental sex determination in the water flea Daphnia pulex. Journal of Insect Physiology, Vol. 80, 22-30p.

VAN DEN BELT, K., VERHEYEN, R., WITTERS, H. 2003. Effects of 17 $\alpha$-ethynylestradiol in a partial life-cycle test with zebrafish (Danio rerio): effects on growth, gonads and female reproductive success. The Science of the Total Environment, Vol. 309, No. 1-3, 127$137 \mathrm{p}$.

VANDENBERGH, G.F., ADRIAENS, D., VERSLYCKE, T., JANSSENA, C.R. 2003. Effects of $17 \alpha$-ethinylestradiol on sexual development of the amphipod Hyalella azteca. Ecotoxicology and Environmental Safety, Vol. 54, 216-222 p.

VOLKOVA, K.; CASPILLO, N.R.; PORSERYD, T.; HALLGREN, S.; DINNETZ, P.; ÖLSEN, H.; HALLSTROM, I.P. 2015a. Developmental exposure of zebrafish (Danio rerio) to $17 \alpha$-ethinylestradiol affects non-reproductive behavior and fertility as adults, and increases anxiety in unexposed progeny. Hormones and Behavior, Vol. 73, 30-80, 2015a.

VOLKOVA, K.; CASPILLO, N.R.; PORSERYD, T.; HALLGREN, S.; DINNETZ, P.; HALLSTROM, I.P. 2015b. Transgerational effects of 17a-ethinylestradiol on anxiety behavior in the guppy, Poecilia reticulata. Gen. and Compar. Endocrinol. Accessed online on www.sciencedirect.com/science/article/pii/S00166480150022713 in 06, Oct., $2015 b$.

WALKER, C.H., HOPKIN, S.P., SIBLY, R.M., PEAKALL, D.B. 2006. Principles of ecotoxicology. $3^{\text {a }}$ Ed. Boca Raton: Taylor \& Francis Group, 315 p.

WALTHER, G.-R., POST, E., CONVEY, P., MENZEL, A., PARMESAN, C., BEEBEE, T.J.C., FROMENTIN, J.-M., HOEGH-GULDBERG, O., BAIRLEIN, F. 2002. Ecological responses to recent climate change. Nature, Vol. 416, 389-395 p.

WANG, K.-S., LU, C.-Y., CHANG, S.-H. 2011. Evaluation of acute toxicity and teratogenic effects of plant growth regulators by Daphnia magna embryo assay. Journal of Hazardous Materials, Vol. 190, 520-528 p. 
WINDER, M., SCHINDLER, D.E. 2004. Climatic effects on the phenology of lake processes. Global Change Biology, Vol. 10, 1844-1856 p.

XU, H., YANG, J., WANG, Y., JIANG, Q., CHEN, H., SONG, H. 2008. Exposure to 17 $\alpha$ ethinylestradiol impairs reproductive functions of both male and female zebrafish (Danio rerio). Aquatic Toxicology, Vol. 88, No. 1, 1-8 p., 2008.

YAN, Z., LU, G., LIU, J., JIN, S. 2012. An integrated assessment of estrogenic contamination and feminization risk in fish in Taihu Lake, China. Ecotoxicology and Environmental Safety, Vol. 84, 334-340 p.

YEOM, D.-H., YUN, H.-G., MIN, J.-E. 2011. Sensitivity comparison of the warning charts established from the results of 5 and 20 successive reference toxicant tests in Daphnia magna. ToxEHS, Vol. 3, No. 3, 175-178 p.

ZAGATTO, P.A., BERTOLETTI, E. (Eds). 2006. Ecotoxicologia aquática: princípios e aplicações. São Carlos, Editora Rima, 2006. 478 p.

ZAR, J.H. 2010. Biostatistical analysis. Pearson Education, Inc., Upper Saddle River, New Jersey, 5 ed., 944 p. 
Apêndices 


\section{APÊNDICE A - Composição e Modo de preparação da Água reconstituída de Elevada Dureza}

A água reconstituída utilizada como meio para o cultivo de Daphnia magna e para o preparo das soluções-teste (água de diluição) é de dureza elevada, e de moderada basicidade, com valores entre 175 e $225 \mathrm{mg} \mathrm{CaCO}_{3} \mathrm{~L}^{-1}$ e pH entre 7,6 e 8,0.

Para o preparo de 1 L da água reconstituída são utilizadas 4 soluções, nos seguintes volumes:

- Solução 1: $3,2 \mathrm{~mL}$

- Solução 2: $0,8 \mathrm{~mL}$

- Solução 3: 0,8 mL

- Solução 4: 0,8 mL

- Água destilada: completar para $1 \mathrm{~L}$, ou seja, 994,4 mL

As soluções são preparadas da seguinte forma:

- Solução 1: $\mathrm{CaCl}_{2} \cdot \mathrm{H}_{2} \mathrm{O} \rightarrow 73,5 \mathrm{~g}$

Dissolver e diluir completando para $1000 \mathrm{~mL}$ com água destilada

- Solução 2: $\mathrm{MgSO}_{4} \cdot 7 \mathrm{H}_{2} \mathrm{O} \rightarrow 123,3 \mathrm{~g}$

Dissolver e diluir completando para $1000 \mathrm{~mL}$ com água destilada

- Solução 3: $\mathrm{KCl} \rightarrow 5,8 \mathrm{~g}$

Dissolver e diluir completando para $1000 \mathrm{~mL}$ com água destilada

- Solução 4: $\mathrm{NaHCO}_{3} \rightarrow 64,8 \mathrm{~g}$

Dissolver e diluir completando para $1000 \mathrm{~mL}$ com água destilada

Antes da sua utilização, a água deve ficar em aeração por, no mínimo, 12 horas, para a solubilização dos sais, estabilização do $\mathrm{pH}$ e saturação do oxigênio dissolvido. Se o pH não estiver dentro da faixa aceita, deve-se ajustá-lo com as soluções de ácido clorídrico $(\mathrm{HCl})$ - para diminuir o $\mathrm{pH}$ - ou de hidróxido de sódio $(\mathrm{NaOH})$ - para aumentar o pH. 


\section{APÊNDICE B - Meio Oligo - Cultivo de alga}

Para o cultivo da alga Pseudokirchneriella subcapitata foi utilizado o meio Oligo (ABNT, 2011), preparado da seguinte forma:

Dissolver em $100 \mathrm{~mL}$ de água destilada

\begin{tabular}{c|c|c}
\hline Solução 1 & $\mathrm{Ca}\left(\mathrm{NO}_{3}\right)_{2} .4 \mathrm{H}_{2} \mathrm{O}$ & $4 \mathrm{~g}$ \\
\hline Solução 2 & $\mathrm{KNO}_{3}$ & $10 \mathrm{~g}$ \\
\hline Solução 3 & $\mathrm{MgSO}_{4} .7 \mathrm{H}_{2} \mathrm{O}$ & $3 \mathrm{~g}$ \\
\hline Solução 4 & $\mathrm{K}_{2} \mathrm{HPO}_{4}$ & $4 \mathrm{~g}$ \\
\hline
\end{tabular}

Dissolver em $1000 \mathrm{~mL}$ de água destilada

\begin{tabular}{c|c|c}
\hline \multirow{4}{*}{ Solução 5 } & $\mathrm{CuSO}_{4} .5 \mathrm{H}_{2} \mathrm{O}$ & $0,03 \mathrm{~g}$ \\
\cline { 2 - 3 } & $\left(\mathrm{NH}_{4}\right)_{6} \mathrm{Mo}_{7} \mathrm{O}_{24} .4 \mathrm{H}_{2} \mathrm{O}$ & $0,06 \mathrm{~g}$ \\
\cline { 2 - 3 } & $\mathrm{ZnSO}_{4} \cdot 7 \mathrm{H}_{2} \mathrm{O}$ & $0,06 \mathrm{~g}$ \\
\cline { 2 - 3 } & $\mathrm{CoCl}_{2} \cdot 6 \mathrm{H}_{2} \mathrm{O}$ & $0,06 \mathrm{~g}$ \\
\cline { 2 - 3 } & $\mathrm{Mn}\left(\mathrm{NO}_{3}\right)_{2} \cdot 4 \mathrm{H}_{2} \mathrm{O}$ & $0,06 \mathrm{~g}$ \\
\cline { 2 - 3 } & $\mathrm{C}_{6} \mathrm{H}_{8} \mathrm{O}_{2} . \mathrm{H}_{2} \mathrm{O}$ & $0,06 \mathrm{~g}$ \\
\hline \multirow{4}{*}{ Solução 6 } & $\mathrm{H}_{3} \mathrm{BO}_{3}$ & $0,06 \mathrm{~g}$ \\
\cline { 2 - 3 } & $\mathrm{C}_{6} \mathrm{H}_{5} \mathrm{FeO}_{7} .5 \mathrm{H}_{2} \mathrm{O}$ & $1,625 \mathrm{~g}$ \\
\cline { 2 - 3 } & $\mathrm{FeCl}_{3} \cdot 6 \mathrm{H}_{2} \mathrm{O}$ & $0,625 \mathrm{~g}$ \\
\hline Solução 7 & $\mathrm{FeSO}_{4} .7 \mathrm{H}_{2} \mathrm{O}$ & $0,625 \mathrm{~g}$ \\
\hline
\end{tabular}

As soluções podem ser guardadas em frascos de vidro escuro em geladeira.

Para preparar $1 \mathrm{~L}$ de meio de cultura, colocar $500 \mathrm{~mL}$ de água destilada em um balão volumétrico de $1000 \mathrm{~mL}$ e adicionar as soluções na seguinte ordem e quantidades:

- Solução 1: 1,0 mL

- Solução 2: 1,0 mL

- Solução 3: 1,0 mL

- Solução 4: 1,0 mL

- Solução 5: 0,5 mL

- Solução 6: 0,5 ml

- Solução 7: 1,0 mL

Completar com água destilada para $1000 \mathrm{~mL}$. Medir o pH, que deve ficar na faixa de 6,0 e 8,0. Agitar por 1 hora e autoclavar por 15 minutos a $121^{\circ} \mathrm{C}$. Antes de inocular a alga, deixar o meio de cultivo esfriar. 


\section{APÊNDICE C - Meio Chu-12, cultivo de alga}

O meio Chu-12 é preparado com:

- $\mathrm{Ca}\left(\mathrm{NO}_{3}\right)_{2} \rightarrow 4,3 \mathrm{~g}$

- $\mathrm{K}_{2} \mathrm{HPO}_{4} \rightarrow 0,5 \mathrm{~g}$

- $\mathrm{MgSO}_{4} .7 \mathrm{H}_{2} \mathrm{O} \rightarrow 7,5 \mathrm{~g}$

$\bullet \mathrm{KCl} \rightarrow 0,5 \mathrm{~g}$

- $\mathrm{Na}_{2} \mathrm{CO}_{3} \rightarrow 2,0 \mathrm{~g}$

- $\mathrm{FeCl}_{3} .6 \mathrm{H}_{2} \mathrm{O} \rightarrow 0,05 \mathrm{~g}$

- Água destilada $\rightarrow 1000 \mathrm{~mL}$

A solução pode ser guardada em vidro âmbar na geladeira.

Para preparar $1500 \mathrm{~mL}$ de meio de cultura, colocar $30 \mathrm{~mL}$ da solução Chu-12 e completar para $1500 \mathrm{~mL}$ com água destilada. Autoclavar por 20 minutos a $121^{\circ} \mathrm{C}$. Antes de inocular a alga, deixar o meio de cultivo esfriar. 


\section{APÊNDICE D - Procedimento de Inoculação da alga}

Para a inoculação da alga Pseudokirchneriella subcapitata, deixar o meio de cultivo (descrito no apêndice 2) esfriar. Se forem preparados $3 \mathrm{~L}$ de meio de cultivo, este deve ser dividido em 2 erlenmeyers de $2 \mathrm{~L}$ (colocando-se $\pm 1350 \mathrm{~mL}$ do meio de cultivo em cada erlenmeyer) e dois erlenmeyers pequenos de $250 \mathrm{~mL}$ (colocando-se $\pm 150 \mathrm{~mL}$ do meio de cultivo em cada erlenmeyer), que serão devidamente tapados com tampões feito de gaze e algodão, com a boca dos erlenmeyers posteriormente envolvidas com papel alumínio e estes colocados para esterilizar em autoclave na temperatura de $120^{\circ} \mathrm{C}$, pressão de 1,0 atmosfera, por 15 minutos. Colocar juntas duas pipetas para esterilizar.

O local onde será feita a inoculação deve estar esterilizado com álcool $70 \%$. A manipulação das vidrarias durante a inoculação deve ser feita próximo ao bico de Bunsen, na área estéril. Após o meio esfriar, inocular a alga, colocando $40 \mathrm{~mL}$ do inóculo (que consiste em uma suspensão desta espécie de alga na concentração aproximada de $10^{7}$ céls $\mathrm{mL}^{-1}$ ) nos erlenmeyers maiores e $20 \mathrm{~mL}$ do inóculo nos pequenos (os quais ficarão crescendo para se tornarem novos inóculos). Colocar, nos frascos maiores, no meio do tampão, uma pipeta esterilizada (esta será ligada no aerador). Anotar a data de inoculação e o nome da alga. Manter os erlenmeyers maiores sob aeração constante e fotoperíodo 12h claro:12 horas escuro, por 7 dias (fase exponencial de crescimento) (Figura 9). Os frascos menores são deixados sem aeração sob as mesmas condições de temperatura e fotoperíodo que os frascos grandes, sendo apenas manualmente agitados 2 ou 3 vezes ao dia.

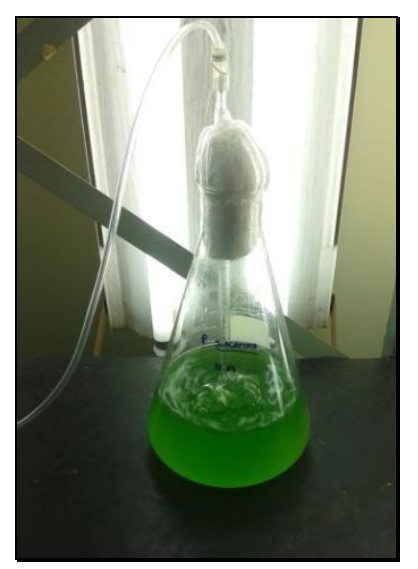

Figura 15-Vista de um cultivo de alga clorofícea em fase exponencial de crescimento, em sala climatizada a $25 \pm 2$ ${ }^{\circ} \mathrm{C}$, aeração constante e fotoperíodo $12 \mathrm{~h}$ claro: $12 \mathrm{~h}$ escuro. 
Decorridos os 7 dias de vigoroso crescimento, deixar os frascos grandes decantarem por algumas horas, retirar uma alíquota e realizar a contagem das células na câmara de Neubauer. Esta suspensão poderá ser utilizada como alimento nos cultivos e testes ecotoxicológicos. Para preparação da suspensão alimentar, centrifugar os volumes necessários a 3000 rpm durante 5 minutos. Descartar o sobrenadante e ressuspender as algas sedimentadas em água destilada em um frasco com tampa e homogeneizar por meio de agitação, para contagem das células. 


\section{APÊNDICE E - Preparo do aditivo alimentar (alimento composto) para o cultivo de microcrustáceos}

Para preparar o alimento composto, que é utilizado como um aditivo à suspensão de algas para alimentação do cladócero Daphnia magna, deve-se:

\section{Suspensão 1:}

- Pesar 5 g de ração Tetramin ${ }^{\circledR}$ e diluir em $1000 \mathrm{~mL}$ de água destilada em um erlenmeyer

- Manter sob aeração constante por uma semana. Durante este período, completar o volume de água de modo a compensar a evaporação

- Após decorrido uma semana sob aeração, filtrar a solução em rede de plâncton com 45 ou $68 \mu \mathrm{m}$ de abertura da malha.

- Distribuir $50 \mathrm{~mL}$ de solução em frascos menores, etiquetados, e mantê-los no congelador até o momento do uso.

\section{$\underline{\text { Suspensão } 2}$}

- Pesar 0,25 g de fermento biológico seco Fleischmann ${ }^{\circledR}$ (que deve ser mantido sob refrigeração) e dissolver em $50 \mathrm{~mL}$ de água destilada

- Agitar até dissolver e misturar o fermento dissolvido em $50 \mathrm{~mL}$ da suspensão preparada com a ração de peixe, previamente descongelada de um dia para o outro, na geladeira.

- Filtrar toda a mistura em rede de plâncton de 45 ou $68 \mu \mathrm{m}$ de abertura de malha, colocar em frasco com tampa e conservar na geladeira, utilizando-a por no máximo uma semana. 


\section{APÊNDICE F - Dados brutos obtidos em cinco testes de toxicidade aguda para}

determinação da sensibilidade do organismo teste Daphnia magna à substância de referência $\mathrm{K}_{2} \mathrm{Cr}_{2} \mathrm{O}_{7}$, nas condições laboratoriais adotadas.

Tabela 5-Valores das concentrações de dicromato de potássio, do número de indivíduos de D. magna imóveis e valores medidos para as variáveis $\mathrm{pH}$, dureza e condutividade elétrica das soluções-teste, para o Teste no. 1. A dureza final não foi medida por falta de volume suficiente de solução teste

\begin{tabular}{|c|c|c|c|c|c|c|c|c|c|c|c|c|}
\hline \multicolumn{2}{|c|}{ Organismo teste: } & \multicolumn{3}{|c|}{ Daphnia magna } & \multicolumn{3}{|c|}{ Teste $\mathbf{N}^{\mathbf{o}}: 01$} & \multicolumn{5}{|c|}{ Solução estoque: Dicromato de potássio } \\
\hline \multirow{3}{*}{$\begin{array}{l}\text { Sol. Teste } \\
\left(100 \mathrm{mg} \mathrm{L}^{-1}\right)\end{array}$} & \multicolumn{6}{|c|}{ Imobilidade } & \multicolumn{6}{|c|}{ Variáveis } \\
\hline & \multirow[t]{2}{*}{1} & \multirow[t]{2}{*}{2} & \multirow[t]{2}{*}{3} & \multirow[t]{2}{*}{4} & \multirow[t]{2}{*}{ Total } & \multirow[t]{2}{*}{$\%$} & \multicolumn{2}{|c|}{ pH } & \multicolumn{2}{|c|}{$\begin{array}{c}\text { Dureza } \\
\left(\mathrm{mg} \mathrm{CaCO}_{3} \mathrm{~L}^{-1}\right)\end{array}$} & \multicolumn{2}{|c|}{$\begin{array}{c}\text { Condutividade } \\
\left(\mu \mathrm{S} \mathrm{cm}^{-1}\right)\end{array}$} \\
\hline & & & & & & & Início & Fim & Início & Fim * & Início & Fim \\
\hline Controle & 1 & 0 & 0 & 1 & 2 & 10 & 7,85 & 8,15 & 220 & - & 926 & 968 \\
\hline $0,1 \mathrm{mg} \mathrm{L}^{-1}$ & 0 & 0 & 0 & 0 & 0 & 0 & 7,95 & 8,4 & 220 & - & 935 & 974 \\
\hline $0,2 \mathrm{mg} \mathrm{L}^{-1}$ & 0 & 0 & 1 & 0 & 1 & 5 & 8,0 & 8,5 & 218 & - & 930 & 983 \\
\hline $0,4 \mathrm{mg} \mathrm{L}^{-1}$ & 2 & 4 & 2 & 3 & 11 & 55 & 8,0 & 8,5 & 224 & - & 936 & 958 \\
\hline $0,8 \mathrm{mg} \mathrm{L}^{-1}$ & 2 & 3 & 2 & 5 & 12 & 60 & 8,0 & 8,5 & 228 & - & 924 & 973 \\
\hline $1,6 \mathrm{mg} \mathrm{L}^{-1}$ & 4 & 5 & 5 & 4 & 18 & 90 & 8,0 & 8,55 & 228 & - & 915 & 967 \\
\hline $3,2 \mathrm{mg} \mathrm{L}^{-1}$ & 5 & 5 & 5 & 5 & 20 & 100 & 8,0 & 8,5 & 224 & - & 899 & 939 \\
\hline
\end{tabular}


Tabela 6-Valores das concentrações de dicromato de potássio, do número de indivíduos de D. magna imóveis e valores medidos para as variáveis $\mathrm{pH}$, dureza e condutividade elétrica das soluções-teste, para o Teste no. 2. A dureza final não foi medida por falta de volume suficiente de solução teste.

\begin{tabular}{|c|c|c|c|c|c|c|c|c|c|c|c|c|}
\hline \multicolumn{2}{|c|}{ Organismo teste: } & \multicolumn{3}{|c|}{ Daphnia magna } & \multicolumn{3}{|c|}{ Teste $\mathbf{N}^{\mathbf{o}}: 02$} & \multirow{2}{*}{\multicolumn{5}{|c|}{$\frac{\text { Solução estoque: Dicromato de potássio }}{\text { Variáveis }}$}} \\
\hline \multirow{3}{*}{$\begin{array}{l}\text { Sol. Teste } \\
\left(100 \mathrm{mg} \mathrm{L}^{-1}\right)\end{array}$} & & & Im & dac & & & & & & & & \\
\hline & \multirow[t]{2}{*}{1} & \multirow[t]{2}{*}{2} & \multirow[t]{2}{*}{3} & \multirow[t]{2}{*}{4} & \multirow[t]{2}{*}{ Total } & \multirow[t]{2}{*}{$\%$} & \multicolumn{2}{|c|}{ pH } & \multicolumn{2}{|c|}{$\begin{array}{c}\text { Dureza } \\
\left(\mathrm{mg} \mathrm{CaCO}_{3} \mathrm{~L}^{-1}\right)\end{array}$} & \multicolumn{2}{|c|}{$\begin{array}{c}\text { Condutividade } \\
\left(\mu \mathrm{S} \mathrm{cm} \mathrm{cm}^{-1}\right)\end{array}$} \\
\hline & & & & & & & Início & Fim & Início & Fim* & Início & Fim \\
\hline Controle & 0 & 0 & 0 & 2 & 2 & 10 & 7,75 & 7,75 & 192 & - & 656 & 684 \\
\hline $0,1 \mathrm{mg} \mathrm{L}^{-1}$ & 0 & 0 & 1 & 3 & 4 & 20 & 7,75 & 7,75 & 172 & - & 649 & 676 \\
\hline $0,2 \mathrm{mg} \mathrm{L}^{-1}$ & 0 & 0 & 1 & 1 & 2 & 10 & 7,75 & 7,8 & 174 & - & 659 & 690 \\
\hline $0,4 \mathrm{mg} \mathrm{L}^{-1}$ & 3 & 2 & 0 & 4 & 9 & 45 & 7.8 & 7,85 & 186 & - & 658 & 695 \\
\hline $0,8 \mathrm{mg} \mathrm{L}^{-1}$ & 4 & 5 & 4 & 5 & 18 & 90 & 7,75 & 7,85 & 180 & - & 650 & 674 \\
\hline $1,6 \mathrm{mg} \mathrm{L}^{-1}$ & 5 & 5 & 5 & 5 & 20 & 100 & 7,8 & 7,85 & 186 & - & 652 & 669 \\
\hline $3,2 \mathrm{mg} \mathrm{L}^{-1}$ & 5 & 5 & 5 & 5 & 20 & 100 & 7,75 & 7,85 & 188 & - & 632 & 675 \\
\hline
\end{tabular}


Tabela 7-Valores das concentrações de dicromato de potássio, do número de indivíduos de D. magna imóveis e valores medidos para as variáveis $\mathrm{pH}$, dureza e condutividade elétrica das soluções-teste, para o Teste no. 3. A dureza final não foi medida por falta de volume suficiente de solução teste.

\begin{tabular}{|c|c|c|c|c|c|c|c|c|c|c|c|c|}
\hline \multicolumn{2}{|c|}{ Organismo teste: } & \multicolumn{3}{|c|}{ Daphnia magna } & \multicolumn{3}{|c|}{ Teste $\mathbf{N}^{\mathbf{o}}: 03$} & \multirow{2}{*}{\multicolumn{5}{|c|}{$\frac{\text { Solução estoque: Dicromato de potássio }}{\text { Variáveis }}$}} \\
\hline \multirow{3}{*}{$\begin{array}{l}\text { Sol. Teste } \\
\left(100 \mathrm{mg} \mathrm{L}^{-1}\right)\end{array}$} & & & Im & dac & & & & & & & & \\
\hline & \multirow[t]{2}{*}{1} & \multirow[t]{2}{*}{2} & \multirow[t]{2}{*}{3} & \multirow[t]{2}{*}{4} & \multirow[t]{2}{*}{ Total } & \multirow[t]{2}{*}{$\%$} & \multicolumn{2}{|c|}{$\mathrm{pH}$} & \multicolumn{2}{|c|}{$\begin{array}{c}\text { Dureza } \\
\left(\mathrm{mg} \mathrm{CaCO}_{3} \mathrm{~L}^{-1}\right) \\
\end{array}$} & \multicolumn{2}{|c|}{$\begin{array}{c}\text { Condutividade } \\
\left(\mu \mathrm{S} \mathrm{cm} \mathrm{cm}^{-1}\right)\end{array}$} \\
\hline & & & & & & & Início & Fim & Início & Fim* & Início & Fim \\
\hline Controle & 0 & 0 & 0 & 0 & 0 & 0 & 7,75 & 7,8 & 184 & - & 657 & 664 \\
\hline $0,1 \mathrm{mg} \mathrm{L}^{-1}$ & 0 & 0 & 0 & 0 & 0 & 0 & 7,75 & 7,75 & 172 & - & 653 & 662 \\
\hline $0,2 \mathrm{mg} \mathrm{L}^{-1}$ & 0 & 0 & 0 & 0 & 0 & 0 & 7,75 & 7,75 & 166 & - & 654 & 678 \\
\hline $0,4 \mathrm{mg} \mathrm{L}^{-1}$ & 1 & 2 & 1 & 2 & 6 & 30 & 7,75 & 7,75 & 172 & - & 658 & 667 \\
\hline $0,8 \mathrm{mg} \mathrm{L}^{-1}$ & 5 & 5 & 5 & 3 & 18 & 90 & 7,75 & 7,75 & 164 & - & 661 & 673 \\
\hline $1,6 \mathrm{mg} \mathrm{L}^{-1}$ & 5 & 5 & 5 & 5 & 20 & 100 & 7,7 & 7,75 & 168 & - & 655 & 654 \\
\hline $3,2 \mathrm{mg} \mathrm{L}^{-1}$ & 5 & 5 & 5 & 5 & 20 & 100 & 7,7 & 7,7 & 168 & - & 640 & 642 \\
\hline
\end{tabular}


Tabela 8-Valores das concentrações de dicromato de potássio, do número de indivíduos de D. magna imóveis e valores medidos para as variáveis $\mathrm{pH}$, dureza e condutividade elétrica das soluções-teste, para o Teste no. 4. A dureza final não foi medida por falta de volume suficiente de solução teste.

\begin{tabular}{|c|c|c|c|c|c|c|c|c|c|c|c|c|}
\hline \multicolumn{2}{|c|}{ Organismo teste: } & \multicolumn{3}{|c|}{ Daphnia magna } & \multicolumn{3}{|c|}{ Teste $\mathbf{N}^{\mathbf{o}}: 04$} & \multirow{2}{*}{\multicolumn{5}{|c|}{$\frac{\text { Solução estoque: Dicromato de potássio }}{\text { Variáveis }}$}} \\
\hline \multirow{3}{*}{$\begin{array}{l}\text { Sol. Teste } \\
\left(100 \mathrm{mg} \mathrm{L}^{-1}\right)\end{array}$} & & & Im & dac & & & & & & & & \\
\hline & \multirow[t]{2}{*}{1} & \multirow[t]{2}{*}{2} & \multirow[t]{2}{*}{3} & \multirow[t]{2}{*}{4} & \multirow[t]{2}{*}{ Total } & \multirow[t]{2}{*}{$\%$} & \multicolumn{2}{|c|}{ pH } & \multicolumn{2}{|c|}{$\begin{array}{c}\text { Dureza } \\
\left(\mathrm{mg} \mathrm{CaCO}_{3} \mathrm{~L}^{-1}\right)\end{array}$} & \multicolumn{2}{|c|}{$\begin{array}{c}\text { Condutividade } \\
\left(\mu \mathrm{S} \mathrm{cm} \mathrm{cm}^{-1}\right)\end{array}$} \\
\hline & & & & & & & Início & Fim & Início & Fim* & Início & Fim \\
\hline Controle & 0 & 0 & 0 & 0 & 0 & 0 & 7,75 & 7,75 & 184 & - & 657 & 704 \\
\hline $0,1 \mathrm{mg} \mathrm{L}^{-1}$ & 2 & 2 & 1 & 3 & 8 & 40 & 7,75 & 7,75 & 172 & - & 653 & 681 \\
\hline $0,2 \mathrm{mg} \mathrm{L}^{-1}$ & 1 & 0 & 0 & 1 & 2 & 10 & 7,75 & 7,75 & 166 & - & 654 & 676 \\
\hline $0,4 \mathrm{mg} \mathrm{L}^{-1}$ & 4 & 5 & 4 & 5 & 18 & 90 & 7,75 & 7,75 & 172 & - & 658 & 684 \\
\hline $0,8 \mathrm{mg} \mathrm{L}^{-1}$ & 5 & 5 & 5 & 5 & 20 & 100 & 7,75 & 7,75 & 164 & - & 661 & 684 \\
\hline $1,6 \mathrm{mg} \mathrm{L}^{-1}$ & 5 & 5 & 5 & 5 & 20 & 100 & 7,7 & 7,85 & 168 & - & 655 & 685 \\
\hline $3,2 \mathrm{mg} \mathrm{L}^{-1}$ & 5 & 5 & 5 & 5 & 20 & 100 & 7,7 & 7,75 & 168 & - & 640 & 677 \\
\hline
\end{tabular}


Tabela 9-Valores das concentrações de dicromato de potássio, do número de indivíduos de D. magna imóveis e valores medidos para as variáveis $\mathrm{pH}$, dureza e condutividade elétrica das soluções-teste, para o Teste no. 5. A dureza final não foi medida por falta de volume suficiente de solução teste.

\begin{tabular}{|c|c|c|c|c|c|c|c|c|c|c|c|c|}
\hline \multicolumn{2}{|c|}{ Organismo teste: } & \multicolumn{3}{|c|}{ Daphnia magna } & \multicolumn{3}{|c|}{ Teste $\mathbf{N}^{\mathbf{o}}: 05$} & \multirow{2}{*}{\multicolumn{5}{|c|}{$\begin{array}{c}\text { Solução estoque: Dicromato de potássio } \\
\text { Variáveis }\end{array}$}} \\
\hline \multirow{3}{*}{$\begin{array}{l}\text { Sol. Teste } \\
\left(100 \mathrm{mg} \mathrm{L}^{-1}\right)\end{array}$} & & & Im & dac & & & & & & & & \\
\hline & \multirow[t]{2}{*}{1} & \multirow[t]{2}{*}{2} & \multirow[t]{2}{*}{3} & \multirow[t]{2}{*}{4} & \multirow[t]{2}{*}{ Total } & \multirow[t]{2}{*}{$\%$} & \multicolumn{2}{|c|}{$\mathrm{pH}$} & \multicolumn{2}{|c|}{$\begin{array}{c}\text { Dureza } \\
\left(\mathrm{mg} \mathrm{CaCO}_{3} \mathrm{~L}^{-1}\right)\end{array}$} & \multicolumn{2}{|c|}{$\begin{array}{c}\text { Condutividade } \\
\left(\mu \mathrm{S} \mathrm{cm} \mathrm{cm}^{-1}\right)\end{array}$} \\
\hline & & & & & & & Início & Fim & Início & Fim* & Início & Fim \\
\hline Controle & 0 & 0 & 1 & 0 & 1 & 5 & 7,75 & 7,95 & 196 & - & 607 & 681 \\
\hline $0,1 \mathrm{mg} \mathrm{L}^{-1}$ & 0 & 1 & 1 & 0 & 2 & 10 & 7,85 & 7,95 & 164 & - & 654 & 678 \\
\hline $0,2 \mathrm{mg} \mathrm{L}^{-1}$ & 0 & 2 & 0 & 2 & 4 & 20 & 7,9 & 7,85 & 124 & - & 646 & 652 \\
\hline $0,4 \mathrm{mg} \mathrm{L}^{-1}$ & 1 & 1 & 3 & 1 & 5 & 25 & 7,85 & 7,65 & 164 & - & 648 & 903 \\
\hline $0,8 \mathrm{mg} \mathrm{L}^{-1}$ & 5 & 5 & 5 & 5 & 20 & 100 & 7,85 & 7,85 & 160 & - & 661 & 696 \\
\hline $1,6 \mathrm{mg} \mathrm{L}^{-1}$ & 5 & 5 & 5 & 5 & 20 & 100 & 7,85 & 7,85 & 148 & - & 654 & 677 \\
\hline $3,2 \mathrm{mg} \mathrm{L}^{-1}$ & 5 & 5 & 5 & 5 & 20 & 100 & 7,8 & 7,85 & 148 & - & 636 & 669 \\
\hline
\end{tabular}




\section{APÊNDICE G - Dados brutos referentes às variáveis físicas e químicas da água durante o teste de toxicidade crônica.}

Tabela 10- Parâmetros iniciais (VI) das variáveis medidas na água. Teste de toxicidade crônica. Geração $\mathrm{F}_{0}$. (OD: Oxigênio dissolvido; C: controle; C+S: controle do solvente). Início do teste: 18/08/2015.

\begin{tabular}{|c|c|c|c|c|}
\hline & OD $\left(\mathrm{mg} \mathrm{L}^{-1}\right)$ & $\mathbf{p H}$ & Dureza $\left(\mathrm{mg} \mathrm{CaCO}_{3} \mathrm{~L}^{-1}\right)$ & Temperatura $\left({ }^{\circ} \mathrm{C}\right)$ \\
\hline $\mathbf{C}$ & 6,13 & 7,75 & 186 & 24,5 \\
\hline $\mathrm{C}+\mathrm{S}$ & 6,35 & 7,75 & 184 & 24,5 \\
\hline $62,5 \mu \mathrm{g} \mathrm{L}^{-1}$ & 7,54 & 7,75 & 184 & 24,5 \\
\hline $125 \mu \mathrm{g} \mathrm{L}^{-1}$ & 7,75 & 7,8 & 184 & 24,5 \\
\hline $250 \mu \mathrm{g} \mathrm{L}^{-1}$ & 7,62 & 7,8 & 188 & 24,5 \\
\hline $500 \mu \mathrm{g} \mathrm{L}^{-1}$ & 8,04 & 7,8 & 188 & 24,5 \\
\hline $1000 \mu \mathrm{g} \mathrm{L}^{-1}$ & 7,54 & 7,85 & 182 & 24,5 \\
\hline $2000 \mu \mathrm{g} \mathrm{L}^{-1}$ & 7,86 & 7,8 & 176 & 24,5 \\
\hline
\end{tabular}


Tabela 11-Parâmetros iniciais (VI) e finais (VF) das variáveis medidas na água. Teste de toxicidade crônica. Geração $\mathrm{F}_{0}$. (OD: Oxigênio dissolvido; C: controle; $\mathrm{C}+\mathrm{S}$ : controle do solvente). Durante o teste foram medidas as variáveis dos controles, menor concentração, concentração média e maior concentração. Final do teste: 30/08/2015.

\begin{tabular}{|c|c|c|c|c|}
\hline VI (20/08) & $\overline{O D}\left(\mathrm{mg} \mathrm{L}^{-1}\right)$ & pH & Dureza $\left(\mathrm{mg} \mathrm{CaCO}_{3} \mathrm{~L}^{-1}\right)$ & Temperatura $\left({ }^{\circ} \mathrm{C}\right)$ \\
\hline $\mathbf{C}$ & 6,98 & 7,75 & 188 & 24,8 \\
\hline $\mathbf{C}+\mathrm{S}$ & 6,18 & 7,75 & 184 & 24,8 \\
\hline $62,5 \mu \mathrm{g} \mathrm{L^{-1 }}$ & 7,01 & 7,75 & 188 & 24,8 \\
\hline $500 \mu \mathrm{g} \mathrm{L}^{-1}$ & 7,13 & 7,8 & 178 & 24,7 \\
\hline $2000 \mu \mathrm{g} \mathrm{L}^{-1}$ & 6,88 & 7,85 & 180 & 24,7 \\
\hline VF (20/08) & OD $\left(\mathrm{mg} \mathrm{L}^{-1}\right)$ & $\mathrm{pH}$ & Dureza $\left(\mathrm{mg} \mathrm{CaCO}_{3} \mathrm{~L}^{-1}\right)$ & Temperatura $\left({ }^{\circ} \mathbf{C}\right)$ \\
\hline $\bar{C}$ & 6,25 & 7,85 & 204 & 25,4 \\
\hline $\mathbf{C}+\mathrm{S}$ & 6,78 & 7,85 & 198 & 25,3 \\
\hline $62,5 \mu g \mathrm{~L}^{-1}$ & 6,57 & 7,9 & 196 & 25,2 \\
\hline $500 \mu \mathrm{g} \mathrm{L}^{-1}$ & 6,63 & 7,9 & 192 & 25,1 \\
\hline $2000 \mu g \mathrm{~L}^{-1}$ & 6,75 & 7,9 & 186 & 25,1 \\
\hline VI (24/08) & $\mathrm{OD}\left(\mathrm{mg} \mathrm{L}^{-1}\right)$ & pH & Dureza $\left(\mathrm{mg} \mathrm{CaCO}_{3} \mathrm{~L}^{-1}\right)$ & Temperatura $\left({ }^{\circ} \mathbf{C}\right)$ \\
\hline $\bar{C}$ & 6,43 & 7,85 & 186 & 25 \\
\hline $\mathrm{C}+\mathrm{S}$ & 6,24 & 7,85 & 186 & 25 \\
\hline $62,5 \mu \mathrm{g} \mathrm{L}^{-1}$ & 7,47 & 7,9 & 184 & 25 \\
\hline $500 \mu \mathrm{g} \mathrm{L}^{-1}$ & 6,40 & 7,9 & 180 & 25 \\
\hline $2000 \mu \mathrm{g} \mathrm{L}^{-1}$ & 7,9 & 7,8 & 178 & 25 \\
\hline VF (24/08) & OD $\left(\mathrm{mg} \mathrm{L}^{-1}\right)$ & pH & Dureza $\left(\mathrm{mg} \mathrm{CaCO}_{3} \mathrm{~L}^{-1}\right)$ & Temperatura $\left({ }^{\circ} \mathbf{C}\right)$ \\
\hline$\overline{\mathrm{C}}$ & 6,04 & 7,8 & 186 & 25 \\
\hline $\mathrm{C}+\mathrm{S}$ & 5,09 & 7,8 & 196 & 25 \\
\hline $62,5 \mu \mathrm{g} \mathrm{L^{-1 }}$ & 6,28 & 7,8 & 192 & 25 \\
\hline $500 \mu \mathrm{g} \mathrm{L}^{-1}$ & 6,55 & 7,85 & 196 & 25 \\
\hline $2000 \mu g L^{-1}$ & 6,63 & 7,85 & 186 & 25 \\
\hline
\end{tabular}


Continuação Tabela 11...

\begin{tabular}{|c|c|c|c|c|}
\hline VI (28/08) & $\mathrm{OD}\left(\mathrm{mg} \mathrm{L}^{-1}\right)$ & pH & Dureza $\left(\mathrm{mg} \mathrm{CaCO}_{3} \mathrm{~L}^{-1}\right)$ & Temperatura $\left({ }^{\circ} \mathrm{C}\right)$ \\
\hline $\mathbf{C}$ & 6,56 & 7,75 & 196 & 25 \\
\hline $\mathrm{C}+\mathrm{S}$ & 6,18 & 7,8 & 192 & 25 \\
\hline $62,5 \mu \mathrm{g} \mathrm{L}^{-1}$ & 6,18 & 7,8 & 188 & 25 \\
\hline $500 \mu \mathrm{g} \mathrm{L}^{-1}$ & 6,63 & 7,8 & 184 & 25 \\
\hline $2000 \mu \mathrm{g} \mathrm{L}^{-1}$ & 7,00 & 7,8 & 182 & 25 \\
\hline VF $(28 / 08)$ & $\mathrm{OD}\left(\mathrm{mg} \mathrm{L}^{-1}\right)$ & pH & Dureza $\left(\mathrm{mg} \mathrm{CaCO}_{3} \mathrm{~L}^{-1}\right)$ & Temperatura $\left({ }^{\circ} \mathrm{C}\right)$ \\
\hline $\mathbf{C}$ & 7,10 & 7,7 & 190 & 25 \\
\hline $\mathrm{C}+\mathrm{S}$ & 6,47 & 7,8 & 184 & 25 \\
\hline $62,5 \mu \mathrm{g} \mathrm{L} \mathrm{L}^{-1}$ & 5,78 & 7,85 & 184 & 25 \\
\hline $500 \mu \mathrm{g} \mathrm{L}^{-1}$ & 5,82 & 7,9 & 178 & 25 \\
\hline $2000 \mu \mathrm{g} \mathrm{L}^{-1}$ & 6,31 & 7,9 & 182 & 25 \\
\hline VF (30/08) & OD $\left(\mathrm{mg} \mathrm{L}^{-1}\right)$ & pH & Dureza $\left(\mathrm{mg} \mathrm{CaCO}_{3} \mathrm{~L}^{-1}\right)$ & Temperatura $\left({ }^{\circ} \mathrm{C}\right)$ \\
\hline $\mathbf{C}$ & 5,22 & 7,7 & 204 & 25 \\
\hline $\mathrm{C}+\mathrm{S}$ & 5,18 & 7,7 & 196 & 25 \\
\hline $62,5 \mu \mathrm{g} \mathrm{L}^{-1}$ & 5,01 & 7,75 & 190 & 25 \\
\hline $500 \mu \mathrm{g} \mathrm{L}^{-1}$ & 5,09 & 7,75 & 172 & 25 \\
\hline $2000 \mu \mathrm{g} \mathrm{L}^{-1}$ & 5,06 & 7,75 & 176 & 25 \\
\hline
\end{tabular}

Conclusão Tabela 11. 
Tabela 12-Parâmetros iniciais (VI) das variáveis medidas na água. Teste de toxicidade crônica. Geração $\mathrm{F}_{1}$. (OD: Oxigênio dissolvido; C: controle; C+S: controle do solvente). Início do teste: 29/08/2015.

\begin{tabular}{ccccc}
\hline $\mathbf{V I}(\mathbf{2 9 / 0 8})$ & $\mathbf{O D}\left(\mathbf{m g ~ L}^{-\mathbf{1}}\right)$ & $\mathbf{p H}$ & Dureza $\left(\mathbf{m g ~ C a C O}_{\mathbf{3}} \mathbf{L}^{-\mathbf{1}}\right)$ & Temperatura $\left({ }^{\circ} \mathbf{C}\right)$ \\
\hline $\mathbf{C}$ & 4,96 & 7,75 & 190 & 21 \\
\hline $\mathbf{C}+\mathbf{S}$ & 4,87 & 7,75 & 196 & 21 \\
\hline $\mathbf{6 2 , 5} \boldsymbol{\mu} \mathbf{g ~ L}^{-1}$ & 4,94 & 7,8 & 194 & 22 \\
\hline $\mathbf{2 5 0} \boldsymbol{\mu} \mathbf{g ~ L}^{-\mathbf{1}}$ & 4,88 & 7,8 & 190 & 21,5 \\
\hline $\mathbf{5 0 0} \boldsymbol{\mu} \mathbf{g ~ L}^{-1}$ & 5,18 & 7,8 & 190 & 19 \\
\hline $\mathbf{2 0 0 0} \boldsymbol{\mu g ~ \mathbf { g ~ L } ^ { - 1 }}$ & 5,8 & 7,8 & 188 & 21 \\
\hline
\end{tabular}


Tabela 13-Parâmetros iniciais (VI) e finais (VF) das variáveis medidas na água. Teste de toxicidade crônica. Geração $\mathrm{F}_{1}$. (OD: Oxigênio dissolvido; $\mathrm{C}$ : controle; $\mathrm{C}+\mathrm{S}$ : controle do solvente). Durante o teste foram medidas as variáveis dos controles, menor concentração, concentração média e maior concentração. Final do teste: 11/09/2015.

\begin{tabular}{|c|c|c|c|c|}
\hline VI (31/08) & $\mathrm{OD}\left(\mathrm{mg} \mathrm{L}^{-1}\right)$ & $\mathbf{p H}$ & Dureza $\left(\mathrm{mg} \mathrm{CaCO}_{3} \mathrm{~L}^{-1}\right)$ & Temperatura $\left({ }^{\circ} \mathbf{C}\right)$ \\
\hline $\bar{C}$ & 4,81 & 7,9 & 164 & 25 \\
\hline $\mathrm{C}+\mathrm{S}$ & 5,01 & 7,7 & 184 & 25 \\
\hline $62,5 \mu \mathrm{g} \mathrm{L}^{-1}$ & 4,74 & 7,8 & 188 & 25 \\
\hline $250 \mu \mathrm{g} \mathrm{L}^{-1}$ & 4,85 & 7,8 & 192 & 25 \\
\hline $500 \mu \mathrm{g} \mathrm{L}^{-1}$ & 4,89 & 7,9 & 172 & 25 \\
\hline $2000 \mu \mathrm{g} \mathrm{L}^{-1}$ & 6,05 & 7,85 & 188 & 25 \\
\hline VF (31/08) & $\mathrm{OD}\left(\mathrm{mg} \mathrm{L}^{-1}\right)$ & $\mathbf{p H}$ & Dureza $\left(\mathrm{mg} \mathrm{CaCO}_{3} \mathrm{~L}^{-1}\right)$ & Temperatura água $\left({ }^{\circ} \mathbf{C}\right)$ \\
\hline $\mathbf{C}$ & 5,00 & 7,75 & 200 & 25 \\
\hline $\mathbf{C}+\mathrm{S}$ & 5,90 & 7,85 & 198 & 25 \\
\hline $62,5 \mu \mathrm{g} \mathrm{L}^{-1}$ & 5,16 & 7,85 & 182 & 25 \\
\hline $250 \mu \mathrm{g} \mathrm{L}^{-1}$ & 5,88 & 7.85 & 182 & 25 \\
\hline $500 \mu \mathrm{g} \mathrm{L}^{-1}$ & 5,60 & 7,85 & 188 & 25 \\
\hline $2000 \mu \mathrm{g} \mathrm{L}^{-1}$ & 5,60 & 7,85 & 194 & 25 \\
\hline VI (06/09) & $\mathrm{OD}\left(\mathrm{mg} \mathrm{L}^{-1}\right)$ & pH & Dureza $\left(\mathrm{mg} \mathrm{CaCO}_{3} \mathrm{~L}^{-1}\right)$ & Temperatura $\left({ }^{\circ} \mathbf{C}\right)$ \\
\hline $\mathbf{C}$ & 4,90 & 7,8 & 182 & 24,3 \\
\hline $\mathbf{C}+\mathrm{S}$ & 4,94 & 7,8 & - & 24 \\
\hline $62,5 \mu \mathrm{g} \mathrm{L}^{-1}$ & 4,72 & 7,7 & 180 & 25 \\
\hline $250 \mu \mathrm{g} \mathrm{L}^{-1}$ & 5,05 & 7,85 & 170 & 25 \\
\hline $500 \mu \mathrm{g} \mathrm{L}^{-1}$ & 4,86 & 7,85 & 188 & 25 \\
\hline $2000 \mu \mathrm{g} \mathrm{L}^{-1}$ & 5,31 & 7,85 & 172 & 24,2 \\
\hline
\end{tabular}

Continua... 
Continuação Tabela 13...

\begin{tabular}{|c|c|c|c|c|}
\hline VF (06/09) & OD $\left(\mathrm{mg} \mathrm{L}^{-1}\right)$ & $\mathbf{p H}$ & Dureza $\left(\mathrm{mg} \mathrm{CaCO}_{3} \mathrm{~L}^{-1}\right)$ & Temperatura $\left({ }^{\circ} \mathbf{C}\right)$ \\
\hline $\bar{C}$ & 5,10 & 7,75 & 198 & 25,3 \\
\hline $\mathbf{C}+\mathbf{S}$ & 4,42 & 7,75 & 185 & 25,6 \\
\hline $62,5 \mu g \mathrm{~L}^{-1}$ & 4,81 & 7,8 & 183 & 25,1 \\
\hline $250 \mu g \mathrm{~L}^{-1}$ & 4,91 & 7,85 & 185 & 25,2 \\
\hline $500 \mu \mathrm{g} \mathrm{L}^{-1}$ & 4,74 & 7,85 & 181 & 25,1 \\
\hline $2000 \mu \mathrm{g} \mathrm{L}^{-1}$ & 4,75 & 7,9 & 172 & 25,6 \\
\hline VI (08/09) & $\mathrm{OD}\left(\mathrm{mg} \mathrm{L}^{-1}\right)$ & $\mathbf{p H}$ & Dureza $\left(\mathrm{mg} \mathrm{CaCO}_{3} \mathrm{~L}^{-1}\right)$ & Temperatura $\left({ }^{\circ} \mathrm{C}\right)$ \\
\hline $\mathbf{C}$ & 4,34 & 7,8 & 189 & 25 \\
\hline $\mathrm{C}+\mathrm{S}$ & 4,57 & 7,85 & 186 & 25 \\
\hline $62,5 \mu \mathrm{g} \mathrm{L}^{-1}$ & 4,44 & 7,85 & 176 & 25 \\
\hline $250 \mu g L^{-1}$ & 5,01 & 7,9 & 179 & 25 \\
\hline $500 \mu g \mathrm{~L}^{-1}$ & 4,80 & 7,9 & 176 & 25 \\
\hline $2000 \mu \mathrm{g} \mathrm{L}^{-1}$ & 4,89 & 7,95 & 180 & 25 \\
\hline VF (08/09) & OD $\left(\mathrm{mg} \mathrm{L}^{-1}\right)$ & $\mathbf{p H}$ & Dureza $\left(\mathrm{mg} \mathrm{CaCO} \mathrm{L}^{-1}\right)$ & Temperatura $\left({ }^{\circ} \mathbf{C}\right)$ \\
\hline $\mathbf{C}$ & 4,16 & 7,75 & 178 & 25 \\
\hline $\mathrm{C}+\mathrm{S}$ & 4,49 & 7,85 & 177 & 25 \\
\hline $62,5 \mu \mathrm{g} \mathrm{L}^{-1}$ & 4,67 & 7,8 & 176 & 25 \\
\hline $250 \mu \mathrm{g} \mathrm{L}^{-1}$ & 4,30 & 7,85 & 175 & 25 \\
\hline $500 \mu g \mathrm{~L}^{-1}$ & 4,13 & 7,95 & 180 & 25 \\
\hline $2000 \mu g L^{-1}$ & 4,20 & 7,95 & 170 & 25 \\
\hline
\end{tabular}


Continuação Tabela 13...

\begin{tabular}{|c|c|c|c|c|}
\hline VF (11/09) & $\mathrm{OD}\left(\mathrm{mg} \mathrm{L}^{-1}\right)$ & pH & Dureza $\left(\mathrm{mg} \mathrm{CaCO}_{3} \mathrm{~L}^{-1}\right)$ & Temperatura $\left({ }^{\circ} \mathrm{C}\right)$ \\
\hline $\mathbf{C}$ & 4,03 & 7,7 & 179 & 25 \\
\hline $\mathrm{C}+\mathrm{S}$ & 4,25 & 7,85 & 176 & 25 \\
\hline $62,5 \mu \mathrm{g} \mathrm{L}^{-1}$ & 4,11 & 7,8 & 172 & 25 \\
\hline $250 \mu \mathrm{g} \mathrm{L}^{-1}$ & 4,16 & 7,8 & 173 & 25 \\
\hline $500 \mu \mathrm{g} \mathrm{L}^{-1}$ & 4,11 & 7,9 & 172 & 25 \\
\hline $2000 \mu \mathrm{g} \mathrm{L}^{-1}$ & 4,60 & 7,95 & 176 & 25 \\
\hline
\end{tabular}

Conclusão Tabela 13. 
APÊNDICE H - Dados brutos obtidos no teste de toxicidade crônica do organismo teste Daphnia magna à substância teste 17 $\alpha$-etinilestradiol, nas condições laboratoriais adotadas.

Tabela 14-Valores das concentrações de $17 \alpha$-etinilestradiol, mortalidade, maturidade, número de neonatas e ninhada dos organismos de Daphnia magna, submetidos ao teste de toxicidade crônica (10 réplicas por concentração, mais controle e controle com solvente) à $25^{\circ} \mathrm{C}$. (M: mortalidade; Mt: maturidade; Ne: número de neonatas; N: ninhada; Im: imatura; OD: ovário desenvolvido; DO: desenvolvimento do ovário; O: ovada; Em: embrionada). Geração $\mathrm{F}_{0}$. Início do teste: 18/08/2015.

\begin{tabular}{|c|c|c|c|c|c|c|c|c|c|c|c|c|c|c|c|c|c|c|c|c|}
\hline & \multicolumn{2}{|c|}{$20 / 08$} & \multicolumn{2}{|c|}{$21 / 08$} & \multicolumn{2}{|c|}{$22 / 08$} & \multicolumn{2}{|c|}{$23 / 08$} & \multicolumn{4}{|c|}{$24 / 08$} & \multicolumn{4}{|c|}{$25 / 08$} & \multicolumn{4}{|c|}{$26 / 08$} \\
\hline & $\overline{\mathbf{M}}$ & Mt & $\overline{\mathbf{M}}$ & $\overline{\mathbf{M t}}$ & $\overline{\mathbf{M}}$ & Mt & $\overline{\mathbf{M}}$ & Mt & $\overline{\mathbf{M}}$ & $\overline{\text { Mt }}$ & $\mathrm{Ne}$ & $\mathbf{N}$ & $\bar{M}$ & $\mathbf{M t}$ & $\mathrm{Ne}$ & $\mathbf{N}$ & $\bar{M}$ & Mt & $\mathrm{Ne}$ & $\mathbf{N}$ \\
\hline$\overline{C_{1}}$ & 0 & $\mathrm{Im}$ & 0 & $\mathrm{Im}$ & 0 & OD & 0 & $\bar{O}$ & 0 & $\overline{\mathrm{Em}}$ & - & - & 0 & $\mathrm{O}$ & 11 & $1^{\mathrm{a}}$ & 0 & $\mathrm{Em}$ & - & $1^{\mathrm{a}}$ \\
\hline $\mathrm{C}_{2}$ & 0 & $\mathrm{Im}$ & 0 & $\mathrm{Im}$ & 0 & $\sigma^{\pi}$ & 0 & $\sigma^{7}$ & 0 & $\sigma^{7}$ & - & - & 0 & $\sigma^{7}$ & - & - & 0 & $\sigma$ & - & - \\
\hline $\mathrm{C}_{3}$ & 0 & $\mathrm{Im}$ & 0 & $\mathrm{Im}$ & 0 & OD & 0 & $\mathrm{O}$ & 0 & Em & - & - & 0 & $\mathrm{O}$ & 14 & $1^{\mathrm{a}}$ & 0 & $\mathrm{Em}$ & - & $1^{\mathrm{a}}$ \\
\hline $\mathrm{C}_{4}$ & 0 & $\mathrm{Im}$ & 0 & $\mathrm{Im}$ & 0 & $\sigma^{\prime}$ & 0 & $\sigma^{\prime}$ & 0 & $\sigma^{7}$ & - & - & 0 & $\sigma^{\top}$ & - & - & 0 & $\sigma^{\prime}$ & - & - \\
\hline $\mathrm{C}_{5}$ & 0 & $\mathrm{Im}$ & 0 & $\mathrm{Im}$ & 0 & OD & 0 & $\mathrm{O}$ & 0 & Em & - & - & 0 & $\mathrm{O}$ & 10 & $1^{\mathrm{a}}$ & 0 & $\mathrm{Em}$ & - & $1^{\mathrm{a}}$ \\
\hline $\mathrm{C}_{6}$ & 0 & $\mathrm{Im}$ & 0 & $\mathrm{Im}$ & 0 & $\sigma^{7}$ & 0 & $\sigma^{7}$ & 0 & $\sigma^{7}$ & - & - & 0 & $\sigma^{7}$ & - & - & 0 & $\sigma$ & - & - \\
\hline $\mathrm{C}_{7}$ & 0 & $\mathrm{Im}$ & 0 & $\mathrm{Im}$ & 0 & OD & 0 & $\mathrm{O}$ & 0 & $\mathrm{Em}$ & - & - & 0 & $\mathrm{O}$ & 9 & $1^{\mathrm{a}}$ & 0 & $\mathrm{Em}$ & - & $1^{\mathrm{a}}$ \\
\hline $\mathrm{C}_{8}$ & 0 & $\mathrm{Im}$ & 0 & $\mathrm{Im}$ & 0 & OD & 0 & $\mathrm{O}$ & 0 & Em & - & - & 0 & $\mathrm{O}$ & 10 & $1^{\mathrm{a}}$ & 0 & $\mathrm{Em}$ & - & $1^{\mathrm{a}}$ \\
\hline $\mathrm{C}_{9}$ & 0 & $\mathrm{Im}$ & 0 & $\mathrm{Im}$ & 0 & OD & 0 & $\mathrm{O}$ & 0 & Em & - & - & 0 & $\mathrm{O}$ & 14 & $1^{\mathrm{a}}$ & 0 & $\mathrm{Em}$ & - & $1^{\mathrm{a}}$ \\
\hline $\mathrm{C}_{10}$ & 0 & $\mathrm{Im}$ & 0 & $\mathrm{Im}$ & 0 & OD & 0 & $\mathrm{O}$ & 0 & Em & - & - & 0 & $\mathrm{O}$ & 10 & $1^{\mathrm{a}}$ & 0 & $\mathrm{Em}$ & - & $1^{\mathrm{a}}$ \\
\hline $\mathrm{C}+\mathrm{S}_{1}$ & 0 & $\mathrm{Im}$ & 0 & $\mathrm{Im}$ & 0 & $\sigma^{\pi}$ & 0 & $\sigma^{7}$ & 0 & $\sigma^{7}$ & - & - & 0 & $\sigma^{7}$ & - & - & 0 & $\sigma$ & - & - \\
\hline $\mathbf{C}+\mathrm{S}_{2}$ & 0 & $\mathrm{Im}$ & 0 & $\mathrm{Im}$ & 0 & OD & 0 & $\mathrm{O}$ & 0 & Em & - & - & 0 & $\mathrm{O}$ & 8 & $1^{\mathrm{a}}$ & 0 & $\mathrm{Em}$ & - & $1^{a}$ \\
\hline $\mathbf{C}+\mathrm{S}_{3}$ & 0 & $\mathrm{Im}$ & 0 & $\mathrm{Im}$ & 0 & $\mathrm{O}$ & 0 & $\mathrm{O}$ & 0 & OD & 10 & $1^{\mathrm{a}}$ & 0 & $\mathrm{O}$ & - & $1^{\mathrm{a}}$ & 0 & $\mathrm{Em}$ & - & $1^{\mathrm{a}}$ \\
\hline $\mathrm{C}+\mathrm{S}_{4}$ & 0 & $\mathrm{Im}$ & 0 & $\mathrm{Im}$ & 0 & $\sigma^{7}$ & 0 & $\sigma^{7}$ & 0 & $\sigma^{7}$ & - & - & 0 & $\sigma^{\top}$ & - & - & 0 & $\sigma$ & - & - \\
\hline $\mathrm{C}+\mathrm{S}_{5}$ & 0 & $\mathrm{Im}$ & 0 & $\mathrm{Im}$ & 0 & $\sigma^{\prime}$ & 0 & $\sigma^{\prime}$ & 0 & $\sigma^{7}$ & - & - & 0 & $\sigma^{7}$ & - & - & 0 & $\sigma^{\prime}$ & - & - \\
\hline $\mathrm{C}+\mathrm{S}_{6}$ & 0 & $\mathrm{Im}$ & 0 & $\mathrm{Im}$ & 0 & OD & 0 & $\mathrm{O}$ & 0 & $\mathrm{Em}$ & - & - & 0 & $\mathrm{O}$ & 8 & $1^{\mathrm{a}}$ & 0 & $\mathrm{Em}$ & - & $1^{\mathrm{a}}$ \\
\hline $\mathbf{C}+\mathrm{S}_{7}$ & 0 & $\mathrm{Im}$ & 0 & $\mathrm{Im}$ & 0 & $\sigma^{\pi}$ & 0 & $\sigma^{7}$ & 0 & $\sigma^{7}$ & - & - & 0 & $\sigma^{\top}$ & - & - & 0 & $\sigma^{7}$ & - & - \\
\hline $\mathbf{C}+\mathrm{S}_{8}$ & 0 & $\mathrm{Im}$ & 0 & $\mathrm{Im}$ & 0 & OD & 0 & $\mathrm{O}$ & 0 & Em & - & - & 0 & $\mathrm{O}$ & 7 & $1^{\mathrm{a}}$ & 0 & $\mathrm{Em}$ & - & $1^{\mathrm{a}}$ \\
\hline
\end{tabular}

Continua... 
Continuação Tabela 14...

\begin{tabular}{|c|c|c|c|c|c|c|c|c|c|c|c|c|c|c|c|c|c|c|c|c|}
\hline & \multicolumn{2}{|c|}{$20 / 08$} & \multicolumn{2}{|c|}{$21 / 08$} & \multicolumn{2}{|c|}{$22 / 08$} & \multicolumn{2}{|c|}{$23 / 08$} & \multicolumn{4}{|c|}{$24 / 08$} & \multicolumn{4}{|c|}{$25 / 08$} & \multicolumn{4}{|c|}{$26 / 08$} \\
\hline & $\mathbf{M}$ & $\overline{\mathbf{M t}}$ & $\overline{\mathbf{M}}$ & $\overline{\mathbf{M t}}$ & $\overline{\mathbf{M}}$ & Mt & $\overline{\mathbf{M}}$ & $\overline{\mathbf{M t}}$ & $\overline{\mathbf{M}}$ & Mt & $\mathrm{Ne}$ & $\mathbf{N}$ & $\overline{\mathbf{M}}$ & Mt & $\mathrm{Ne}$ & $\mathbf{N}$ & $\overline{\mathbf{M}}$ & Mt & $\mathrm{Ne}$ & $\mathbf{N}$ \\
\hline $\mathrm{C}+\mathrm{S} 9$ & 0 & $\mathrm{Im}$ & 0 & $\mathrm{Im}$ & 0 & OD & 0 & $\mathrm{O}$ & 0 & $\overline{\mathrm{Em}}$ & - & - & 0 & $\overline{\mathrm{O}}$ & 7 & $1^{\mathrm{a}}$ & 0 & $\overline{\mathrm{Em}}$ & - & $1^{\mathrm{a}}$ \\
\hline $\mathrm{C}+\mathrm{S}_{10}$ & 0 & $\mathrm{Im}$ & 0 & $\mathrm{Im}$ & 0 & $\sigma^{\pi}$ & 0 & $\sigma^{7}$ & 0 & $\sigma^{\prime}$ & - & - & 0 & $\sigma^{7}$ & - & - & 0 & $\sigma^{7}$ & - & - \\
\hline $62,5_{1}$ & 0 & $\mathrm{Im}$ & 0 & $\mathrm{Im}$ & 0 & $\mathrm{O}$ & 0 & $\mathrm{O}$ & 0 & OD & 10 & $1^{\mathrm{a}}$ & 0 & $\mathrm{O}$ & - & $1^{\mathrm{a}}$ & 0 & Em & - & $1^{\mathrm{a}}$ \\
\hline $62,5_{2}$ & 0 & $\mathrm{Im}$ & 0 & $\mathrm{Im}$ & 0 & $\sigma^{\prime}$ & 0 & $\sigma^{\prime}$ & 0 & $\sigma^{7}$ & - & - & 0 & $\sigma^{\prime}$ & - & - & 0 & $\sigma^{7}$ & - & - \\
\hline 62,53 & 0 & $\mathrm{Im}$ & 0 & $\mathrm{Im}$ & 0 & $\sigma^{7}$ & 0 & $\sigma^{7}$ & 0 & $\sigma^{7}$ & - & - & 0 & $\sigma^{7}$ & - & - & 0 & $\sigma^{7}$ & - & - \\
\hline 62,54 & 0 & $\mathrm{Im}$ & 0 & $\mathrm{Im}$ & 0 & OD & 0 & $\mathrm{O}$ & 0 & Em & - & - & 0 & $\mathrm{O}$ & 9 & $1^{\mathrm{a}}$ & 0 & Em & - & $1^{\mathrm{a}}$ \\
\hline $62,5_{5}$ & 0 & $\mathrm{Im}$ & 0 & $\mathrm{Im}$ & 0 & OD & 0 & $\mathrm{O}$ & 0 & Em & - & - & 0 & $\mathrm{O}$ & 10 & $1^{\mathrm{a}}$ & 0 & Em & - & $1^{\mathrm{a}}$ \\
\hline 62,56 & 0 & $\mathrm{Im}$ & 0 & $\mathrm{Im}$ & 0 & OD & 0 & $\mathrm{O}$ & 0 & Em & - & - & 0 & $\mathrm{O}$ & 10 & $1^{a}$ & 0 & Em & - & $1^{\mathrm{a}}$ \\
\hline $62,5_{7}$ & 0 & $\mathrm{Im}$ & 0 & $\mathrm{Im}$ & 0 & $\mathrm{O}$ & 0 & $\mathrm{O}$ & 0 & $\mathrm{O}$ & 12 & $1^{\mathrm{a}}$ & 0 & $\mathrm{O}$ & - & $1^{\mathrm{a}}$ & 0 & $\mathrm{DO}$ & 12 & $2^{\mathrm{a}}$ \\
\hline 62,58 & 0 & $\mathrm{Im}$ & 0 & $\mathrm{Im}$ & 0 & $\sigma^{7}$ & 0 & $\sigma^{7}$ & 0 & $\sigma^{7}$ & - & - & 0 & $\sigma^{7}$ & - & - & 0 & $\sigma^{7}$ & - & - \\
\hline 62,59 & 0 & $\mathrm{Im}$ & 0 & $\mathrm{Im}$ & 0 & OD & 0 & $\mathrm{O}$ & 0 & Em & - & - & 0 & $\mathrm{O}$ & 9 & $1^{a}$ & 0 & Em & - & $1^{\mathrm{a}}$ \\
\hline $62,5_{10}$ & 0 & $\mathrm{Im}$ & 0 & $\mathrm{Im}$ & 0 & $\sigma^{\top}$ & 0 & $\sigma^{\top}$ & 0 & $\sigma^{7}$ & - & - & 0 & $\sigma^{7}$ & - & - & 0 & $\sigma^{7}$ & & \\
\hline $125_{1}$ & 0 & $\mathrm{Im}$ & 0 & $\mathrm{Im}$ & 0 & OD & 0 & $\mathrm{O}$ & 0 & Em & - & - & 0 & $\mathrm{O}$ & 9 & $1^{\mathrm{a}}$ & 0 & Em & - & $1^{\mathrm{a}}$ \\
\hline $125_{2}$ & 0 & $\mathrm{Im}$ & 0 & $\mathrm{Im}$ & 0 & $\mathrm{O}$ & 0 & $\mathrm{O}$ & 0 & $\mathrm{DO}$ & 9 & $1^{\mathrm{a}}$ & 0 & $\mathrm{O}$ & - & $1^{\mathrm{a}}$ & 0 & Em & - & $1^{\mathrm{a}}$ \\
\hline $125_{3}$ & 0 & $\mathrm{Im}$ & 0 & $\mathrm{Im}$ & 0 & $\sigma^{7}$ & 0 & $\sigma^{7}$ & 0 & $\sigma^{7}$ & - & - & 0 & $\sigma^{7}$ & - & - & 0 & $\sigma^{7}$ & - & - \\
\hline $125_{4}$ & 0 & $\mathrm{Im}$ & 0 & $\mathrm{Im}$ & 0 & OD & 0 & $\mathrm{O}$ & 0 & Em & - & - & 0 & $\mathrm{O}$ & 7 & $1^{\mathrm{a}}$ & 0 & Em & - & $1^{\mathrm{a}}$ \\
\hline 1255 & 0 & $\mathrm{Im}$ & 0 & $\mathrm{Im}$ & 0 & $\sigma^{\prime}$ & 0 & $\sigma^{7}$ & 0 & $\sigma^{7}$ & - & - & 0 & $\sigma^{7}$ & - & - & 0 & $\sigma^{7}$ & - & - \\
\hline $125_{6}$ & 0 & $\mathrm{Im}$ & 0 & $\mathrm{Im}$ & 0 & OD & 0 & $\mathrm{O}$ & 0 & Em & - & - & 0 & $\mathrm{O}$ & 8 & $1^{\mathrm{a}}$ & 0 & Em & - & $1^{\mathrm{a}}$ \\
\hline $125_{7}$ & 0 & $\mathrm{Im}$ & 0 & $\mathrm{Im}$ & 0 & $\sigma^{7}$ & 0 & $\sigma^{7}$ & 0 & $\sigma^{7}$ & - & - & 0 & $\sigma^{7}$ & - & - & 0 & $\sigma^{7}$ & - & - \\
\hline 1258 & 0 & $\mathrm{Im}$ & 0 & $\mathrm{Im}$ & 0 & OD & 0 & $\mathrm{O}$ & 0 & Em & - & - & 0 & $\mathrm{O}$ & 8 & $1^{\mathrm{a}}$ & 0 & Em & - & $1^{\mathrm{a}}$ \\
\hline 1259 & 0 & $\mathrm{Im}$ & 0 & $\mathrm{Im}$ & 0 & OD & 0 & $\mathrm{O}$ & 0 & Em & - & - & 0 & $\mathrm{O}$ & 8 & $1^{a}$ & 0 & Em & - & $1^{\mathrm{a}}$ \\
\hline $125_{10}$ & 0 & $\mathrm{Im}$ & 0 & $\mathrm{Im}$ & 0 & OD & 0 & $\mathrm{O}$ & 0 & Em & - & - & 0 & $\mathrm{O}$ & 7 & $1^{\mathrm{a}}$ & 0 & Em & - & $1^{\mathrm{a}}$ \\
\hline $250_{1}$ & 0 & $\mathrm{Im}$ & 0 & $\mathrm{Im}$ & 0 & $\sigma^{\prime}$ & 0 & $\sigma^{\prime}$ & 0 & $\sigma^{7}$ & - & - & 0 & $\sigma^{\prime}$ & - & - & 0 & $\sigma^{7}$ & - & - \\
\hline
\end{tabular}

Сопtinua... 
Continuação Tabela 14...

\begin{tabular}{|c|c|c|c|c|c|c|c|c|c|c|c|c|c|c|c|c|c|c|c|c|}
\hline & \multicolumn{2}{|c|}{$20 / 08$} & \multicolumn{2}{|c|}{$21 / 08$} & \multicolumn{2}{|c|}{$22 / 08$} & \multicolumn{2}{|c|}{$23 / 08$} & \multicolumn{4}{|c|}{$24 / 08$} & \multicolumn{4}{|c|}{$25 / 08$} & \multicolumn{4}{|c|}{$26 / 08$} \\
\hline & $\mathbf{M}$ & $\overline{\mathbf{M t}}$ & $\overline{\mathbf{M}}$ & $\overline{\mathbf{M t}}$ & $\overline{\mathbf{M}}$ & $\overline{\mathbf{M t}}$ & $\overline{\mathbf{M}}$ & $\overline{\mathbf{M t}}$ & $\overline{\mathbf{M}}$ & $\mathbf{M t}$ & $\mathrm{Ne}$ & $\overline{\mathbf{N}}$ & $\overline{\mathbf{M}}$ & $\overline{\text { Mt }}$ & $\mathrm{Ne}$ & $\overline{\mathbf{N}}$ & $\overline{\mathbf{M}}$ & $\overline{\text { Mt }}$ & $\mathrm{Ne}$ & $\overline{\mathbf{N}}$ \\
\hline $250_{2}$ & 0 & $\mathrm{Im}$ & 0 & $\mathrm{Im}$ & 0 & $\mathrm{O}$ & 0 & $\mathrm{O}$ & 0 & $\overline{\mathrm{OD}}$ & 9 & $1^{\mathrm{a}}$ & 0 & $\mathrm{O}$ & - & $1^{\mathrm{a}}$ & 0 & $\mathrm{Em}$ & - & $1^{\mathrm{a}}$ \\
\hline 2503 & 0 & $\mathrm{Im}$ & 0 & $\mathrm{Im}$ & 0 & $\mathrm{Im}$ & 0 & DO & 0 & $\mathrm{O}$ & - & - & 0 & Em & - & - & 0 & $\mathrm{O}$ & 7 & $1^{\mathrm{a}}$ \\
\hline $250_{4}$ & 0 & $\mathrm{Im}$ & 0 & $\mathrm{Im}$ & 0 & OD & 0 & $\mathrm{O}$ & 0 & Em & - & - & 0 & $\mathrm{O}$ & 10 & $1^{\mathrm{a}}$ & 0 & Em & - & $1^{\mathrm{a}}$ \\
\hline $250_{5}$ & 0 & $\mathrm{Im}$ & 0 & $\mathrm{Im}$ & 0 & OD & 0 & $\mathrm{O}$ & 0 & Em & - & - & 0 & $\mathrm{O}$ & 9 & $1^{\mathrm{a}}$ & 0 & Em & - & $1^{\mathrm{a}}$ \\
\hline 2506 & 0 & $\mathrm{Im}$ & 0 & $\mathrm{Im}$ & 0 & $\sigma^{7}$ & 0 & $\sigma^{7}$ & 0 & $\sigma^{7}$ & - & - & 0 & $\sigma^{7}$ & - & - & 0 & $\sigma^{7}$ & - & - \\
\hline $250_{7}$ & 0 & $\mathrm{Im}$ & 0 & $\mathrm{Im}$ & 0 & $\mathrm{O}$ & 0 & $\mathrm{O}$ & 0 & Em & - & - & 0 & $\mathrm{O}$ & 10 & $1^{\mathrm{a}}$ & 0 & $\mathrm{Em}$ & - & $1^{\mathrm{a}}$ \\
\hline 2508 & 0 & $\mathrm{Im}$ & 0 & $\mathrm{Im}$ & 0 & OD & 0 & $\mathrm{O}$ & 0 & Em & - & - & 0 & $\mathrm{O}$ & 9 & $1^{\mathrm{a}}$ & 0 & Em & - & $1^{\mathrm{a}}$ \\
\hline 2509 & 0 & $\mathrm{Im}$ & 0 & $\mathrm{Im}$ & 0 & OD & 0 & OD & 0 & $\mathrm{DO}$ & - & - & 0 & OD & - & - & 0 & OD & - & - \\
\hline $250_{10}$ & 0 & $\mathrm{Im}$ & 0 & $\mathrm{Im}$ & 0 & OD & 0 & $\mathrm{O}$ & 0 & Em & - & - & 0 & $\mathrm{O}$ & 10 & $1^{\mathrm{a}}$ & 0 & Em & - & $1^{\mathrm{a}}$ \\
\hline $500_{1}$ & 0 & $\mathrm{Im}$ & 0 & $\mathrm{Im}$ & 0 & $\mathrm{O}$ & 0 & $\mathrm{O}$ & 0 & Em & - & - & 0 & $\mathrm{O}$ & 9 & $1^{\mathrm{a}}$ & 0 & Em & - & $1^{\mathrm{a}}$ \\
\hline $500_{2}$ & 0 & $\mathrm{Im}$ & 0 & $\mathrm{Im}$ & 0 & $\sigma^{7}$ & 0 & $\sigma^{7}$ & 0 & $\sigma^{7}$ & - & - & 0 & $\sigma^{7}$ & - & - & 0 & $\sigma^{7}$ & - & - \\
\hline $500_{3}$ & 0 & $\mathrm{Im}$ & 0 & $\mathrm{Im}$ & 0 & OD & 0 & $\mathrm{O}$ & 0 & Em & - & - & 0 & $\mathrm{O}$ & 7 & $1^{\mathrm{a}}$ & 0 & Em & - & $1^{\mathrm{a}}$ \\
\hline $500_{4}$ & 0 & $\mathrm{Im}$ & 0 & $\mathrm{Im}$ & 0 & $\sigma^{7}$ & 0 & $\sigma^{7}$ & 0 & $\sigma^{7}$ & - & - & 0 & $\sigma^{7}$ & - & - & 0 & $\sigma^{7}$ & - & - \\
\hline $500_{5}$ & 0 & Im & 0 & $\mathrm{Im}$ & 0 & OD & 0 & $\mathrm{O}$ & 0 & Em & - & - & 1 & - & - & - & - & - & - & - \\
\hline $500_{6}$ & 0 & $\mathrm{Im}$ & 0 & $\mathrm{Im}$ & 0 & $\mathrm{Im}$ & 0 & $\mathrm{Im}$ & 0 & DO & - & - & 0 & $\mathrm{O}$ & - & - & 0 & Em & - & 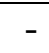 \\
\hline $500_{7}$ & 0 & $\mathrm{Im}$ & 0 & $\mathrm{Im}$ & 0 & $\mathrm{O}$ & 0 & $\mathrm{O}$ & 0 & $\mathrm{O}$ & 7 & $1^{\mathrm{a}}$ & 0 & Em & - & $1^{\mathrm{a}}$ & 0 & Em & - & $1^{\mathrm{a}}$ \\
\hline $500_{8}$ & 0 & $\mathrm{Im}$ & 0 & $\mathrm{Im}$ & 0 & OD & 0 & $\mathrm{O}$ & 0 & Em & - & - & 0 & $\mathrm{O}$ & 7 & $1^{\mathrm{a}}$ & 0 & Em & - & $1^{\mathrm{a}}$ \\
\hline 5009 & 0 & $\mathrm{Im}$ & 0 & $\mathrm{Im}$ & 0 & OD & 0 & $\mathrm{O}$ & 0 & $\mathrm{Em}$ & - & - & 0 & $\mathrm{O}$ & 8 & $1^{\mathrm{a}}$ & 0 & $\mathrm{Em}$ & - & $1^{\mathrm{a}}$ \\
\hline $500_{10}$ & 0 & $\mathrm{Im}$ & 0 & $\mathrm{Im}$ & 0 & $\mathrm{O}$ & 0 & $\mathrm{O}$ & 0 & $\mathrm{O}$ & 9 & $1^{\mathrm{a}}$ & 0 & $\mathrm{O}$ & - & $1^{\mathrm{a}}$ & 0 & Em & - & $1^{\mathrm{a}}$ \\
\hline $1000_{1}$ & 0 & $\mathrm{Im}$ & 0 & $\mathrm{Im}$ & 0 & OD & 0 & $\mathrm{O}$ & 0 & $\mathrm{Em}$ & - & - & 0 & $\mathrm{O}$ & 6 & $1^{\mathrm{a}}$ & 0 & $\mathrm{Em}$ & - & $1^{\mathrm{a}}$ \\
\hline $1000_{2}$ & 0 & $\mathrm{Im}$ & 0 & $\mathrm{Im}$ & 0 & OD & 0 & $\mathrm{O}$ & 0 & $\mathrm{Em}$ & - & - & 0 & $\mathrm{O}$ & 7 & $1^{\mathrm{a}}$ & 0 & $\mathrm{Em}$ & - & $1^{\mathrm{a}}$ \\
\hline $1000_{3}$ & 0 & $\mathrm{Im}$ & 0 & $\mathrm{Im}$ & 0 & $\sigma^{7}$ & 0 & $\sigma^{7}$ & 0 & $\sigma^{7}$ & - & - & 0 & $\sigma^{\prime}$ & - & - & 0 & $\sigma^{7}$ & - & - \\
\hline $1000_{4}$ & 0 & $\mathrm{Im}$ & 0 & $\mathrm{Im}$ & 0 & $\mathrm{OD}$ & 0 & $\mathrm{O}$ & 0 & $\mathrm{Em}$ & - & - & 0 & $\mathrm{O}$ & 9 & $1^{\mathrm{a}}$ & 0 & $\mathrm{Em}$ & - & $1^{\mathrm{a}}$ \\
\hline
\end{tabular}

Continua... 
Continução Tabela 14...

\begin{tabular}{|c|c|c|c|c|c|c|c|c|c|c|c|c|c|c|c|c|c|c|c|c|}
\hline & \multicolumn{2}{|c|}{$20 / 08$} & \multicolumn{2}{|c|}{$21 / 08$} & \multicolumn{2}{|c|}{$22 / 08$} & \multicolumn{2}{|c|}{$23 / 08$} & \multicolumn{4}{|c|}{$24 / 08$} & \multicolumn{4}{|c|}{$25 / 08$} & \multicolumn{4}{|c|}{$26 / 08$} \\
\hline & $\mathbf{M}$ & $\overline{\mathbf{M t}}$ & $\overline{\mathbf{M}}$ & $\overline{\mathbf{M t}}$ & $\overline{\mathbf{M}}$ & $\overline{\mathbf{M t}}$ & $\mathbf{M}$ & $\overline{\text { Mt }}$ & $\overline{\mathbf{M}}$ & $\overline{\mathbf{M t}}$ & $\mathrm{Ne}$ & $\mathbf{N}$ & $\mathbf{M}$ & Mt & $\mathrm{Ne}$ & $\mathbf{N}$ & $\mathbf{M}$ & $\mathbf{M t}$ & $\mathrm{Ne}$ & $\overline{\mathbf{N}}$ \\
\hline $1000_{5}$ & 0 & $\mathrm{Im}$ & 0 & $\mathrm{Im}$ & 0 & $\sigma^{7}$ & 0 & $\sigma^{7}$ & $\overline{0}$ & $\sigma^{\prime}$ & & - & 0 & $\sigma$ & - & - & 0 & $\sigma^{7}$ & - & - \\
\hline $1000_{6}$ & 0 & $\mathrm{Im}$ & 0 & $\mathrm{Im}$ & 0 & $\mathrm{O}$ & 0 & $\mathrm{O}$ & 0 & OD & 9 & $1^{\mathrm{a}}$ & 0 & $\mathrm{O}$ & - & $1^{\mathrm{a}}$ & 0 & $\mathrm{Em}$ & - & $1^{\mathrm{a}}$ \\
\hline $1000_{7}$ & 0 & $\mathrm{Im}$ & 1 & - & - & - & - & - & - & - & - & - & - & - & - & - & - & - & - & - \\
\hline 10008 & 0 & $\mathrm{Im}$ & 0 & $\mathrm{Im}$ & 0 & $\sigma^{7}$ & 0 & $\sigma^{7}$ & 0 & $\sigma^{\prime}$ & - & - & 0 & $\sigma$ & - & - & 0 & $\sigma^{7}$ & - & - \\
\hline 10009 & 0 & $\mathrm{Im}$ & 1 & 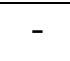 & - & - & - & - & - & - & - & - & - & - & - & - & - & - & - & - \\
\hline $1000_{10}$ & 0 & $\mathrm{Im}$ & 0 & $\mathrm{Im}$ & 0 & OD & 0 & $\mathrm{O}$ & 0 & Em & - & - & 0 & $\mathrm{O}$ & 7 & $1^{a}$ & 0 & $\mathrm{Em}$ & - & $1^{\mathrm{a}}$ \\
\hline $2000_{1}$ & 0 & $\mathrm{Im}$ & 0 & $\mathrm{Im}$ & 0 & - & 0 & DO & 0 & $\mathrm{O}$ & - & - & 0 & $\mathrm{Em}$ & - & - & 0 & $\mathrm{O}$ & 9 & $1^{a}$ \\
\hline $2000_{2}$ & 1 & - & - & - & - & - & - & - & - & - & - & - & - & - & - & - & - & - & - & - \\
\hline $2000_{3}$ & 0 & $\mathrm{Im}$ & 0 & $\mathrm{Im}$ & 0 & $\sigma^{7}$ & 0 & $\sigma^{7}$ & 0 & $\sigma^{7}$ & - & - & 0 & $\sigma^{7}$ & - & - & 0 & $\sigma^{7}$ & - & - \\
\hline $2000_{4}$ & 0 & $\mathrm{Im}$ & 0 & $\mathrm{Im}$ & 0 & $\sigma^{7}$ & 0 & $\sigma^{7}$ & 0 & $\sigma^{7}$ & - & - & 0 & $\sigma^{\prime}$ & - & - & 0 & $\sigma^{7}$ & - & - \\
\hline 20005 & 0 & $\mathrm{Im}$ & 0 & $\mathrm{Im}$ & 0 & $\sigma^{7}$ & 0 & $\sigma^{7}$ & 0 & $\sigma^{\prime}$ & - & - & 0 & $\sigma^{\prime}$ & - & - & 0 & $\sigma^{7}$ & - & - \\
\hline $2000_{6}$ & 0 & $\mathrm{Im}$ & 0 & $\mathrm{Im}$ & 0 & DO & 0 & $\mathrm{O}$ & 0 & Em & - & - & 0 & $\mathrm{O}$ & 6 & $1^{\mathrm{a}}$ & 0 & Em & - & $1^{\mathrm{a}}$ \\
\hline $2000_{7}$ & 0 & $\mathrm{Im}$ & 0 & $\mathrm{Im}$ & 0 & DO & 0 & $\mathrm{O}$ & 0 & Em & - & - & 0 & $\mathrm{O}$ & 8 & $1^{a}$ & 0 & $\mathrm{Em}$ & - & $1^{\mathrm{a}}$ \\
\hline 20008 & 0 & $\mathrm{Im}$ & 0 & $\mathrm{Im}$ & 0 & $\mathrm{Im}$ & 0 & $\mathrm{Im}$ & 0 & DO & - & - & 0 & $\mathrm{O}$ & - & 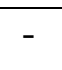 & 0 & $\mathrm{O}$ & $1-\mathrm{M}$ & $1^{\mathrm{a}}$ \\
\hline 20009 & 0 & $\mathrm{Im}$ & 0 & $\mathrm{Im}$ & 0 & DO & 0 & $\mathrm{O}$ & 0 & $\mathrm{O}$ & - & - & 0 & $\mathrm{O}$ & 7 & $1^{\mathrm{a}}$ & 0 & $\mathrm{O}$ & - & $1^{\mathrm{a}}$ \\
\hline $2000_{10}$ & 1 & - & - & - & - & - & - & - & - & - & - & - & - & - & - & - & - & - & - & - \\
\hline & & \multicolumn{4}{|c|}{$27 / 08$} & \multicolumn{5}{|c|}{$28 / 08$} & \multicolumn{4}{|c|}{$29 / 08$} & \multicolumn{6}{|c|}{$30 / 08$} \\
\hline & & $\mathbf{M}$ & $\overline{\mathbf{M t}}$ & $\mathrm{Ne}$ & $\mathbf{N}$ & $\overline{\mathbf{M}}$ & $\overline{\mathbf{M}}$ & & $\mathrm{Je}$ & $\mathbf{N}$ & $\mathbf{M}$ & $\mathbf{M t}$ & $\mathrm{Ne}$ & $\mathbf{N}$ & $\overline{\mathbf{M}}$ & & $\overline{M t}$ & & $\mathrm{Ne}$ & $\mathbf{N}$ \\
\hline $\mathrm{C}_{1}$ & & 0 & $\mathrm{O}$ & 12 & $2^{\mathrm{a}}$ & 0 & $\overline{\mathrm{En}}$ & & - & $2^{\mathrm{a}}$ & $\overline{0}$ & $\mathrm{O}$ & 6 & $3^{a}$ & 0 & & $\mathrm{O}$ & & - & $3^{\mathrm{a}}$ \\
\hline $\mathrm{C}_{2}$ & & 0 & $\sigma^{7}$ & - & - & 0 & $\sigma$ & & - & - & 0 & $\sigma^{\prime}$ & - & - & 0 & & $\sigma^{\prime}$ & & - & - \\
\hline $\mathrm{C}_{3}$ & & 0 & $\mathrm{O}$ & 10 & $2^{a}$ & 0 & $\mathrm{En}$ & & - & $2^{\mathrm{a}}$ & 0 & $\mathrm{O}$ & 8 & $3^{a}$ & 0 & & $\mathrm{O}$ & & - & $3^{\mathrm{a}}$ \\
\hline $\mathrm{C}_{4}$ & & 0 & $\sigma^{7}$ & - & - & 0 & 8 & & - & - & 0 & $\sigma^{7}$ & - & - & 0 & & $\sigma^{7}$ & & - & - \\
\hline $\mathrm{C}_{5}$ & & 0 & $\mathrm{O}$ & 13 & $2^{\mathrm{a}}$ & 0 & En & & - & $2^{a}$ & 0 & OD & 7 & $3^{a}$ & 0 & & $\mathrm{O}$ & & - & $3^{a}$ \\
\hline
\end{tabular}

Continua... 
Continuação Tabela 14...

\begin{tabular}{|c|c|c|c|c|c|c|c|c|c|c|c|c|c|c|c|c|}
\hline & \multicolumn{4}{|c|}{$27 / 08$} & \multicolumn{4}{|c|}{$28 / 08$} & \multicolumn{4}{|c|}{$29 / 08$} & \multicolumn{4}{|c|}{$30 / 08$} \\
\hline & $\mathbf{M}$ & Mt & $\mathrm{Ne}$ & $\mathbf{N}$ & $\bar{M}$ & Mt & $\mathrm{Ne}$ & $\mathbf{N}$ & $\mathbf{M}$ & $\mathbf{M t}$ & $\mathrm{Ne}$ & $\mathbf{N}$ & $\mathbf{M}$ & $\mathbf{M t}$ & $\mathrm{Ne}$ & $\mathbf{N}$ \\
\hline$\overline{\mathrm{C}_{6}}$ & 0 & $\sigma^{\prime}$ & - & - & 0 & $\sigma^{\prime}$ & - & - & 0 & $\sigma^{\prime}$ & - & - & 0 & $\sigma^{\prime}$ & - & - \\
\hline $\mathrm{C}_{7}$ & 0 & $\mathrm{O}$ & 12 & $2^{a}$ & 0 & $\mathrm{Em}$ & - & $2^{a}$ & 0 & $\mathrm{O}$ & 11 & $3^{a}$ & 0 & $\mathrm{O}$ & - & $3^{a}$ \\
\hline $\mathrm{Cs}$ & 0 & $\mathrm{O}$ & 15 & $2^{a}$ & 0 & $\mathrm{Em}$ & - & $2^{a}$ & 0 & $\mathrm{O}$ & 9 & $3^{a}$ & 0 & $\mathrm{O}$ & - & $3^{a}$ \\
\hline $\mathrm{C}_{9}$ & 0 & $\mathrm{O}$ & 15 & $2^{a}$ & 0 & $\mathrm{Em}$ & - & $2^{a}$ & 0 & OD & 8 & $3^{a}$ & 0 & $\mathrm{O}$ & 7 & $4^{a}$ \\
\hline $\mathrm{C}_{10}$ & 0 & $\mathrm{O}$ & 14 & $2^{a}$ & 0 & $\mathrm{Em}$ & - & $2^{a}$ & 0 & $\mathrm{O}$ & 9 & $3^{a}$ & 0 & $\mathrm{O}$ & - & $3^{a}$ \\
\hline $\mathbf{C}+\mathrm{S}_{1}$ & 0 & $\sigma^{\prime}$ & - & - & 0 & $\sigma^{\prime}$ & - & - & 1 & - & - & - & - & - & - & - \\
\hline $\mathbf{C}+\mathbf{S}_{2}$ & 0 & $\mathrm{O}$ & 4 & $2^{\mathrm{a}}$ & 0 & Em & - & $2^{a}$ & 0 & $\mathrm{O}$ & 9 & $3^{a}$ & 0 & $\mathrm{O}$ & - & $3^{a}$ \\
\hline $\mathbf{C}+\mathrm{S}_{3}$ & 0 & $\mathrm{O}$ & 11 & $2^{a}$ & 0 & $\mathrm{Em}$ & - & $2^{a}$ & 0 & $?$ & 6 & $3^{a}$ & 1 & - & - & - \\
\hline $\mathrm{C}+\mathrm{S}_{4}$ & 0 & $\sigma^{\top}$ & - & - & 0 & $\sigma^{\prime}$ & - & - & 0 & $\sigma^{\prime}$ & - & - & 0 & $\sigma^{\prime}$ & - & - \\
\hline $\mathrm{C}+\mathrm{S}_{5}$ & 0 & $\sigma^{7}$ & - & - & 0 & $\sigma^{7}$ & - & - & 0 & $\sigma^{\top}$ & - & - & 0 & $\sigma^{7}$ & - & - \\
\hline $\mathrm{C}+\mathrm{S}_{6}$ & 0 & $\mathrm{O}$ & 13 & $2^{a}$ & 0 & $\mathrm{Em}$ & - & $2^{a}$ & 0 & $\mathrm{O}$ & 10 & $3^{a}$ & 0 & $\mathrm{O}$ & - & $3^{a}$ \\
\hline $\mathbf{C}+\mathbf{S}_{7}$ & 0 & $\sigma^{\prime}$ & - & - & 0 & $\sigma^{7}$ & - & - & 0 & $\sigma^{\pi}$ & - & - & 0 & $\sigma^{\pi}$ & - & - \\
\hline $\mathbf{C}+\mathrm{S}_{8}$ & 0 & $\mathrm{O}$ & 10 & $2^{a}$ & 0 & Em & - & $2^{a}$ & 0 & $\mathrm{O}$ & 12 & $3^{a}$ & 0 & $\mathrm{O}$ & - & $3^{a}$ \\
\hline $\mathrm{C}+\mathrm{S}_{9}$ & 0 & $\mathrm{O}$ & 7 & $2^{a}$ & 0 & Em & - & $2^{a}$ & 0 & OD & 8 & $3^{a}$ & 0 & $\mathrm{O}$ & - & $3^{a}$ \\
\hline $\mathrm{C}+\mathrm{S}_{10}$ & 0 & $\sigma^{\prime}$ & - & - & 0 & $\sigma^{\prime}$ & - & - & 0 & $\sigma^{\top}$ & - & - & 0 & $\sigma^{\prime}$ & - & - \\
\hline 62,51 & 0 & $\mathrm{O}$ & 11 & $2^{a}$ & 0 & $\mathrm{Em}$ & - & $2^{a}$ & 0 & $\mathrm{O}$ & 10 & $3^{a}$ & 0 & $\mathrm{O}$ & - & $3^{a}$ \\
\hline $62,5_{2}$ & 0 & $\sigma^{\top}$ & - & - & 0 & $\sigma^{\prime}$ & - & - & 0 & $\sigma^{\top}$ & - & - & 1 & - & - & - \\
\hline 62,53 & 0 & $\sigma^{\prime}$ & - & - & 0 & $\sigma^{\prime}$ & - & - & 0 & $\sigma^{\prime}$ & - & - & 0 & $\sigma^{\prime}$ & - & - \\
\hline $62,5_{4}$ & 0 & $\mathrm{O}$ & 14 & $2^{a}$ & 0 & $\mathrm{Em}$ & - & $2^{a}$ & 0 & $\mathrm{O}$ & 8 & $3^{a}$ & 0 & $\mathrm{O}$ & - & $3^{a}$ \\
\hline 62,55 & 0 & $\mathrm{O}$ & 14 & $2^{a}$ & 0 & $\mathrm{Em}$ & - & $2^{a}$ & 0 & OD & 9 & $3^{a}$ & 0 & $\mathrm{O}$ & - & $3^{a}$ \\
\hline 62,56 & 0 & $\mathrm{O}$ & 12 & $2^{a}$ & 0 & $\mathrm{Em}$ & - & $2^{a}$ & 0 & $\mathrm{O}$ & 6 & $3^{a}$ & 0 & $\mathrm{O}$ & - & $3^{a}$ \\
\hline 62,57 & 0 & $\mathrm{O}$ & 2 & $3^{a}$ & 0 & $\mathrm{Em}$ & - & $3^{a}$ & 0 & $\mathrm{O}$ & 9 & $4^{a}$ & 0 & Em & - & $4^{a}$ \\
\hline 62,58 & 0 & $\sigma^{\prime}$ & - & - & 0 & $\sigma^{\prime}$ & - & - & 0 & $\sigma^{\prime}$ & - & - & 0 & $\sigma^{\prime}$ & - & - \\
\hline
\end{tabular}

Continua... 
Continuação Tabela 14...

\begin{tabular}{|c|c|c|c|c|c|c|c|c|c|c|c|c|c|c|c|c|}
\hline & \multicolumn{4}{|c|}{$27 / 08$} & \multicolumn{4}{|c|}{$28 / 08$} & \multicolumn{4}{|c|}{$29 / 08$} & \multicolumn{4}{|c|}{$30 / 08$} \\
\hline & $\mathbf{M}$ & Mt & $\mathrm{Ne}$ & $\mathbf{N}$ & $\mathbf{M}$ & Mt & $\mathrm{Ne}$ & $\mathbf{N}$ & $\mathbf{M}$ & Mt & $\mathrm{Ne}$ & $\mathbf{N}$ & $\mathbf{M}$ & Mt & $\mathrm{Ne}$ & $\mathbf{N}$ \\
\hline 62,59 & 0 & $\mathrm{O}$ & 8 & $2^{a}$ & 0 & Em & - & $2^{a}$ & 0 & $\mathrm{DO}$ & 7 & $3^{a}$ & 0 & $\mathrm{O}$ & - & $3^{a}$ \\
\hline 62,510 & 0 & $\sigma^{\pi}$ & - & - & 0 & $\sigma^{7}$ & - & - & 0 & $\sigma^{\pi}$ & - & - & 0 & $\sigma^{\pi}$ & - & - \\
\hline $125_{1}$ & 1 & - & 11 & $2^{a}$ & - & - & - & - & - & - & - & - & - & - & - & - \\
\hline $125_{2}$ & 0 & $\mathrm{O}$ & 9 & $2^{a}$ & 0 & Em & - & $2^{a}$ & 0 & $\mathrm{O}$ & 9 & $3^{a}$ & 0 & $\mathrm{O}$ & - & $3^{a}$ \\
\hline 1253 & 0 & $\sigma^{7}$ & - & - & 0 & $\sigma^{\top}$ & - & - & 0 & $\sigma^{\top}$ & - & - & 0 & $\sigma^{\pi}$ & - & - \\
\hline $125_{4}$ & 0 & $\mathrm{O}$ & 12 & $2^{a}$ & 0 & Em & - & $2^{a}$ & 0 & $\mathrm{O}$ & 16 & $3^{a}$ & 0 & $\mathrm{O}$ & - & $3^{a}$ \\
\hline 1255 & 0 & $\sigma^{7}$ & - & - & 0 & $\sigma^{7}$ & - & - & 0 & $\sigma^{7}$ & - & - & 0 & $\sigma$ & - & - \\
\hline $125_{6}$ & 0 & $\mathrm{O}$ & 6 & $2^{a}$ & 0 & Em & - & $2^{a}$ & 0 & $\mathrm{O}$ & 8 & $3^{a}$ & 0 & $\mathrm{O}$ & - & $3^{a}$ \\
\hline $125_{7}$ & 0 & $\sigma^{\top}$ & - & - & 0 & $\sigma^{\top}$ & - & - & 0 & $\sigma^{7}$ & - & - & 0 & $\sigma^{\top}$ & - & - \\
\hline 1258 & 0 & $\mathrm{O}$ & 8 & $2^{a}$ & 1 & - & - & - & - & - & - & - & - & - & - & - \\
\hline 1259 & 0 & $\mathrm{O}$ & 7 & $2^{a}$ & 0 & Em & - & $2^{a}$ & 0 & $\mathrm{O}$ & 9 & $3^{a}$ & 0 & $\mathrm{O}$ & - & $3^{a}$ \\
\hline $125_{10}$ & 0 & $\mathrm{O}$ & 7 & $2^{a}$ & 0 & Em & - & $2^{a}$ & 0 & $\mathrm{O}$ & 8 & $3^{a}$ & 0 & $\mathrm{O}$ & - & $3^{a}$ \\
\hline $250_{1}$ & 0 & $\sigma^{x}$ & - & - & 0 & $\sigma^{7}$ & - & - & 0 & $\sigma^{\prime}$ & - & - & 0 & $\sigma^{7}$ & - & - \\
\hline $250_{2}$ & 0 & $\mathrm{O}$ & 6 & $2^{a}$ & 0 & Em & - & $2^{a}$ & 0 & $\mathrm{O}$ & 7 & $3^{a}$ & 0 & $\mathrm{O}$ & - & $3^{a}$ \\
\hline 2503 & 0 & $\mathrm{O}$ & - & $1^{\mathrm{a}}$ & 0 & Em & - & $1^{a}$ & 0 & $\mathrm{O}$ & 7 & $2^{a}$ & 0 & $\mathrm{Em}$ & - & $2^{a}$ \\
\hline $250_{4}$ & 0 & $\mathrm{O}$ & 6 & $2^{a}$ & 0 & $\mathrm{O}$ & - & $2^{a}$ & 0 & $\mathrm{OD}$ & 2 & $3^{a}$ & 0 & $\mathrm{O}$ & - & $3^{a}$ \\
\hline 2505 & 0 & $\mathrm{O}$ & 12 & $2^{a}$ & 0 & Em & - & $2^{a}$ & 0 & OD & 8 & $3^{a}$ & 0 & $\mathrm{O}$ & - & $3^{a}$ \\
\hline $250_{6}$ & 0 & $\sigma^{7}$ & - & - & 0 & $\sigma^{7}$ & - & - & 0 & $\sigma^{\prime}$ & - & - & 0 & $\sigma^{7}$ & - & - \\
\hline $250_{7}$ & 0 & $\mathrm{O}$ & 11 & $2^{a}$ & 0 & Em & - & $2^{a}$ & 0 & $\mathrm{O}$ & 6 & $3^{a}$ & 0 & $\mathrm{O}$ & - & $3^{a}$ \\
\hline 2508 & 0 & $\mathrm{O}$ & 12 & $2^{a}$ & 0 & Em & - & $2^{a}$ & 0 & $\mathrm{O}$ & 6 & $3^{a}$ & 0 & $\mathrm{O}$ & - & $3^{a}$ \\
\hline 2509 & 0 & $\begin{array}{l}\mathrm{O} \\
\mathrm{D}\end{array}$ & - & - & 0 & OD & - & - & 0 & OD & - & - & 0 & OD & - & - \\
\hline $250_{10}$ & 0 & $\mathrm{O}$ & 10 & $2^{a}$ & 0 & $\mathrm{O}$ & - & $2^{a}$ & 0 & OD & 5 & $3^{a}$ & 0 & $\mathrm{O}$ & - & $3^{a}$ \\
\hline
\end{tabular}

Continua... 
Continuação Tabela 14...

\begin{tabular}{|c|c|c|c|c|c|c|c|c|c|c|c|c|c|c|c|c|}
\hline & \multicolumn{4}{|c|}{$27 / 08$} & \multicolumn{4}{|c|}{$28 / 08$} & \multicolumn{4}{|c|}{$29 / 08$} & \multicolumn{4}{|c|}{$30 / 08$} \\
\hline & $\overline{\mathbf{M}}$ & $\mathbf{M t}$ & $\mathrm{Ne}$ & $\mathbf{N}$ & $\overline{\mathbf{M}}$ & $\mathbf{M t}$ & $\mathrm{Ne}$ & $\overline{\mathbf{N}}$ & $\overline{\mathbf{M}}$ & $\overline{\text { Mt }}$ & $\mathrm{Ne}$ & $\mathbf{N}$ & $\overline{\mathbf{M}}$ & $\overline{\mathbf{M t}}$ & $\mathrm{Ne}$ & $\overline{\mathbf{N}}$ \\
\hline $500_{1}$ & 0 & $\mathrm{O}$ & 6 & $2^{\mathrm{a}}$ & 0 & $\overline{E m}$ & - & $2^{a}$ & $\overline{0}$ & - & 4 & $3^{\mathrm{a}}$ & 0 & - & - & $3^{\mathrm{a}}$ \\
\hline $500_{2}$ & 0 & $\sigma^{7}$ & - & - & 0 & $\sigma^{7}$ & - & - & 0 & $\sigma^{7}$ & - & - & 0 & $\sigma^{7}$ & - & - \\
\hline $500_{3}$ & 0 & $\mathrm{O}$ & 11 & $2^{\mathrm{a}}$ & 0 & $\mathrm{O}$ & - & $2^{a}$ & 0 & Em & - & $2^{\mathrm{a}}$ & 0 & $\mathrm{O}$ & 2 & $3^{a}$ \\
\hline $500_{4}$ & 0 & $\sigma^{7}$ & - & - & 0 & $\sigma^{\prime}$ & - & - & 0 & $\sigma^{7}$ & - & - & 0 & $\sigma^{7}$ & - & - \\
\hline $500_{5}$ & - & - & - & - & - & - & - & - & - & - & - & - & - & - & - & - \\
\hline $500_{6}$ & 0 & $\mathrm{O}$ & 4 & $1^{\mathrm{a}}$ & 0 & $\mathrm{Em}$ & - & $1^{\mathrm{a}}$ & 0 & $\mathrm{O}$ & 9 & $2^{\mathrm{a}}$ & 0 & $\mathrm{O}$ & - & $2^{\mathrm{a}}$ \\
\hline $\mathbf{5 0 0}_{7}$ & 0 & $\mathrm{O}$ & 11 & $2^{\mathrm{a}}$ & 0 & Em & - & $2^{\mathrm{a}}$ & 0 & $\mathrm{O}$ & 10 & $3^{\mathrm{a}}$ & 0 & $\mathrm{O}$ & - & $3^{\mathrm{a}}$ \\
\hline $500_{8}$ & 0 & $\mathrm{O}$ & 10 & $2^{\mathrm{a}}$ & 0 & $\mathrm{Em}$ & - & $2^{a}$ & 0 & $\mathrm{O}$ & 11 & $3^{a}$ & 0 & $\mathrm{O}$ & - & $3^{a}$ \\
\hline $509_{9}$ & 0 & $\mathrm{O}$ & 9 & $2^{\mathrm{a}}$ & 0 & Em & - & $2^{a}$ & 0 & $\mathrm{O}$ & 9 & $3^{\mathrm{a}}$ & 0 & $\mathrm{O}$ & - & $3^{\mathrm{a}}$ \\
\hline $500_{10}$ & 0 & $\mathrm{O}$ & 9 & $2^{\mathrm{a}}$ & 0 & $\mathrm{Em}$ & - & $2^{\mathrm{a}}$ & 0 & $\mathrm{O}$ & 10 & $3^{\mathrm{a}}$ & 0 & $\mathrm{O}$ & - & $3^{\mathrm{a}}$ \\
\hline $100_{1}$ & 0 & $\mathrm{O}$ & 10 & $2^{\mathrm{a}}$ & 0 & $\mathrm{Em}$ & - & $2^{\mathrm{a}}$ & 0 & OD & 5 & $3^{\mathrm{a}}$ & 0 & $\mathrm{O}$ & - & $3^{\mathrm{a}}$ \\
\hline $100_{2}$ & 0 & $\mathrm{O}$ & 10 & $2^{\mathrm{a}}$ & 0 & $\mathrm{Em}$ & - & $2^{a}$ & 0 & $\mathrm{O}$ & 3 & $3^{a}$ & 0 & $\mathrm{O}$ & - & $3^{\mathrm{a}}$ \\
\hline $1000_{3}$ & 0 & $\sigma^{7}$ & - & - & 0 & $\sigma^{\prime}$ & - & - & 0 & $\sigma^{7}$ & - & - & 0 & $\sigma^{7}$ & - & - \\
\hline $1000_{4}$ & 0 & $\mathrm{O}$ & 5 & $2^{\mathrm{a}}$ & 0 & Em & - & $2^{\mathrm{a}}$ & 0 & $\mathrm{O}$ & 5 & $3^{\mathrm{a}}$ & 0 & $\mathrm{O}$ & - & $3^{\mathrm{a}}$ \\
\hline $1000_{5}$ & 0 & $0^{7}$ & - & - & 0 & $\sigma^{7}$ & - & - & 0 & $\sigma^{7}$ & - & - & 0 & $0^{7}$ & - & - \\
\hline $100_{6}$ & 0 & $\mathrm{O}$ & 8 & $2^{\mathrm{a}}$ & 0 & $\mathrm{Em}$ & - & $2^{\mathrm{a}}$ & 0 & $\mathrm{O}$ & 10 & $3^{\mathrm{a}}$ & 0 & $\mathrm{Em}$ & - & $3^{\mathrm{a}}$ \\
\hline $1000_{7}$ & - & - & - & - & - & - & - & - & - & - & - & - & - & - & - & - \\
\hline $1000_{8}$ & 0 & $\sigma^{7}$ & - & - & 0 & $\sigma^{\prime}$ & - & - & 0 & $\sigma^{7}$ & - & - & 0 & $\sigma^{7}$ & - & - \\
\hline 10009 & - & - & - & - & - & - & - & - & - & - & - & - & - & - & - & - \\
\hline $1000_{10}$ & 0 & $\mathrm{O}$ & 10 & $2^{\mathrm{a}}$ & 0 & $\mathrm{Em}$ & - & $2^{\mathrm{a}}$ & 0 & DO & 4 & $3^{\mathrm{a}}$ & 0 & $\mathrm{O}$ & - & $3^{\mathrm{a}}$ \\
\hline $2000_{1}$ & 0 & Em & - & $1^{a}$ & 0 & $\mathrm{O}$ & 11 & $2^{a}$ & 0 & Em & - & $2^{\mathrm{a}}$ & 0 & OD & 13 & $3^{a}$ \\
\hline $2000_{2}$ & - & - & - & - & - & - & - & - & - & - & - & - & - & - & - & - \\
\hline $2000_{3}$ & 0 & $\sigma^{\prime}$ & - & - & 0 & $\sigma^{\prime}$ & - & - & 0 & $\sigma^{\prime}$ & - & - & 0 & $\sigma^{\prime \prime}$ & - & - \\
\hline
\end{tabular}

Continua... 
Continuação tabela 14...

\begin{tabular}{|c|c|c|c|c|c|c|c|c|c|c|c|c|c|c|c|c|}
\hline & \multicolumn{4}{|c|}{$27 / 08$} & \multicolumn{4}{|c|}{$28 / 08$} & \multicolumn{4}{|c|}{$29 / 08$} & \multicolumn{4}{|c|}{$30 / 08$} \\
\hline & $\bar{M}$ & Mt & $\overline{\mathrm{Ne}}$ & $\mathbf{N}$ & $\bar{M}$ & Mt & $\mathrm{Ne}$ & $\mathbf{N}$ & $\bar{M}$ & $\overline{\mathbf{M t}}$ & $\mathrm{Ne}$ & $\mathbf{N}$ & $\bar{M}$ & $\overline{\mathbf{M t}}$ & $\mathrm{Ne}$ & $\overline{\mathbf{N}}$ \\
\hline $2000_{4}$ & 0 & $\sigma^{\prime}$ & - & - & 0 & $\sigma^{\prime}$ & - & - & 0 & $\sigma^{\prime}$ & - & - & 0 & $\sigma^{\prime}$ & - & - \\
\hline 20005 & 0 & $\sigma^{7}$ & - & - & 0 & $\sigma^{7}$ & - & - & 0 & $\sigma^{\top}$ & - & - & 0 & $\sigma^{\pi}$ & - & - \\
\hline $2000_{6}$ & 0 & $\mathrm{O}$ & 12 & $2^{a}$ & 0 & Em & - & $2^{a}$ & 0 & Em & - & $2^{a}$ & 0 & $\mathrm{O}$ & 7 & $3^{a}$ \\
\hline $2000_{7}$ & 0 & $\mathrm{O}$ & 12 & $2^{a}$ & 0 & Em & - & $2^{a}$ & 0 & $\mathrm{DO}$ & 11 & $3^{a}$ & 0 & $\mathrm{O}$ & - & $3^{\mathrm{a}}$ \\
\hline 20008 & 0 & $\mathrm{O}$ & 6 & $2^{a}$ & 0 & Em & - & $2^{a}$ & 0 & $\mathrm{DO}$ & 6 & $3^{a}$ & 0 & $\mathrm{O}$ & - & $3^{a}$ \\
\hline 20009 & 0 & $\mathrm{Em}$ & 9 & $2^{a}$ & 1 & - & - & - & - & - & - & - & - & - & - & - \\
\hline $2000_{10}$ & - & - & - & - & - & - & - & - & - & - & - & - & - & - & - & - \\
\hline
\end{tabular}

Conclusão Tabela 14. 
Tabela 15-Valores das concentrações de 17 $\alpha$-etinilestradiol, mortalidade, maturidade, número de neonatas e ninhada dos organismos de Daphnia magna, submetidos ao teste de toxicidade crônica (10 réplicas por concentração, mais controle e controle com solvente) à $25^{\circ} \mathrm{C}$. (M: mortalidade; Mt: maturidade; Ne: número de neonatas; $\mathrm{N}$ : ninhada; Im: imatura; OD: ovário desenvolvido; DO: desenvolvimento do ovário; O: ovada; Em: embrionada). Geração $\mathrm{F}_{1}$. Início do teste: 29/08/2015.

\begin{tabular}{|c|c|c|c|c|c|c|c|c|c|c|c|c|c|c|c|c|c|c|}
\hline & \multicolumn{2}{|c|}{$31 / 08$} & \multicolumn{2}{|c|}{$02 / 09$} & \multicolumn{2}{|c|}{$03 / 09$} & \multicolumn{4}{|c|}{$04 / 09$} & \multicolumn{4}{|c|}{$05 / 09$} & \multicolumn{4}{|c|}{$06 / 09$} \\
\hline & $\bar{M}$ & $\overline{\text { Mt }}$ & $\overline{\mathbf{M}}$ & $\overline{\text { Mt }}$ & $\overline{\mathbf{M}}$ & $\overline{\mathbf{M t}}$ & $\bar{M}$ & Mt & $\mathrm{Ne}$ & $\overline{\mathbf{N}}$ & $\mathbf{M}$ & Mt & $\mathrm{Ne}$ & $\mathbf{N}$ & $\overline{\mathbf{M}}$ & Mt & $\mathrm{Ne}$ & $\overline{\mathbf{N}}$ \\
\hline $\mathrm{C}_{1}$ & 0 & $\mathrm{Im}$ & 0 & $\overline{\mathrm{OD}}$ & 0 & $\mathrm{O}$ & 0 & $\mathrm{Em}$ & - & - & 0 & $\mathrm{O}$ & 8 & $1^{\mathrm{a}}$ & 0 & $\mathrm{Em}$ & - & $1^{\mathrm{a}}$ \\
\hline $\mathrm{C}_{2}$ & 0 & $\mathrm{Im}$ & 0 & $\mathrm{O}$ & 0 & Em & 0 & $\mathrm{O}$ & 8 & $1^{\mathrm{a}}$ & 0 & Em & - & $1^{\mathrm{a}}$ & 0 & $\mathrm{O}$ & 14 & $2^{\mathrm{a}}$ \\
\hline $\mathrm{C}_{3}$ & 0 & $\mathrm{Im}$ & 0 & $\mathrm{O}$ & 0 & Em & 0 & $\mathrm{O}$ & 9 & $1^{a}$ & 0 & $\mathrm{Em}$ & - & $1^{a}$ & 0 & $\mathrm{O}$ & 8 & $2^{\mathrm{a}}$ \\
\hline $\mathrm{C}_{4}$ & 0 & $\mathrm{Im}$ & 0 & OD & 0 & $\mathrm{O}$ & 0 & Em & - & - & 0 & $\mathrm{O}$ & 9 & $1^{a}$ & 0 & Em & - & $1^{\mathrm{a}}$ \\
\hline $\mathrm{C}_{5}$ & 0 & $\mathrm{Im}$ & 0 & $\mathrm{O}$ & 0 & $\mathrm{Em}$ & 0 & $\mathrm{O}$ & 7 & $1^{a}$ & 0 & Em & - & $1^{\mathrm{a}}$ & 0 & $\mathrm{O}$ & 10 & $2^{\mathrm{a}}$ \\
\hline $\mathrm{C}_{6}$ & 0 & Im & 0 & OD & 0 & $\mathrm{O}$ & 0 & Em & - & - & 0 & $\mathrm{O}$ & 9 & $1^{a}$ & 0 & Em & - & $1^{\mathrm{a}}$ \\
\hline $\mathrm{C}_{7}$ & 0 & $\mathrm{Im}$ & 0 & OD & 0 & $\mathrm{O}$ & 0 & Em & - & - & 0 & $\mathrm{O}$ & 10 & $1^{\mathrm{a}}$ & 0 & Em & - & $1^{\mathrm{a}}$ \\
\hline $\mathrm{C}_{8}$ & 0 & $\mathrm{Im}$ & 0 & OD & 0 & $\mathrm{O}$ & 0 & Em & - & - & 0 & $\mathrm{O}$ & 10 & $1^{\mathrm{a}}$ & 0 & $\mathrm{Em}$ & - & $1^{\mathrm{a}}$ \\
\hline $\mathrm{C}_{9}$ & 0 & $\mathrm{Im}$ & 0 & OD & 0 & $\mathrm{O}$ & 0 & Em & - & - & 0 & OD & 9 & $1^{a}$ & 0 & $\mathrm{O}$ & - & $1^{\mathrm{a}}$ \\
\hline $\mathrm{C}_{10}$ & 0 & $\mathrm{Im}$ & 0 & $\mathrm{Im}$ & 0 & DO & 0 & OD & - & - & 0 & $\mathrm{O}$ & - & - & 0 & $\mathrm{Em}$ & - & - \\
\hline $\mathbf{C}+\mathbf{S}_{1}$ & 0 & $\mathrm{Im}$ & 0 & OD & 0 & $\mathrm{O}$ & 0 & Em & - & - & 0 & $\mathrm{O}$ & 8 & $1^{a}$ & 0 & $\mathrm{Em}$ & - & $1^{\mathrm{a}}$ \\
\hline $\mathbf{C}+\mathbf{S}_{2}$ & 0 & $\mathrm{Im}$ & 0 & OD & 0 & $\mathrm{O}$ & 0 & Em & - & - & 0 & $\mathrm{O}$ & 8 & $1^{\mathrm{a}}$ & 0 & $\mathrm{Em}$ & - & $1^{\mathrm{a}}$ \\
\hline $\mathrm{C}+\mathrm{S}_{3}$ & 0 & $\mathrm{Im}$ & 0 & OD & 0 & $\mathrm{O}$ & 0 & Em & - & - & 0 & $\mathrm{O}$ & 10 & $1^{\mathrm{a}}$ & 0 & $\mathrm{Em}$ & - & $1^{\mathrm{a}}$ \\
\hline $\mathbf{C}+\mathbf{S}_{4}$ & 0 & $\mathrm{Im}$ & 0 & OD & 0 & $\mathrm{O}$ & 0 & Em & - & - & 0 & $\mathrm{O}$ & 7 & $1^{a}$ & 0 & Em & - & $1^{\mathrm{a}}$ \\
\hline $\mathbf{C}+\mathrm{S}_{5}$ & 0 & $\mathrm{Im}$ & 0 & $\mathrm{OD}$ & 0 & $\mathrm{O}$ & 0 & Em & - & - & 0 & $\mathrm{O}$ & 9 & $1^{\mathrm{a}}$ & 0 & $\mathrm{Em}$ & - & $1^{\mathrm{a}}$ \\
\hline $\mathbf{C}+\mathbf{S}_{6}$ & 0 & $\mathrm{Im}$ & 0 & OD & 0 & $\mathrm{O}$ & 0 & Em & - & - & 0 & $\mathrm{O}$ & 8 & $1^{a}$ & 0 & Em & - & $1^{\mathrm{a}}$ \\
\hline $\mathbf{C}+\mathbf{S}_{7}$ & 0 & $\mathrm{Im}$ & 0 & OD & 0 & $\mathrm{O}$ & 0 & Em & - & - & 0 & $\mathrm{O}$ & 9 & $1^{\mathrm{a}}$ & 0 & $\mathrm{Em}$ & - & $1^{\mathrm{a}}$ \\
\hline $\mathbf{C}+\mathbf{S} 8$ & 0 & $\mathrm{Im}$ & 0 & DO & 0 & $\mathrm{O}$ & 0 & Em & - & - & 0 & $\mathrm{O}$ & 4 & $1^{\mathrm{a}}$ & 0 & Em & - & $1^{\mathrm{a}}$ \\
\hline $\mathbf{C}+\mathbf{S}_{9}$ & 0 & $\mathrm{Im}$ & 0 & $\mathrm{Im}$ & 0 & DO & 0 & OD & - & - & 0 & $\mathrm{O}$ & - & - & 0 & $\mathrm{Em}$ & - & - \\
\hline $\mathrm{C}+\mathrm{S}_{10}$ & 0 & $\mathrm{Im}$ & 0 & DO & 0 & $\mathrm{O}$ & 0 & Em & - & - & 0 & $\mathrm{O}$ & 7 & $1^{a}$ & 0 & $\mathrm{Em}$ & - & $1^{\mathrm{a}}$ \\
\hline
\end{tabular}

Continua... 
Continuação Tabela 15...

\begin{tabular}{|c|c|c|c|c|c|c|c|c|c|c|c|c|c|c|c|c|c|c|}
\hline & \multicolumn{2}{|c|}{$31 / 08$} & \multicolumn{2}{|c|}{$02 / 09$} & \multicolumn{2}{|c|}{$03 / 09$} & \multicolumn{4}{|c|}{$04 / 09$} & \multicolumn{4}{|c|}{$05 / 09$} & \multicolumn{4}{|c|}{$06 / 09$} \\
\hline & $\mathbf{M}$ & Mt & $\mathbf{M}$ & Mt & $\mathbf{M}$ & Mt & $\mathbf{M}$ & Mt & $\mathrm{Ne}$ & $\mathbf{N}$ & $\mathbf{M}$ & Mt & $\mathrm{Ne}$ & $\mathbf{N}$ & $\mathbf{M}$ & $\mathbf{M t}$ & $\mathrm{Ne}$ & $\mathbf{N}$ \\
\hline 62,51 & 0 & $\mathrm{Im}$ & 0 & OD & 0 & $\mathrm{O}$ & 0 & Em & - & - & 0 & $\mathrm{O}$ & 6 & $1^{\mathrm{a}}$ & 0 & Em & - & $1^{\mathrm{a}}$ \\
\hline 62,52 & 0 & $\mathrm{Im}$ & 0 & OD & 0 & $\mathrm{O}$ & 0 & Em & - & - & 0 & $\mathrm{O}$ & 8 & $1^{\mathrm{a}}$ & 0 & Em & - & $1^{\mathrm{a}}$ \\
\hline 62,53 & 0 & $\mathrm{Im}$ & 0 & OD & 0 & $\mathrm{O}$ & 0 & Em & - & - & 0 & $\mathrm{O}$ & 10 & $1^{a}$ & 0 & Em & - & $1^{a}$ \\
\hline $62,5_{4}$ & 0 & $\mathrm{Im}$ & 0 & OD & 0 & $\mathrm{O}$ & 0 & $\mathrm{Em}$ & - & - & 0 & $\mathrm{O}$ & 11 & $1^{\mathrm{a}}$ & 0 & $\mathrm{Em}$ & - & $1^{\mathrm{a}}$ \\
\hline 62,55 & 0 & $\mathrm{Im}$ & 0 & OD & 0 & $\mathrm{O}$ & 0 & Em & - & - & 1 & - & 9 & $1^{\mathrm{a}}$ & - & - & - & - \\
\hline 62,56 & 0 & $\mathrm{Im}$ & 0 & OD & 0 & $\mathrm{O}$ & 0 & Em & - & - & 0 & $\mathrm{O}$ & 6 & $1^{a}$ & 0 & Em & - & $1^{a}$ \\
\hline $62,5_{7}$ & 0 & $\mathrm{Im}$ & 0 & OD & 0 & $\mathrm{O}$ & 0 & Em & - & - & 0 & $\mathrm{O}$ & 9 & $1^{\mathrm{a}}$ & 0 & $\mathrm{Em}$ & - & $1^{\mathrm{a}}$ \\
\hline 62,58 & 0 & $\mathrm{Im}$ & 0 & OD & 0 & $\mathrm{O}$ & 0 & Em & - & - & 0 & $\mathrm{O}$ & 8 & $1^{\mathrm{a}}$ & 0 & $\mathrm{Em}$ & - & $1^{\mathrm{a}}$ \\
\hline 62,59 & 0 & $\mathrm{Im}$ & 0 & OD & 0 & $\mathrm{O}$ & 0 & Em & - & - & 0 & $\mathrm{O}$ & 9 & $1^{\mathrm{a}}$ & 0 & Em & - & $1^{\mathrm{a}}$ \\
\hline $62,5_{10}$ & 0 & $\mathrm{Im}$ & 0 & DO & 0 & $\mathrm{O}$ & 0 & $\mathrm{Em}$ & - & - & 0 & $\mathrm{O}$ & 9 & $1^{\mathrm{a}}$ & 0 & $\mathrm{Em}$ & - & $1^{\mathrm{a}}$ \\
\hline 1251 & 0 & $\mathrm{Im}$ & 0 & DO & 0 & $\mathrm{O}$ & 0 & $\mathrm{O}$ & - & - & 0 & $\mathrm{O}$ & 5 & $1^{\mathrm{a}}$ & 0 & $\mathrm{Em}$ & - & $1^{\mathrm{a}}$ \\
\hline 1252 & 0 & $\mathrm{Im}$ & 0 & DO & 0 & $\mathrm{O}$ & 0 & Em & - & - & 0 & $\mathrm{O}$ & 6 & $1^{a}$ & 0 & Em & - & $1^{a}$ \\
\hline 1253 & 0 & $\mathrm{Im}$ & 0 & OD & 0 & $\mathrm{O}$ & 0 & Em & - & - & 0 & $\mathrm{O}$ & 8 & $1^{\mathrm{a}}$ & 0 & $\mathrm{Em}$ & - & $1^{\mathrm{a}}$ \\
\hline $125_{4}$ & 0 & $\mathrm{Im}$ & 0 & DO & 0 & $\mathrm{O}$ & 0 & Em & - & - & 0 & $\mathrm{O}$ & 5 & $1^{\mathrm{a}}$ & 0 & Em & - & $1^{\mathrm{a}}$ \\
\hline 1255 & 0 & $\mathrm{Im}$ & 0 & DO & 0 & $\mathrm{O}$ & 0 & Em & - & - & 0 & $\mathrm{O}$ & 5 & $1^{a}$ & 0 & Em & - & $1^{a}$ \\
\hline 1256 & 0 & $\mathrm{Im}$ & 0 & OD & 0 & $\mathrm{O}$ & 0 & $\mathrm{Em}$ & - & - & 0 & $\mathrm{O}$ & 8 & $1^{\mathrm{a}}$ & 0 & Em & - & $1^{a}$ \\
\hline 1257 & 0 & $\mathrm{Im}$ & 0 & DO & 0 & $\mathrm{O}$ & 0 & Em & - & - & 0 & $\mathrm{O}$ & 7 & $1^{\mathrm{a}}$ & 0 & Em & - & $1^{\mathrm{a}}$ \\
\hline 1258 & 0 & $\mathrm{Im}$ & 0 & DO & 0 & $\mathrm{O}$ & 0 & Em & - & - & 0 & $\mathrm{O}$ & 8 & $1^{a}$ & 0 & Em & - & $1^{a}$ \\
\hline 1259 & 0 & $\mathrm{Im}$ & 0 & DO & 0 & $\mathrm{O}$ & 0 & Em & - & - & 0 & $\mathrm{O}$ & 4 & $1^{\mathrm{a}}$ & 0 & Em & - & $1^{\mathrm{a}}$ \\
\hline $125_{10}$ & 0 & $\mathrm{Im}$ & 0 & DO & 0 & $\mathrm{O}$ & 0 & Em & - & - & 0 & $\mathrm{O}$ & 8 & $1^{\mathrm{a}}$ & 0 & $\mathrm{Em}$ & - & $1^{\mathrm{a}}$ \\
\hline $250_{1}$ & 0 & $\mathrm{Im}$ & 0 & $\mathrm{DO}$ & 0 & $\mathrm{O}$ & 0 & Em & - & - & 0 & $\mathrm{O}$ & 6 & $1^{\mathrm{a}}$ & 0 & Em & - & $1^{\mathrm{a}}$ \\
\hline 2502 & 0 & $\mathrm{Im}$ & 0 & DO & 0 & $\mathrm{O}$ & 0 & Em & - & - & 0 & $\mathrm{O}$ & 8 & $1^{a}$ & 0 & Em & - & $1^{a}$ \\
\hline 2503 & 0 & $\mathrm{Im}$ & 0 & OD & 0 & $\mathrm{O}$ & 0 & Em & - & - & 0 & $\mathrm{O}$ & 8 & $1^{a}$ & 0 & Em & - & $1^{a}$ \\
\hline
\end{tabular}

Continua... 
Continuação Tabela 15...

\begin{tabular}{|c|c|c|c|c|c|c|c|c|c|c|c|c|c|c|c|c|c|c|}
\hline & \multicolumn{2}{|c|}{$31 / 08$} & \multicolumn{2}{|c|}{$02 / 09$} & \multicolumn{2}{|c|}{$03 / 09$} & \multicolumn{4}{|c|}{$04 / 09$} & \multicolumn{4}{|c|}{$05 / 09$} & \multicolumn{4}{|c|}{$06 / 09$} \\
\hline & $\bar{M}$ & Mt & $\overline{\mathbf{M}}$ & Mt & $\bar{M}$ & Mt & $\bar{M}$ & Mt & $\mathrm{Ne}$ & $\mathbf{N}$ & $\mathbf{M}$ & Mt & $\mathrm{Ne}$ & $\mathbf{N}$ & $\mathbf{M}$ & $\mathbf{M t}$ & $\mathrm{Ne}$ & $\mathbf{N}$ \\
\hline $250_{4}$ & 0 & $\mathrm{Im}$ & 0 & OD & 0 & $\mathrm{O}$ & 0 & $\mathrm{Em}$ & - & $\overline{-}$ & 0 & $\mathrm{O}$ & 8 & $1^{\mathrm{a}}$ & 0 & $\mathrm{Em}$ & - & $1^{a}$ \\
\hline 2505 & 0 & $\mathrm{Im}$ & 0 & $\mathrm{DO}$ & 0 & $\mathrm{O}$ & 0 & Em & - & - & 0 & $\mathrm{O}$ & 8 & $1^{\mathrm{a}}$ & 0 & $\mathrm{Em}$ & - & $1^{\mathrm{a}}$ \\
\hline $250_{6}$ & 0 & $\mathrm{Im}$ & 0 & $\mathrm{DO}$ & 0 & $\mathrm{O}$ & 0 & Em & - & - & 0 & $\mathrm{O}$ & 7 & $1^{\mathrm{a}}$ & 0 & $\mathrm{Em}$ & - & $1^{\mathrm{a}}$ \\
\hline $250_{7}$ & 0 & $\mathrm{Im}$ & 0 & DO & 0 & $\mathrm{O}$ & 0 & $\mathrm{Em}$ & - & - & 0 & $\mathrm{O}$ & 9 & $1^{\mathrm{a}}$ & 0 & $\mathrm{Em}$ & - & $1^{\mathrm{a}}$ \\
\hline 2508 & 0 & $\mathrm{Im}$ & 0 & $\mathrm{O}$ & 0 & Em & 0 & $\mathrm{O}$ & 5 & $1^{\mathrm{a}}$ & 0 & Em & - & $1^{\mathrm{a}}$ & 0 & $\mathrm{O}$ & 10 & $2^{a}$ \\
\hline 2509 & 0 & $\mathrm{Im}$ & 0 & $\mathrm{DO}$ & 0 & $\mathrm{O}$ & 0 & $\mathrm{Em}$ & - & - & 0 & $\mathrm{O}$ & 10 & $1^{\mathrm{a}}$ & 0 & $\mathrm{Em}$ & - & $1^{a}$ \\
\hline $250_{10}$ & 0 & $\mathrm{Im}$ & 0 & $\mathrm{O}$ & 0 & Em & 0 & $\mathrm{O}$ & 5 & $1^{a}$ & 0 & Em & - & $1^{a}$ & 0 & $\mathrm{O}$ & 12 & $2^{a}$ \\
\hline $500_{1}$ & 0 & $\mathrm{Im}$ & 0 & $\mathrm{DO}$ & 0 & $\mathrm{O}$ & 0 & $\mathrm{Em}$ & - & - & 0 & $\mathrm{O}$ & 8 & $1^{a}$ & 0 & $\mathrm{Em}$ & - & $1^{a}$ \\
\hline $500_{2}$ & 0 & $\mathrm{Im}$ & 0 & OD & 0 & $\mathrm{O}$ & 0 & $\mathrm{Em}$ & - & - & 0 & $\mathrm{O}$ & 7 & $1^{a}$ & 0 & $\mathrm{Em}$ & - & $1^{a}$ \\
\hline $500_{3}$ & 0 & $\mathrm{Im}$ & 0 & $\mathrm{DO}$ & 0 & $\mathrm{O}$ & 0 & Em & - & - & 0 & $\mathrm{O}$ & 8 & $1^{\mathrm{a}}$ & 0 & $\mathrm{Em}$ & - & $1^{a}$ \\
\hline $500_{4}$ & 0 & $\mathrm{Im}$ & 0 & $\mathrm{DO}$ & 0 & $\mathrm{O}$ & 0 & Em & - & - & 0 & $\mathrm{O}$ & 8 & $1^{\mathrm{a}}$ & 0 & $\mathrm{Em}$ & - & $1^{\mathrm{a}}$ \\
\hline $500_{5}$ & 0 & $\mathrm{Im}$ & 0 & $\mathrm{DO}$ & 0 & $\mathrm{O}$ & 0 & $\mathrm{Em}$ & - & - & 0 & $\mathrm{O}$ & 9 & $1^{a}$ & 0 & $\mathrm{Em}$ & - & $1^{\mathrm{a}}$ \\
\hline $500_{6}$ & 0 & $\mathrm{Im}$ & 0 & OD & 0 & $\mathrm{O}$ & 0 & $\mathrm{Em}$ & - & - & 0 & $\mathrm{O}$ & 7 & $1^{a}$ & 0 & $\mathrm{Em}$ & - & $1^{a}$ \\
\hline $\mathbf{5 0 0}_{7}$ & 0 & $\mathrm{Im}$ & 0 & $\mathrm{DO}$ & 0 & $\mathrm{O}$ & 0 & Em & - & - & 0 & $\mathrm{O}$ & 5 & $1^{\mathrm{a}}$ & 0 & $\mathrm{Em}$ & - & $1^{\mathrm{a}}$ \\
\hline 5008 & 0 & $\mathrm{Im}$ & 0 & $\mathrm{DO}$ & 0 & $\mathrm{O}$ & 0 & $\mathrm{Em}$ & - & - & 0 & $\mathrm{O}$ & 8 & $1^{a}$ & 0 & $\mathrm{Em}$ & - & $1^{a}$ \\
\hline 5009 & 0 & $\mathrm{Im}$ & 0 & $\mathrm{DO}$ & 0 & $\mathrm{O}$ & 0 & $\mathrm{Em}$ & - & - & 0 & $\mathrm{O}$ & 8 & $1^{\mathrm{a}}$ & 0 & $\mathrm{Em}$ & - & $1^{a}$ \\
\hline $500_{10}$ & 0 & $\mathrm{Im}$ & 0 & $\mathrm{DO}$ & 0 & $\mathrm{O}$ & 0 & Em & - & - & 0 & $\mathrm{O}$ & 7 & $1^{\mathrm{a}}$ & 1 & - & - & - \\
\hline $1000_{1}$ & 0 & $\mathrm{Im}$ & 0 & $\mathrm{O}$ & 0 & $\mathrm{O}$ & 0 & $\mathrm{O}$ & 5 & $1^{\mathrm{a}}$ & 0 & Em & - & $1^{a}$ & 0 & OD & 10 & $2^{a}$ \\
\hline $1000_{2}$ & 0 & $\mathrm{Im}$ & 0 & $\mathrm{O}$ & 0 & $\mathrm{O}$ & 0 & $\mathrm{O}$ & 6 & $1^{a}$ & 0 & $\mathrm{Em}$ & - & $1^{a}$ & 0 & OD & 9 & $2^{a}$ \\
\hline $1000_{3}$ & 0 & $\mathrm{Im}$ & 0 & $\mathrm{O}$ & 0 & $\mathrm{O}$ & 0 & $\mathrm{O}$ & 6 & $1^{\mathrm{a}}$ & 0 & Em & - & $1^{\mathrm{a}}$ & 0 & OD & 10 & $2^{a}$ \\
\hline $1000_{4}$ & 0 & $\mathrm{Im}$ & 0 & $\mathrm{O}$ & 0 & $\mathrm{O}$ & 0 & $\mathrm{O}$ & 6 & $1^{\mathrm{a}}$ & 0 & Em & - & $1^{\mathrm{a}}$ & 0 & $\mathrm{Em}$ & - & $1^{\mathrm{a}}$ \\
\hline 10005 & 0 & $\mathrm{Im}$ & 0 & $\mathrm{O}$ & 0 & $\mathrm{O}$ & 0 & $\mathrm{O}$ & 7 & $1^{a}$ & 0 & $\mathrm{Em}$ & - & $1^{a}$ & 0 & $\mathrm{Em}$ & - & $1^{a}$ \\
\hline $1000_{6}$ & 0 & $\mathrm{Im}$ & 0 & $\mathrm{O}$ & 0 & $\mathrm{O}$ & 0 & $\mathrm{O}$ & 6 & $1^{\mathrm{a}}$ & 0 & Em & - & $1^{\mathrm{a}}$ & 0 & $\mathrm{DO}$ & 8 & $2^{a}$ \\
\hline
\end{tabular}

Continua... 
Continuação Tabela 15...

\begin{tabular}{|c|c|c|c|c|c|c|c|c|c|c|c|c|c|c|c|c|c|c|c|c|c|}
\hline & \multicolumn{2}{|c|}{$31 / 08$} & \multicolumn{2}{|c|}{$02 / 09$} & \multicolumn{2}{|c|}{$03 / 09$} & \multicolumn{5}{|c|}{$04 / 09$} & \multicolumn{4}{|c|}{$05 / 09$} & \multicolumn{4}{|c|}{$06 / 09$} & \\
\hline & & $\bar{M}$ & $\mathbf{M t}$ & $\mathbf{M}$ & Mt & $\bar{M}$ & $\mathbf{M}$ & \begin{tabular}{l|l}
$\mathbf{t}$ & $\mathrm{M}$ \\
\end{tabular} & & It & $\mathrm{Ne}$ & \begin{tabular}{l|l}
$\mathbf{N}$ & $\mathbf{M}$
\end{tabular} & \begin{tabular}{l|l}
$\mathbf{I}$ & $\mathrm{M}$
\end{tabular} & & $\mathrm{Ne}$ & \begin{tabular}{l|l}
$\mathbf{N}$ & $\mathbf{M}$ \\
\end{tabular} & & $\overline{\mathrm{Mt}}$ & $\mathrm{Ne}$ & $\overline{\mathbf{N}}$ & \\
\hline \multicolumn{2}{|c|}{$\overline{1000_{7}}$} & 0 & $\mathrm{Im}$ & 0 & $\mathrm{O}$ & 0 & $\mathrm{O}$ & 0 & ( & 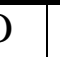 & 6 & $1^{\mathrm{a}}$ & $\bar{E}$ & & - & $1^{\mathrm{a}}$ & & $\mathrm{DD}$ & 7 & $2^{a}$ & \\
\hline \multicolumn{2}{|c|}{10008} & 0 & $\mathrm{Im}$ & 0 & $\mathrm{O}$ & 0 & $\mathrm{O}$ & 0 & $\mathrm{E}$ & & - & - & $C$ & & 3 & $1^{\mathrm{a}}$ & & $\mathrm{Em}$ & - & $1^{\mathrm{a}}$ & \\
\hline \multicolumn{2}{|c|}{10009} & 0 & $\mathrm{Im}$ & 0 & $\mathrm{DO}$ & 0 & $\mathrm{O}$ & 0 & $\mathrm{E}$ & & - & - & $C$ & & 6 & $1^{\mathrm{a}}$ & & $\mathrm{Em}$ & - & $1^{a}$ & \\
\hline \multicolumn{2}{|c|}{$1000_{10}$} & 0 & $\mathrm{Im}$ & 0 & OD & 0 & $\mathrm{O}$ & 0 & $\mathrm{E}$ & $m$ & - & - & $\mathrm{C}$ & ) & 7 & \begin{tabular}{l|l}
$1^{\mathrm{a}}$ & 0
\end{tabular} & & $\mathrm{Em}$ & - & $1^{\mathrm{a}}$ & \\
\hline \multicolumn{2}{|c|}{$2000_{1}$} & 0 & $\mathrm{Im}$ & 0 & $\mathrm{DO}$ & 0 & $\overline{\mathrm{DC}}$ & O & ( & 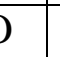 & - & 0 & $\mathrm{Er}$ & & - & - & & $\mathrm{O}$ & 4 & $1^{\mathrm{a}}$ & \\
\hline \multicolumn{2}{|c|}{$2000_{2}$} & 0 & $\mathrm{Im}$ & 0 & $\mathrm{Im}$ & 1 & - & - & 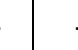 & 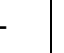 & - & - & - & & - & - & & - & - & - & \\
\hline \multicolumn{2}{|c|}{20003} & 0 & $\mathrm{Im}$ & 0 & $\mathrm{DO}$ & 0 & $\mathrm{OI}$ & D & ( & D & - & - & $\mathrm{Er}$ & & - & - & & $\mathrm{O}$ & 9 & $1^{a}$ & \\
\hline \multicolumn{2}{|c|}{$2000_{4}$} & 0 & $\mathrm{Im}$ & 0 & $\mathrm{DO}$ & 0 & $\mathrm{DC}$ & O & ( & D & - & - & $\mathrm{Er}$ & & - & - & & $\mathrm{O}$ & 6 & $1^{\mathrm{a}}$ & \\
\hline \multicolumn{2}{|c|}{20005} & 0 & $\mathrm{Im}$ & 0 & $\mathrm{DO}$ & 0 & DC & O & ( & D & - & - & $\mathrm{Er}$ & & - & - & & $\mathrm{O}$ & 7 & $1^{a}$ & \\
\hline \multicolumn{2}{|c|}{$2000_{6}$} & 0 & $\mathrm{Im}$ & 0 & $\mathrm{DO}$ & 0 & $\mathrm{OI}$ & D & ( & D & - & - & $\mathrm{Er}$ & & - & 0 & & $\mathrm{O}$ & 8 & $1^{a}$ & \\
\hline \multicolumn{2}{|c|}{$2000_{7}$} & 0 & $\mathrm{Im}$ & 0 & $\mathrm{DO}$ & 0 & $\mathrm{OI}$ & D & ( & D & - & 0 & $\mathrm{Er}$ & & - & - & & $\mathrm{O}$ & 6 & $1^{\mathrm{a}}$ & \\
\hline \multicolumn{2}{|c|}{20008} & 0 & $\mathrm{Im}$ & 0 & $\mathrm{DO}$ & 0 & $\mathrm{OI}$ & 0 & ( & D & - & 0 & $\mathrm{Er}$ & & - & 0 & & $\mathrm{O}$ & 11 & $1^{a}$ & \\
\hline \multicolumn{2}{|c|}{20009} & 0 & $\mathrm{Im}$ & 0 & $\mathrm{DO}$ & 0 & DC & 0 & C & & - & - & En & & - & 0 & & $\mathrm{O}$ & 7 & $1^{a}$ & \\
\hline \multicolumn{2}{|c|}{$2000_{10}$} & 0 & $\mathrm{Im}$ & 0 & $\mathrm{Im}$ & 1 & - & - & 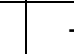 & & - & - & - & & - & - & & - & - & - & \\
\hline & \multicolumn{4}{|c|}{$07 / 09$} & \multicolumn{5}{|c|}{ 08/09 } & \multicolumn{4}{|c|}{$09 / 09$} & \multicolumn{4}{|c|}{$10 / 09$} & \multicolumn{4}{|c|}{$11 / 09$} \\
\hline & $\mathbf{M}$ & Mt & $\mathrm{Ne}$ & $\mathbf{N}$ & $\mathbf{M}$ & $\mathbf{M}$ & It & $\mathrm{Ne}$ & $\mathbf{N}$ & $\mathbf{M}$ & Mt & $\mathrm{Ne}$ & $\mathbf{N}$ & $\mathbf{M}$ & Mt & $\mathrm{Ne}$ & $\mathbf{N}$ & $\mathbf{M}$ & Mt & $\mathrm{Ne}$ & $\mathbf{N}$ \\
\hline $\mathrm{C}_{1}$ & 0 & OD & 8 & $2^{a}$ & 0 & $\mathrm{C}$ & 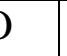 & - & $2^{a}$ & 0 & $\mathrm{Em}$ & - & $2^{a}$ & 0 & $\mathrm{O}$ & 8 & $3^{a}$ & 0 & $\mathrm{Em}$ & - & $3^{a}$ \\
\hline $\mathrm{C}_{2}$ & 0 & Em & - & $2^{a}$ & 0 & $\mathrm{O}$ & & 16 & $3^{a}$ & 0 & $\mathrm{O}$ & - & $3^{\mathrm{a}}$ & 0 & $\mathrm{Em}$ & - & $3^{a}$ & 0 & $\mathrm{O}$ & 14 & $4^{a}$ \\
\hline $\mathrm{C}_{3}$ & 0 & $\mathrm{Em}$ & - & $2^{a}$ & 0 & C & ) & 12 & $3^{a}$ & 0 & $\mathrm{O}$ & - & $3^{a}$ & 0 & DO & 8 & $4^{a}$ & 0 & $\mathrm{O}$ & - & $3^{a}$ \\
\hline $\mathrm{C}_{4}$ & 0 & $\mathrm{O}$ & 7 & $2^{a}$ & 0 & C & 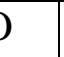 & - & $2^{a}$ & 0 & $\mathrm{Em}$ & - & $2^{a}$ & 0 & $\mathrm{O}$ & 5 & $3^{a}$ & 0 & $\mathrm{Em}$ & - & $3^{a}$ \\
\hline$\overline{C 5}$ & 0 & $\mathrm{Em}$ & - & $2^{a}$ & 0 & $\mathrm{E}_{1}$ & & - & $2^{a}$ & 0 & $\mathrm{O}$ & 9 & $3^{a}$ & 0 & $\mathrm{Em}$ & - & $3^{a}$ & 0 & $\mathrm{O}$ & 10 & $4^{a}$ \\
\hline $\mathrm{C}_{6}$ & 0 & $\mathrm{O}$ & 9 & $2^{a}$ & 0 & $\mathrm{E}_{1}$ & & - & $2^{a}$ & 0 & DO & 10 & $3^{a}$ & 0 & $\mathrm{Em}$ & - & $3^{a}$ & 0 & $\mathrm{Em}$ & - & $3^{a}$ \\
\hline $\mathrm{C}_{7}$ & 0 & OD & 10 & $2^{a}$ & 0 & C & ) & - & $2^{a}$ & 0 & $\mathrm{Em}$ & - & $2^{a}$ & 0 & $\mathrm{O}$ & 9 & $3^{\mathrm{a}}$ & 0 & Em & - & $3^{a}$ \\
\hline
\end{tabular}

Continua... 
Continuação Tabela 15...

\begin{tabular}{|c|c|c|c|c|c|c|c|c|c|c|c|c|c|c|c|c|c|c|c|c|}
\hline & \multicolumn{4}{|c|}{$07 / 09$} & \multicolumn{4}{|c|}{$08 / 09$} & \multicolumn{4}{|c|}{$09 / 09$} & \multicolumn{4}{|c|}{$10 / 09$} & \multicolumn{4}{|c|}{$11 / 09$} \\
\hline & $\overline{\mathbf{M}}$ & $\overline{M t}$ & $\mathbf{N e}$ & $\overline{\mathbf{N}}$ & $\overline{\mathbf{M}}$ & $\overline{\text { Mt }}$ & $\overline{\mathrm{Ne}}$ & $\overline{\mathbf{N}}$ & $\overline{\mathbf{M}}$ & Mt & $\mathrm{Ne}$ & $\overline{\mathbf{N}}$ & $\overline{\mathbf{M}}$ & $\overline{\text { Mt }}$ & $\mathrm{Ne}$ & $\mathbf{N}$ & $\overline{\mathbf{M}}$ & Mt & $\mathrm{Ne}$ & $\overline{\mathbf{N}}$ \\
\hline $\mathrm{C}_{8}$ & 0 & $\mathrm{O}$ & 6 & $2^{\mathrm{a}}$ & 0 & Em & - & $2^{a}$ & 0 & Em & - & $2^{a}$ & 0 & $\mathrm{O}$ & 12 & $3^{\mathrm{a}}$ & 0 & Em & - & $3^{\mathrm{a}}$ \\
\hline $\mathrm{C}_{9}$ & 0 & Em & - & $1^{\mathrm{a}}$ & 0 & $\mathrm{O}$ & 3 & $2^{a}$ & 0 & Em & - & $2^{a}$ & 0 & $\mathrm{O}$ & 11 & $3^{a}$ & 0 & Em & - & $3^{\mathrm{a}}$ \\
\hline $\mathrm{C}_{10}$ & 0 & $\mathrm{O}$ & 10 & $1^{\mathrm{a}}$ & 0 & Em & - & $1^{\mathrm{a}}$ & 0 & $\mathrm{O}$ & 11 & $2^{a}$ & 0 & Em & 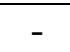 & $2^{\mathrm{a}}$ & 0 & DO & 6 & $3^{\mathrm{a}}$ \\
\hline $\mathbf{C}+\mathbf{S}_{1}$ & 0 & $\mathrm{O}$ & 12 & $2^{\mathrm{a}}$ & 0 & Em & - & $2^{\mathrm{a}}$ & 0 & OD & 14 & $3^{\mathrm{a}}$ & 0 & $\mathrm{O}$ & - & $3^{\mathrm{a}}$ & 0 & Em & - & $3^{\mathrm{a}}$ \\
\hline $\mathbf{C}+\mathbf{S}_{\mathbf{2}}$ & 0 & $\mathrm{O}$ & 10 & $2^{\mathrm{a}}$ & 0 & Em & - & $2^{\mathrm{a}}$ & 0 & OD & 10 & $3^{\mathrm{a}}$ & 0 & $\mathrm{O}$ & - & $3^{\mathrm{a}}$ & 0 & Em & - & $3^{\mathrm{a}}$ \\
\hline $\mathbf{C}+\mathbf{S}_{3}$ & 0 & $\mathrm{O}$ & 12 & $2^{\mathrm{a}}$ & 0 & Em & - & $2^{a}$ & 0 & $\mathrm{O}$ & 11 & $3^{\mathrm{a}}$ & 0 & Em & - & $3^{\mathrm{a}}$ & 0 & Em & - & $3^{\mathrm{a}}$ \\
\hline $\mathbf{C}+\mathbf{S}_{4}$ & 0 & $\mathrm{O}$ & 8 & $2^{\mathrm{a}}$ & 0 & Em & - & $2^{\mathrm{a}}$ & 0 & OD & 9 & $3^{\mathrm{a}}$ & 0 & $\mathrm{O}$ & - & $3^{\mathrm{a}}$ & 0 & Em & - & $3^{\mathrm{a}}$ \\
\hline $\mathbf{C}+\mathbf{S}_{5}$ & 0 & $\mathrm{O}$ & 11 & $2^{\mathrm{a}}$ & 0 & Em & - & $2^{a}$ & 0 & $\mathrm{O}$ & 13 & $3^{\mathrm{a}}$ & 0 & $\mathrm{O}$ & - & $3^{\mathrm{a}}$ & 0 & Em & - & $3^{\mathrm{a}}$ \\
\hline $\mathbf{C}+\mathrm{S}_{6}$ & 0 & - & 6 & $2^{\mathrm{a}}$ & 1 & - & - & - & - & - & - & - & - & - & - & - & - & - & - & - \\
\hline $\mathbf{C}+\mathbf{S}_{7}$ & 0 & $\mathrm{O}$ & 12 & $2^{\mathrm{a}}$ & 0 & Em & - & $2^{a}$ & 0 & $\mathrm{O}$ & 15 & $3^{\mathrm{a}}$ & 0 & Em & - & $3^{\mathrm{a}}$ & 0 & $\mathrm{O}$ & 9 & $4^{\mathrm{a}}$ \\
\hline $\mathbf{C}+\mathbf{S}_{8}$ & 0 & $\mathrm{O}$ & 10 & $2^{\mathrm{a}}$ & 0 & Em & - & $2^{a}$ & 0 & $\mathrm{O}$ & 13 & $3^{\mathrm{a}}$ & 0 & Em & - & $3^{a}$ & 0 & DO & 11 & $4^{\mathrm{a}}$ \\
\hline $\mathbf{C}+\mathbf{S}_{9}$ & 0 & $\mathrm{O}$ & 5 & $1^{\mathrm{a}}$ & 0 & Em & - & $1^{\mathrm{a}}$ & 0 & $\mathrm{O}$ & 9 & $3^{a}$ & 0 & Em & - & $3^{a}$ & 0 & $\mathrm{O}$ & 11 & $4^{\mathrm{a}}$ \\
\hline $\mathrm{C}+\mathrm{S}_{10}$ & 0 & $\mathrm{O}$ & 8 & $2^{\mathrm{a}}$ & 0 & Em & - & $2^{a}$ & 0 & $\mathrm{O}$ & 11 & $3^{\mathrm{a}}$ & 0 & Em & & $3^{\mathrm{a}}$ & 0 & OD & 13 & $4^{\mathrm{a}}$ \\
\hline $62,5_{1}$ & 0 & $\mathrm{O}$ & 5 & $2^{\mathrm{a}}$ & 0 & Em & - & $2^{\mathrm{a}}$ & 0 & DO & 5 & $3^{\mathrm{a}}$ & 0 & $\mathrm{O}$ & - & $3^{\mathrm{a}}$ & 0 & Em & 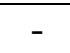 & $3^{\mathrm{a}}$ \\
\hline $62,5_{2}$ & 0 & $\mathrm{O}$ & 12 & $2^{\mathrm{a}}$ & 0 & Em & - & $2^{\mathrm{a}}$ & 0 & $\mathrm{O}$ & 10 & $3^{\mathrm{a}}$ & 0 & $\mathrm{O}$ & - & $3^{\mathrm{a}}$ & 0 & Em & - & $3^{\mathrm{a}}$ \\
\hline 62,53 & 0 & $\mathrm{O}$ & 2 & $2^{\mathrm{a}}$ & 0 & Em & - & $2^{a}$ & 0 & $\mathrm{O}$ & 9 & $3^{\mathrm{a}}$ & 0 & $\mathrm{O}$ & - & $3^{\mathrm{a}}$ & 0 & Em & - & $3^{\mathrm{a}}$ \\
\hline 62,54 & 0 & $\mathrm{O}$ & 9 & $2^{\mathrm{a}}$ & 0 & Em & - & $2^{\mathrm{a}}$ & 0 & Em & - & $2^{\mathrm{a}}$ & 0 & $\mathrm{O}$ & 9 & $3^{a}$ & 0 & Em & - & $3^{\mathrm{a}}$ \\
\hline 62,55 & - & - & - & - & - & - & - & - & - & - & - & - & - & - & - & - & - & - & - & - \\
\hline 62,56 & 0 & OD & 5 & $2^{\mathrm{a}}$ & 0 & Em & - & $2^{\mathrm{a}}$ & 0 & $\mathrm{Em}$ & - & $2^{\mathrm{a}}$ & 0 & $\mathrm{O}$ & 8 & $3^{\mathrm{a}}$ & 0 & Em & - & $3^{\mathrm{a}}$ \\
\hline $62,5_{7}$ & 0 & $\mathrm{O}$ & 10 & $2^{\mathrm{a}}$ & 0 & Em & - & $2^{a}$ & 0 & DO & 10 & $3^{a}$ & 0 & $\mathrm{O}$ & - & $3^{\mathrm{a}}$ & 0 & Em & - & $3^{\mathrm{a}}$ \\
\hline 62,58 & 0 & $\mathrm{O}$ & 8 & $2^{\mathrm{a}}$ & 0 & Em & - & $2^{a}$ & 0 & $\mathrm{Em}$ & - & $2^{\mathrm{a}}$ & 0 & $\mathrm{O}$ & 10 & $3^{\mathrm{a}}$ & 0 & Em & - & $3^{\mathrm{a}}$ \\
\hline 62,59 & 0 & OD & 8 & $2^{\mathrm{a}}$ & 0 & $\mathrm{O}$ & - & $2^{\mathrm{a}}$ & 0 & Em & - & $2^{\mathrm{a}}$ & 0 & $\mathrm{O}$ & 11 & $3^{\mathrm{a}}$ & 0 & Em & - & $3^{\mathrm{a}}$ \\
\hline $62,5_{10}$ & 0 & Em & - & $1^{\mathrm{a}}$ & 0 & $\mathrm{O}$ & 8 & $2^{a}$ & 0 & Em & - & $2^{a}$ & 0 & $\mathrm{O}$ & 8 & $3^{\mathrm{a}}$ & 0 & Em & - & $3^{\mathrm{a}}$ \\
\hline
\end{tabular}

Continua... 
Continuação Tabela 15...

\begin{tabular}{|c|c|c|c|c|c|c|c|c|c|c|c|c|c|c|c|c|c|c|c|c|}
\hline & \multicolumn{4}{|c|}{ 07/09 } & \multicolumn{4}{|c|}{$08 / 09$} & \multicolumn{4}{|c|}{$09 / 09$} & \multicolumn{4}{|c|}{$10 / 09$} & \multicolumn{4}{|c|}{$11 / 09$} \\
\hline & $\bar{M}$ & Mt & $\mathbf{N e}$ & $\overline{\mathbf{N}}$ & $\bar{M}$ & $\mathbf{M t}$ & $\mathbf{\mathrm { Ne }}$ & $\mathbf{N}$ & $\bar{M}$ & Mt & $\mathrm{Ne}$ & $\mathbf{N}$ & $\bar{M}$ & Mt & $\mathrm{Ne}$ & $\mathbf{N}$ & $\bar{M}$ & Mt & $\mathrm{Ne}$ & $\mathbf{N}$ \\
\hline $125_{1}$ & $\overline{0}$ & $\mathrm{Em}$ & - & $1^{\mathrm{a}}$ & 0 & $\mathrm{O}$ & 7 & $2^{a}$ & 0 & $\mathrm{Em}$ & - & $2^{a}$ & 0 & $\mathrm{O}$ & 10 & $3^{\mathrm{a}}$ & $\overline{0}$ & Em & - & $3^{\mathrm{a}}$ \\
\hline $125_{2}$ & 0 & OD & 7 & $2^{\mathrm{a}}$ & 0 & $\mathrm{O}$ & - & $2^{\mathrm{a}}$ & 0 & Em & - & $2^{\mathrm{a}}$ & 0 & $\mathrm{O}$ & 12 & $3^{a}$ & 0 & Em & - & $3^{\mathrm{a}}$ \\
\hline $125_{3}$ & 0 & OD & 8 & $2^{\mathrm{a}}$ & 0 & $\mathrm{O}$ & - & $2^{a}$ & 0 & $\mathrm{Em}$ & - & $2^{a}$ & 0 & $\mathrm{O}$ & 5 & $3^{\mathrm{a}}$ & 0 & Em & - & $3^{\mathrm{a}}$ \\
\hline $125_{4}$ & 1 & - & 5 & $2^{\mathrm{a}}$ & - & 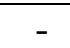 & - & - & - & - & - & - & - & - & - & - & - & - & - & - \\
\hline 1255 & 0 & $\mathrm{O}$ & 5 & $2^{\mathrm{a}}$ & 0 & $\mathrm{O}$ & - & $2^{a}$ & 0 & Em & - & $2^{a}$ & 0 & $\mathrm{O}$ & 7 & $3^{\mathrm{a}}$ & 0 & Em & - & $3^{\mathrm{a}}$ \\
\hline $125_{6}$ & 0 & $\mathrm{O}$ & 8 & $2^{\mathrm{a}}$ & 0 & $\mathrm{O}$ & - & $2^{a}$ & 0 & $\mathrm{DO}$ & 6 & $3^{\mathrm{a}}$ & 0 & $\mathrm{O}$ & - & $3^{\mathrm{a}}$ & 0 & $\mathrm{Em}$ & - & $3^{\mathrm{a}}$ \\
\hline $125_{7}$ & 0 & $\mathrm{O}$ & 10 & $2^{\mathrm{a}}$ & 0 & Em & - & $2^{\mathrm{a}}$ & 0 & $\mathrm{O}$ & 10 & $3^{\mathrm{a}}$ & 0 & $\mathrm{O}$ & - & $3^{\mathrm{a}}$ & 0 & DO & 8 & $4^{\mathrm{a}}$ \\
\hline $125_{8}$ & 0 & $\mathrm{O}$ & 10 & $2^{\mathrm{a}}$ & 0 & Em & - & $2^{a}$ & 0 & $\mathrm{O}$ & 9 & $3^{\mathrm{a}}$ & 0 & $\mathrm{O}$ & - & $3^{\mathrm{a}}$ & 0 & DO & 11 & $4^{\mathrm{a}}$ \\
\hline 1259 & 0 & $\mathrm{O}$ & 9 & $2^{\mathrm{a}}$ & 0 & Em & - & $2^{\mathrm{a}}$ & 0 & DO & 9 & $3^{a}$ & 0 & $\mathrm{O}$ & - & $3^{a}$ & 0 & $\mathrm{Em}$ & - & $3^{\mathrm{a}}$ \\
\hline $125_{10}$ & 0 & OD & 9 & $2^{\mathrm{a}}$ & 0 & Em & - & $2^{a}$ & 0 & Em & - & $2^{a}$ & 0 & $\mathrm{O}$ & 12 & $3^{\mathrm{a}}$ & 0 & Em & - & $3^{\mathrm{a}}$ \\
\hline $250_{1}$ & 0 & $\mathrm{O}$ & 4 & $2^{\mathrm{a}}$ & 0 & Em & - & $2^{a}$ & 0 & $\mathrm{DO}$ & 5 & $3^{\mathrm{a}}$ & 0 & $\mathrm{O}$ & - & $3^{a}$ & 0 & Em & - & $3^{\mathrm{a}}$ \\
\hline $250_{2}$ & 0 & $\mathrm{O}$ & 6 & $2^{\mathrm{a}}$ & 0 & Em & - & $2^{\mathrm{a}}$ & 0 & Em & - & $2^{a}$ & 0 & $\mathrm{O}$ & 6 & $3^{a}$ & 0 & Em & - & $3^{\mathrm{a}}$ \\
\hline $250_{3}$ & 0 & $\mathrm{O}$ & 10 & $2^{\mathrm{a}}$ & 0 & Em & - & $2^{a}$ & 0 & $\mathrm{O}$ & 10 & $3^{\mathrm{a}}$ & 0 & Em & & $3^{\mathrm{a}}$ & 0 & Em & 8 & $4^{\mathrm{a}}$ \\
\hline $250_{4}$ & 0 & $\mathrm{O}$ & 9 & $2^{\mathrm{a}}$ & 0 & Em & - & $2^{\mathrm{a}}$ & 0 & $\mathrm{O}$ & 9 & $3^{\mathrm{a}}$ & 0 & Em & & $3^{\mathrm{a}}$ & 0 & DO & 8 & $4^{\mathrm{a}}$ \\
\hline $250_{5}$ & 0 & $\mathrm{Em}$ & - & $1^{\mathrm{a}}$ & 0 & $\mathrm{O}$ & 6 & $2^{\mathrm{a}}$ & 0 & $\mathrm{Em}$ & - & $2^{\mathrm{a}}$ & 0 & $\mathrm{O}$ & 10 & $3^{\mathrm{a}}$ & 0 & $\mathrm{O}$ & - & $3^{\mathrm{a}}$ \\
\hline $250_{6}$ & 0 & $\mathrm{O}$ & 7 & $2^{\mathrm{a}}$ & 0 & $\mathrm{O}$ & - & $2^{a}$ & 0 & Em & - & $2^{a}$ & 0 & $\mathrm{O}$ & 7 & $3^{\mathrm{a}}$ & 0 & Em & - & $3^{\mathrm{a}}$ \\
\hline $250_{7}$ & 0 & OD & 7 & $2^{\mathrm{a}}$ & 0 & $\mathrm{O}$ & - & $2^{\mathrm{a}}$ & 0 & Em & - & $2^{\mathrm{a}}$ & 0 & $\mathrm{O}$ & 8 & $3^{\mathrm{a}}$ & 0 & Em & - & $3^{\mathrm{a}}$ \\
\hline $250_{8}$ & 1 & - & - & - & 1 & - & - & - & - & - & - & - & - & - & - & - & - & - & - & - \\
\hline 2509 & 0 & OD & 9 & $2^{\mathrm{a}}$ & 0 & $\mathrm{O}$ & - & $2^{\mathrm{a}}$ & 0 & Em & - & $2^{\mathrm{a}}$ & 0 & $\mathrm{O}$ & 8 & $3^{\mathrm{a}}$ & 0 & Em & - & $3^{\mathrm{a}}$ \\
\hline $250_{10}$ & 0 & $\mathrm{Em}$ & - & $2^{\mathrm{a}}$ & 0 & Em & - & $2^{a}$ & 0 & $\mathrm{O}$ & 9 & $3^{\mathrm{a}}$ & 0 & Em & - & $3^{\mathrm{a}}$ & 0 & $\mathrm{O}$ & 8 & $4^{\mathrm{a}}$ \\
\hline $50_{1}$ & 0 & $\mathrm{O}$ & 10 & $2^{\mathrm{a}}$ & 0 & $\mathrm{Em}$ & - & $2^{a}$ & 0 & $\mathrm{O}$ & 11 & $3^{a}$ & 0 & $\mathrm{O}$ & - & $3^{\mathrm{a}}$ & 0 & - & 6 & $4^{\mathrm{a}}$ \\
\hline $500_{2}$ & 0 & $\mathrm{O}$ & 9 & $2^{\mathrm{a}}$ & 0 & Em & - & $2^{\mathrm{a}}$ & 0 & $\mathrm{O}$ & 10 & $3^{\mathrm{a}}$ & 0 & Em & - & $3^{\mathrm{a}}$ & 0 & OD & 9 & $4^{\mathrm{a}}$ \\
\hline $500_{3}$ & 0 & $\mathrm{O}$ & 11 & $2^{\mathrm{a}}$ & 0 & Em & - & $2^{a}$ & 0 & $\mathrm{O}$ & 14 & $3^{\mathrm{a}}$ & 0 & $\mathrm{Em}$ & 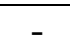 & $3^{\mathrm{a}}$ & 0 & DO & 10 & $4^{\mathrm{a}}$ \\
\hline
\end{tabular}

Cоntinua... 
Continuação Tabela 15...

\begin{tabular}{|c|c|c|c|c|c|c|c|c|c|c|c|c|c|c|c|c|c|c|c|c|}
\hline & \multicolumn{4}{|c|}{$07 / 09$} & \multicolumn{4}{|c|}{$08 / 09$} & \multicolumn{4}{|c|}{$09 / 09$} & \multicolumn{4}{|c|}{$10 / 09$} & \multicolumn{4}{|c|}{$11 / 09$} \\
\hline & $\overline{\mathbf{M}}$ & Mt & $\mathbf{N e}$ & $\overline{\mathbf{N}}$ & $\overline{\mathbf{M}}$ & $\overline{M t}$ & $\mathbf{\mathrm { Ne }}$ & $\overline{\mathbf{N}}$ & $\overline{\mathbf{M}}$ & Mt & $\mathrm{Ne}$ & $\overline{\mathbf{N}}$ & $\overline{\mathbf{M}}$ & Mt & $\mathrm{Ne}$ & $\overline{\mathbf{N}}$ & $\overline{\mathbf{M}}$ & Mt & $\mathrm{Ne}$ & $\overline{\mathbf{N}}$ \\
\hline $500_{4}$ & $\overline{0}$ & $\overline{\mathrm{O}}$ & 9 & $2^{\mathrm{a}}$ & $\overline{0}$ & $\mathrm{O}$ & - & $2^{a}$ & 0 & $\mathrm{Em}$ & - & $2^{a}$ & 0 & $\mathrm{O}$ & 8 & $3^{a}$ & $\overline{0}$ & Em & - & $3^{a}$ \\
\hline $500_{5}$ & 0 & $\mathrm{O}$ & 9 & $2^{\mathrm{a}}$ & 0 & Em & - & $2^{a}$ & 0 & $\mathrm{O}$ & 9 & $3^{a}$ & 0 & $\mathrm{O}$ & - & $3^{a}$ & 0 & Em & - & $3^{\mathrm{a}}$ \\
\hline $500_{6}$ & 0 & $\mathrm{O}$ & 8 & $2^{\mathrm{a}}$ & 0 & Em & - & $2^{a}$ & 0 & $\mathrm{O}$ & 8 & $3^{\mathrm{a}}$ & 0 & $\mathrm{O}$ & - & $3^{a}$ & 0 & - & 6 & $4^{\mathrm{a}}$ \\
\hline $\mathbf{5 0 0}_{7}$ & 0 & OD & 8 & $2^{\mathrm{a}}$ & 0 & $\mathrm{O}$ & - & $2^{\mathrm{a}}$ & 0 & Em & - & $2^{a}$ & 0 & $\mathrm{O}$ & 4 & $3^{a}$ & 0 & Em & - & $3^{\mathrm{a}}$ \\
\hline 5008 & 0 & $\mathrm{O}$ & 9 & $2^{\mathrm{a}}$ & 0 & Em & - & $2^{a}$ & 0 & $\mathrm{O}$ & 5 & $3^{\mathrm{a}}$ & 0 & Em & - & $3^{a}$ & 1 & - & 5 & $4^{\mathrm{a}}$ \\
\hline 5009 & 0 & $\mathrm{O}$ & 10 & $2^{\mathrm{a}}$ & 0 & Em & - & $2^{a}$ & 0 & $\mathrm{DO}$ & 2 & $3^{\mathrm{a}}$ & 0 & $\mathrm{O}$ & - & $3^{a}$ & 0 & Em & - & $3^{\mathrm{a}}$ \\
\hline $500_{10}$ & - & - & - & - & - & - & - & - & - & - & $\begin{array}{lll}- & \\
\end{array}$ & - & - & - & - & - & - & - & - & - \\
\hline $1000_{1}$ & 0 & Em & - & $2^{\mathrm{a}}$ & 0 & Em & - & $2^{a}$ & 0 & $\mathrm{O}$ & 11 & $3^{\mathrm{a}}$ & 0 & Em & - & $3^{a}$ & 0 & - & 8 & $4^{\mathrm{a}}$ \\
\hline $1000_{2}$ & 0 & Em & - & $2^{\mathrm{a}}$ & 0 & Em & - & $2^{\mathrm{a}}$ & 0 & $\mathrm{O}$ & 7 & $3^{a}$ & 0 & $\mathrm{Em}$ & - & $3^{a}$ & 0 & $\mathrm{O}$ & 6 & $4^{\mathrm{a}}$ \\
\hline $1000_{3}$ & 0 & Em & - & $2^{\mathrm{a}}$ & 0 & Em & - & $2^{a}$ & 0 & $\mathrm{O}$ & 10 & $3^{\mathrm{a}}$ & 0 & Em & - & $3^{a}$ & 0 & $\mathrm{O}$ & 8 & $4^{\mathrm{a}}$ \\
\hline $1000_{4}$ & 0 & $\mathrm{O}$ & 8 & $2^{\mathrm{a}}$ & 0 & Em & - & $2^{a}$ & 0 & $\mathrm{O}$ & 6 & $3^{\mathrm{a}}$ & 0 & Em & - & $3^{a}$ & 0 & DO & 6 & $4^{\mathrm{a}}$ \\
\hline $1000_{5}$ & 0 & $\mathrm{O}$ & 10 & $2^{\mathrm{a}}$ & 0 & Em & - & $2^{a}$ & 0 & $\mathrm{O}$ & 10 & $3^{a}$ & 0 & Em & - & $3^{a}$ & 0 & $\mathrm{O}$ & 8 & $4^{\mathrm{a}}$ \\
\hline $1000_{6}$ & 0 & Em & - & $2^{\mathrm{a}}$ & 0 & Em & - & $2^{a}$ & 0 & $\mathrm{O}$ & 9 & $3^{\mathrm{a}}$ & 0 & Em & & $3^{a}$ & 0 & $\mathrm{O}$ & 9 & $4^{\mathrm{a}}$ \\
\hline $\mathrm{1000}_{7}$ & 0 & Em & - & $2^{\mathrm{a}}$ & 0 & Em & - & $2^{\mathrm{a}}$ & 0 & $\mathrm{O}$ & 7 & $3^{\mathrm{a}}$ & 0 & Em & - & $3^{a}$ & 0 & $\mathrm{O}$ & 2 & $4^{\mathrm{a}}$ \\
\hline 10008 & 0 & $\mathrm{O}$ & 7 & $2^{\mathrm{a}}$ & 0 & Em & - & $2^{a}$ & 0 & $\mathrm{O}$ & 7 & $3^{\mathrm{a}}$ & 0 & Em & - & $3^{a}$ & 0 & DO & 7 & $4^{\mathrm{a}}$ \\
\hline 10009 & 0 & OD & 9 & $2^{\mathrm{a}}$ & 0 & $\mathrm{O}$ & - & $2^{a}$ & 0 & $\mathrm{Em}$ & - & $2^{a}$ & 0 & $\mathrm{O}$ & 5 & $3^{a}$ & 0 & Em & - & $3^{\mathrm{a}}$ \\
\hline $1000_{10}$ & 0 & $\mathrm{O}$ & 7 & $2^{\mathrm{a}}$ & 0 & Em & - & $2^{\mathrm{a}}$ & 0 & DO & 7 & $3^{\mathrm{a}}$ & 0 & $\mathrm{O}$ & & $3^{\mathrm{a}}$ & 0 & Em & - & $3^{\mathrm{a}}$ \\
\hline $2000_{1}$ & 0 & Em & - & $1^{\mathrm{a}}$ & 0 & $\mathrm{O}$ & 10 & $2^{a}$ & 0 & $\mathrm{Em}$ & - & $2^{a}$ & 0 & DO & 18 & $3^{a}$ & 0 & $\mathrm{O}$ & - & $3^{\mathrm{a}}$ \\
\hline $2000_{2}$ & - & - & - & - & - & - & - & - & - & - & - & - & - & - & - & - & - & - & - & - \\
\hline $2000_{3}$ & 0 & Em & - & $1^{\mathrm{a}}$ & 0 & OD & 6 & $2^{a}$ & 0 & Em & - & $2^{a}$ & 0 & Em & - & $2^{a}$ & 0 & $\mathrm{O}$ & 11 & $3^{\mathrm{a}}$ \\
\hline $2000_{4}$ & 0 & Em & - & $1^{\mathrm{a}}$ & 0 & Em & - & $1^{\mathrm{a}}$ & 0 & $\mathrm{O}$ & 6 & $2^{a}$ & 0 & Em & - & $2^{\mathrm{a}}$ & 0 & $\mathrm{O}$ & 9 & $3^{a}$ \\
\hline $2000_{5}$ & 0 & Em & - & $1^{\mathrm{a}}$ & 0 & Em & - & $1^{\mathrm{a}}$ & 0 & $\mathrm{O}$ & 9 & $2^{\mathrm{a}}$ & 0 & Em & - & $2^{\mathrm{a}}$ & 0 & $\mathrm{O}$ & 10 & $3^{\mathrm{a}}$ \\
\hline $2000_{6}$ & 0 & Em & - & $1^{\mathrm{a}}$ & 0 & $\mathrm{O}$ & 10 & $2^{a}$ & 0 & $\mathrm{Em}$ & - & $2^{a}$ & 0 & DO & 10 & $3^{a}$ & 0 & $\mathrm{O}$ & - & $3^{\mathrm{a}}$ \\
\hline
\end{tabular}

Continua... 
Continuação Tabela 15...

\begin{tabular}{|c|c|c|c|c|c|c|c|c|c|c|c|c|c|c|c|c|c|c|c|c|}
\hline & \multicolumn{4}{|c|}{ 07/09 } & \multicolumn{4}{|c|}{ 08/09 } & \multicolumn{4}{|c|}{ 09/09 } & \multicolumn{4}{|c|}{$10 / 09$} & \multicolumn{4}{|c|}{$11 / 09$} \\
\hline & $\bar{M}$ & $\mathbf{M t}$ & $\mathrm{Ne}$ & $\overline{\mathbf{N}}$ & $\bar{M}$ & Mt & $\mathbf{N e}$ & $\mathbf{N}$ & $\bar{M}$ & $\mathbf{M t}$ & $\mathrm{Ne}$ & $\mathbf{N}$ & $\overline{\mathbf{M}}$ & Mt & $\mathrm{Ne}$ & $\mathbf{N}$ & $\bar{M}$ & Mt & $\mathrm{Ne}$ & $\overline{\mathbf{N}}$ \\
\hline $2000_{7}$ & 0 & $\overline{\mathrm{Em}}$ & - & $1^{\mathrm{a}}$ & 0 & $\mathrm{O}$ & 7 & $2^{a}$ & 0 & $\overline{E m}$ & - & $2^{a}$ & 0 & $\mathrm{O}$ & 9 & $3^{a}$ & 0 & $\mathrm{O}$ & - & $3^{a}$ \\
\hline 20008 & 0 & $\mathrm{Em}$ & - & $1^{\mathrm{a}}$ & 0 & $\mathrm{O}$ & 9 & $2^{a}$ & 0 & Em & - & $2^{a}$ & 0 & $\mathrm{O}$ & 10 & $3^{a}$ & 1 & - & - & - \\
\hline 20009 & 0 & $\mathrm{Em}$ & - & $1^{\mathrm{a}}$ & 0 & $\mathrm{O}$ & 11 & $2^{a}$ & 0 & Em & - & $2^{a}$ & 0 & $\mathrm{O}$ & 14 & $3^{a}$ & 0 & $\mathrm{O}$ & - & $3^{a}$ \\
\hline $2000_{10}$ & - & - & - & - & - & - & - & - & - & - & - & - & - & - & - & - & - & - & - & - \\
\hline
\end{tabular}

Conclusão Tabela 15. 